\title{
IV. Justiz in diktaturvergleichender Perspektive
}

Wie nur wenige andere Themen der DDR-Geschichte ist die Beurteilung der Justiz umstritten. Um aber aus den Gräben der politischen Frontverläufe herauszukommen und auf eine wissenschaftliche Ebene vorzustoßen, sollte ein Versuch unternommen werden, tragfähige Kriterien zur Analyse zu entwickeln. Dies erscheint in erster Linie möglich, wenn man die Entwicklung der DDR aus vergleichender Perspektive betrachtet. Dazu bieten sich zunächst andere Diktaturen an, in denen die Staatsführung die Justiz ebenso für ihre politischen Ziele instrumentalisierte und die Justiz in eklatanter Form Menschenrechte verletzte ${ }^{1}$. Bei der Gegenüberstellung der DDR-Justiz mit dem Rechtsapparat anderer Diktaturen sollte es nicht darum gehen, das eine System auf Kosten des anderen zu belasten oder zu entlasten. Vielmehr kann allein der Vergleich die Bildung von Kriterien zur Interpretation im größeren Rahmen ermöglichen.

Allerdings soll an dieser Stelle kein echter systematischer Vergleich geboten werden, weil dazu eine gleichgewichtige Erforschung und Präsentation der Vergleichspartner vonnöten gewesen wäre, was aber in der Untersuchung nicht vorgesehen war. Die Aussagen zur Justiz anderer Systeme und Staaten beruhen deshalb auf der Auswertung der einschlägigen Literatur. Die Entwicklung der Westzonen und der frühen Bundesrepublik wurde in die Darstellung synchron vergleichend ins Auge gefaßt, da hier ein gemeinsamer Ausgangspunkt vorhanden und das Auseinanderdriften chronologisch festzuhalten war. Ein Problem des Vergleichs stellt die Ausgangsebene der Untersuchung dar, die regionale bzw. Landesjustiz. Von Zuschnitt und Quellenfundierung adäquate Monographien liegen nur für die Zeit des Nationalsozialismus vor. Da tiefgehende Studien zur regionalen Entwicklung von Politik und Justiz für die Sowjetunion und Polen fehlen, wird in diesen Fällen auf die allgemeineren Strukturmerkmale ausgewichen.

Während der - empirisch fundierte - Diktaturvergleich zwischen der DDR und dem Dritten Reich noch in den Anfängen steckt ${ }^{2}$, hat die Komparatistik zwischen den kommunistischen Systemen bereits eine längere Tradition. Insbesondere seit den sechziger Jahren gab es eine Reihe politikwissenschaftlicher Versuche, Unterschiede und Gemeinsamkeiten der Staaten des Ostblocks herauszuarbeiten. In unserem Zusammenhang ist auch auf die vergleichende Ostrechtsforschung hin-

1 Zum Vergleich von sozialistischen "aktivistischen“ mit anderen "reaktiven“ Rechtssystemen vgl. Damaška, Faces of Justice, bes. S. $84 \mathrm{ff}$.

2 Vgl. als ersten Versuch für einen empirischen Ansatz Ansorg, Kinder im Klassenkampf, S. 176-209; perspektivenreich: Heydemann/Jesse, Diktaturvergleich; mit Schwerpunkt Kirchenpolitik: Heydemann/Beckmann, Zwei Diktaturen in Deutschland; Sozialpolitik: Hockerts, Drei Wege. Für die Justiz bisher vor allem Kirchheimer, Politische Justiz; und der Tagungsbericht Buschfort, Wie Äpfel mit Birnen. 
zuweisen ${ }^{3}$. Allerdings waren diese Forschungen fast durchweg zeitgenössisch gegenwartsbezogen und klammerten den hier interessierenden Zeitraum von 1944/45 bis 1956 weitgehend aus. Eine historiographische vergleichende Ostblock-Forschung gelangte bisher über Ansätze nicht hinaus ${ }^{4}$ und ist erst in jüngster Zeit richtig in Gang gekommen.

An Prolegomena für den Vergleich von Diktaturen des 20. Jahrhunderts mangelt es nicht. Gerade für die Analyse der Justiz stellt sich die Frage, ob hier nicht eines der Totalitarismus-Konzepte, die seit dem Zusammenbruch der kommunistischen Systeme eine Renaissance erleben, nutzbringend ins Spiel gebracht werden kann'. Zwar zeichnet sich insbesondere bei osteuropäischen Autoren eine inflationäre Nutzung der Totalitarismus-Begrifflichkeit ab, deren Trennschärfe kaum noch sichtbar ist? ${ }^{7}$. Dieser Rahmen bietet sich aber insofern an, als diese Modelle - im Gegensatz etwa zu modernisierungstheoretischen Ansätzen ${ }^{8}$ - den besonderen Schwerpunkt auf die Analyse von politischen Systemen und Sanktionsmechanismen legen. Zunächst ist jedoch vorwegzunehmen, daß eine Verwendung nur sinnvoll erscheint, wenn sie durch die neuen empirischen Ergebnisse reguliert wird. Es kann hierbei nicht um das lineare Anknüpfen an die Thesen der fünfziger Jahre gehen', deren Schwächen inzwischen zutage getreten sind. Weder besaß das Dritte Reich eine Zentralverwaltungswirtschaft wie die Sowjetunion, noch waren Staatspartei, Geheimpolizei und Propaganda ausschließlich in totalitären Regimen von Bedeutung. Es muß also die Entwicklung eines Analyserahmens ausschließlich zu heuristischen Zwecken angestrebt werden, der empirisch trennscharf ist und für den Diktaturvergleich einen echten Nutzen erbringt. Ohne den Vergleich, also die übergeordnete Kriterienbildung, bleibt ein Totalitarismus-Konzept weniger fruchtbar ${ }^{10}$.

3 Vgl. auch die apologetischen Arbeiten aus sozialistischen Staaten: Karew/Radkow, Sudoustrojstwo; Rácz, Courts and Tribunals, S. $48 \mathrm{ff}$.

4 Diepenthal, Drei Volksdemokratien; White, De-Stalinization; und zahllose Sammelbände zum Thema, in denen je ein Länderexperte einen Aufsatz verfaßte.

5 Vgl. John Francis Connelly, Creating the Socialist Elite. Communist Higher Education Policies in the Czech Lands, East Germany and Poland 1945-1954. Diss. Harvard 1994; ders., Foundations for Reconstructing Elites.

61947 wehrte sich der spätere Justizminister Fechner gegen den „Vorwurf, daß wir zum Totalitarismus drängen", Protokoll der Verhandlungen des 2. Parteitages, S. 54.

7 Dazu kritisch: Schröder, Stalinismus; Gleason, Totalitarianism, S. 172 ff., 212 ff.; Ryszka, Totalitarismus.

8 Wenig weiterführend für unseren Zusammenhang ist das - enger verstandene - Konzept der „modernen Diktatur" (Kocka), weil es für die Zeit von 1945 bis 1955 nicht anwendbar ist: Nachkriegszerstörung, De-Professionalisierung durch Elitenaustausch bzw. Flucht, Irrationalität, Willkür und Abbau institutioneller Verfahren lassen sich damit nicht erfassen. Dies gilt analog für das Modell vom „bürokratischen Sozialismus": Hier wird im übrigen der hohe Grad an Informalität und Korruption vernachlässigt (vgl. Rittersporn, Soviet Officialdom, S. 231). Ebenso kann vor 1954 kaum von einer „durchherrschten Gesellschaft" (Lüdtke) wie etwa in den siebziger Jahren gesprochen werden, abgesehen von der Frage der Trennschärfe dieses Begriffs; vgl. die Einschränkung in Lüdtke, DDR als Geschichte, S. 12. Größeren heuristischen Nutzen hat das gesellschaftsgeschichtliche Konzept der „Entdifferenzierung" (Pirker/Lepsius), das durchaus komplementär zum Totalitarismus zu sehen ist. Eine präzisere Positionierung jetzt bei Lindenberger, Diktatur der Grenzen.

9 Hannah Arendt erklärte, die totale Herrschaft habe ,in Deutschland mit dem Tod Hitlers ihr Ende“ gefunden, Elemente und Ursprünge totaler Herrschaft, S. 25 (Vorwort von 1966); vgl. schon dies.: Totalitarian Imperialism, S.6.

10 Vgl. Kleßmann, Zwei Diktaturen, S. 603. 
Angesichts der verwirrenden Vielfalt von Ansätzen und Diskussionsbeiträgen zum Totalitarismus-Problem ${ }^{11}$ sei hier die Wahl eines eingegrenzten Analyserahmens vorgeschlagen: Zu unterscheiden ist dabei zwischen 1. der Zielsetzung, 2. der Implementation bzw. den Apparaten und schließlich 3. der Durchsetzung. Dieser Zugriff erscheint für unser Thema geeignet, da er den Apparat, hier also die Justiz, zunächst isoliert. Die Hypothese lautet: Totalitäre Diktaturen oder Weltanschauungsdiktaturen bestimmen sich in erster Linie durch ihre Zielsetzung, die auf Umwälzung und Homogenisierung der Gesellschaft angelegt ist; hier wird angenommen, daß sie sich zu einem erheblichen Teil durch ihre ImplementationsMechanismen definieren, aber nur zu einem geringen Teil über ihre Durchsetzung, nämlich vor allem in der Mobilisierung der Bevölkerung. Nur so läßt sich das Modell universell anwenden und erstens ein gemeinsamer Überbegriff für die vom Massenmord geprägten Regime des Dritten Reiches und des Stalinismus einerseits und die DDR bzw. Polen andererseits finden sowie zweitens darüber hinaus eine klare Abgrenzung zu zeitgenössischen autoritären Regimen erzielen ${ }^{12}$. Dieses Konzept entspricht in etwa dem „tendenziellen Totalitarismus“, wie er bereits frühzeitig von Karl-Dietrich Bracher und Hans Buchheim in die Diskussion eingeführt wurde ${ }^{13}$.

Gemessen an diesem Rahmen ergibt sich die Konsequenz, daß das politische System der SBZ hier nicht als totalitär, die DDR aber ab 1951/52 als totalitär eingestuft wird ${ }^{14}$, weil die utopischen Staatsziele nur sukzessive, offen erst im Juli 1952 verkündet wurden. Auch die Besatzungsdiktatur der SMAD wird hier nicht als totalitär verstanden, weil sie das implizite Ziel „Sozialismus“ nicht propagieren durfte, ihre härtesten Herrschaftsinstrumente - Geheimpolizei und Speziallager in dieser Form ähnlich in autoritären Systemen wie etwa Franco-Spanien existierten. Außerdem ist die totalitäre Omnipräsenz des MGB in der Besatzungszone wohl eher ein Mythos ${ }^{15}$.

Mit ähnlicher Begründung wird die Entwicklung Polens erst ab 1948/49 als totalitär eingestuft, die der Sowjetunion hingegen durchgängig. Retrospektiv betrachtet, verfällt der Totalitarismus in Polen immer weiter, vor allem in den siebziger Jahren, während er in der UdSSR und der DDR bis in die achtziger Jahre anhält ${ }^{16}$. Gemessen an diesen Kriterien machte das Dritte Reich erst im Laufe der dreißiger Jahre die Entwicklung zum Totalitarismus durch, als es sich ab etwa

1 Zuletzt der Überblick: Jesse, Totalitarismus im 20. Jahrhundert.

12 Von daher gesehen wird die These vom Übergang der DDR von der totalitären zur autoritären Diktatur problematisch, vgl. Jesse, War die DDR totalitär.

13 Buchheim, Totalitäre Herrschaft, S. 24, 43; Bracher in: Totalitarismus und Faschismus, S. $13 \mathrm{f}$. Ähnlich Drath, Totalitarismus, S. XXVII (Drath war übrigens 1947 Mitglied des rechtspolitischen Ausschusses beim ZS der SED). Bracher, 20. Jahrhundert, S. 148, spricht bei den kommunistischen Diktaturen nach 1953 vom "Spät-Totalitarismus“. Damit verwandt ist das Konzept der „monoorganisatorischen" oder "monistischen " Herrschaft, das von Hough und Rigby für die nachstalinistische Sowjetunion vorgeschlagen wurde: Hough, Soviet Prefects, S. $289 \mathrm{ff}$.; Rigby, Stalinism and the Mono-Organisational Society.

14 Eine ähnliche Datierung bei Schroeder, SED-Staat, S. 644, der aber hier das klassische Totalitarismus-Modell verwirklicht sieht. Kritisch zuletzt: Jessen, DDR-Geschichte und Totalitarismustheorie.

15 Foitzik, Der sowjetische Terrorapparat, S. 28.

16 Vgl. die Totalitarismus-Diskussion in Polen: Friszke, War die Volksrepublik Polen, S. 238-243; Magierska, Dylematy historii PRL, S. $50 \mathrm{ff}$. 
1935 mit der Propagierung einer „rassischen Neugestaltung" zusehends von den Formen autoritärer Diktaturen, die vor allem ihre politischen Gegner bekämpfen, löste.

Dies sind alles heuristische Überlegungen, die keinen Anspruch auf Ausschließlichkeit haben. In ein flexibles Totalitarismus-Modell läßt sich aber die Justiz einigermaßen sinnvoll einordnen. Dies zeigen etwa die propagierten Ziele der Rechtsprechung in allen Systemen, das Bemühen um Konformität und Steuerung in Richtung der Staatsideologie. Der Grad der Repression durch politische Justiz hingegen war in allen Systemen konstellations- bzw. phasenabhängig, ähnlich wie in autoritären Staaten.

Kann es überhaupt eine totalitäre Justiz geben? Diese Frage ist nicht eindeutig zu beantworten; dies hängt vielmehr von den Kriterien ab, die einer totalitären Justiz zugeordnet werden. Die Justiz ist in den klassischen Totalitarismus-Modellen nicht enthalten. Ihre Eigengesetzlichkeit und ihre Verfahrensweisen verliehen ihr in den Augen der Bevölkerung eine gewisse eigene Legitimität außerhalb der Ideologie. Die Abgrenzung zu einer autoritären Justiz bleibt also immer unscharf ${ }^{17}$. Auch in totalitären Regimen verwendet das Rechtssystem einen erheblichen Teil seiner Energie auf normale Regelungstätigkeiten, die sich nicht stark von demokratischen Systemen unterschieden. Typisch für die Justiz in totalitären Staaten ist aber ihre inhaltliche Veränderung und ihre Aufweichung gegenüber anderen Instanzen, besonders der - eindeutiger als totalitär einzustufenden - Geheimpolizei. Also: Vor allem die Auflösung der klassischen Justiz erscheint als Kennzeichen totalitärer Herrschaft.

Analytisch wichtig ist die Abgrenzung zur Justiz in autoritären Diktaturen des 20. Jahrhunderts ${ }^{18}$. Zwar ist das Ausmaß politischer Unterdrückung in den autoritären Systemen außerordentlich unterschiedlich, manche tendierten zeitweise sogar zu rechtsstaatlichen Elementen. Aber selbst europäische Diktaturen wie in Spanien und Griechenland, die ebenso wie die DDR nach dem Krieg existierten, trugen das Signum massenhafter politischer Justiz und politischer Todesurteile. Auch hier spielten Interventionen in die Justiz, Geheim- bzw. Militärpolizei, Internierungslager und systematische Menschenrechtsverletzungen oft eine große Rolle. Im Unterschied zu totalitären Systemen fehlte ihnen jedoch die utopische Ideologie und der daraus resultierende totalitäre Anspruch, die ganze Gesellschaft zu durchdringen und zu gestalten.

Der Umbau des Staatsapparates hält sich in autoritären Regimen in Grenzen. Zwar werden auch dort meist neue Staatsspitzen wie Konsultationsgremien geschaffen und parlamentarische Institutionen ausgehöhlt oder beseitigt, die Staatsparteien und ihre Organisationen gewinnen aber keine starke institutionelle Bedeutung. Auffällig ist die Militarisierung der politischen Justiz in autoritären Diktaturen, die aus Krieg, Bürgerkrieg und Militärputsch resultierte. Sie gab es in

17 Zwei profilierte Kenner der NS-Justiz rechnen sowohl das Dritte Reich als auch die DDR unter die autoritären Systeme: Bästlein, Funktion und Struktur der Justiz, S. 41 ff.; Majer, Überlegungen, S. $17 \mathrm{f}$. Dagegen macht der Rechtsvergleich bei Schneider, Rechtsgedanken und Rechtstechniken, nicht hinreichend die Abgrenzung von totalitären zu autoritären Elementen deutlich.

18 Zum folgenden: Linz, Totalitarian and Authoritarian Regimes, S. 264 ff.; ders., Typen politischer Regime, S. $503 \mathrm{ff}$.; ders., Totalitarianism and Authoritarianism, S. $145 \mathrm{ff}$.; Draht, Totalitarismus, S. XXIII ff. 
Spanien vor allem während des Zweiten Weltkrieges, in Griechenland und in vielen anderen Systemen auch später. In Spanien wurde die politische Justiz vor allem von der Militärgerichtsbarkeit ausgeübt, die parallel zu einem - durchaus unabhängigen - traditionellen Rechtsapparat bestand ${ }^{19}$. Von entscheidender Bedeutung bei der Abgrenzung totalitärer von autoritären Regimen ist schließlich, daß letztere ihre Legitimation viel stärker aus dem vorhergehenden politischen System ziehen, während totalitäre Regime den Bruch suchen.

In der Konsequenz dieser Überlegungen ist vor allem folgenden Problemen nachzugehen: Wie lassen sich autoritäre und totalitäre Phasen und Übergänge identifizieren? Welchen Platz nahm die Justiz in der Diktatur ein? Welche Rolle spielte die Ideologie in den Rechtssystemen? Wie wurde die Gleichschaltung des Rechtsapparates erreicht, wie lange dauerte dies? Wie wirkten sich die recht unterschiedlichen geschichtlichen Voraussetzungen der Diktaturen aus, welche Ursachen hatte die ungleiche Ausprägung der politischen Justiz?

Schließlich noch ein letztes Wort zum Thema Vergleichen: Angesichts der hier gewählten Konstruktion, statt einer voll entwickelten Komparatistik lediglich einige vergleichende Überlegungen ans Ende zu stellen, beschränken sich die Ausführungen auf den Vergleich einiger weniger Faktoren. Dabei stehen insbesondere historische Rahmenbedingungen und Zielsetzung, Implementation und Organisation sowie die Rechtsprechung und ihre Vollstreckung im Vordergrund. Erst nach diesem Abgleich ist angestrebt, die Justiz der DDR diktaturgeschichtlich einzuordnen.

\section{Das „Schreckbild“ NS-Justiz und sein Verblassen}

Für einen Diktaturvergleich bieten sich für die DDR zunächst die vorhergehenden Jahre des Nationalsozialismus an ${ }^{20}$, da hier der Raum und die betroffene Bevölkerung weitgehend identisch waren. Leider ist die Geschichte der brandenburgischen Justiz im Dritten Reich, die allein den methodisch besten Vergleichspartner repräsentiert hätte, bisher kaum erforscht ${ }^{21}$. Deshalb muß auf andere Regionen zurückgegriffen werden, zu denen bereits Monographien vorliegen. An solchen Studien besteht kein Mangel. Vor allem für viele Gebiete West- und Nordwestdeutschlands liegen zum Teil hervorragende Untersuchungen vor. Aber auch die Zentralinstanzen der Reichsjustiz sind vergleichsweise gut untersucht $^{22}$.

19 Vgl. Refoja, Francos politische Justiz, S. 105; Toharia, Judicial Independance, S. 476.

20 Vgl. Möller, Geschichte des Nationalsozialismus; Thamer, Staatsmacht; zur Justiz den konzisen Vergleich in Bästlein, Funktion und Struktur der Justiz, S. 41 ff. Wenig überzeugend: Schöneburg, Recht im nazifaschistischen und im „realsozialistischen " deutschen Staat. Die normative Untersuchung von Schneider, Rechtsgedanken und Rechtstechniken, bes. S. $197 \mathrm{ff}$., konzentriert sich auf den Vergleich des öffentlichen Dienstes beider Systeme.

21 Vgl. aber Püschel, ... der Angeklagte; dies., Widerspiegelung. Daneben existieren einige Publikationen aus der DDR zum kommunistischen Widerstand in brandenburgischen Zuchthäusern.

22 Insbesondere seit Lothar Gruchmanns Monographie zum Reichsjustizministerium bis 1940: Gruchmann, Justiz im Dritten Reich. 


\section{a. Grundprobleme}

Jeder systematische Vergleich muß mit der Betrachtung der Rahmenbedingungen einsetzen, die auch den Bereich der Justiz in erheblichem Ausmaß geformt haben. Die entscheidende Rahmenbedingung für die Entwicklung der SBZ, und nicht nur in der Justiz, war die sowjetische Besatzung im Gefolge der Niederlage des NS-Systems. Von ganz anderen Voraussetzungen nahm die NS-Justiz im Jahre 1933 ihren Anfang, vom Rechtsstaat der Weimarer Republik. Die Nationalsozialisten trafen auf ein gefestigtes Rechtssystem, das wiederum von einem stabilen "Juristenmilieu“ getragen wurde. Ganz anders 1945 im Osten Deutschlands: Die Justiz war materiell und moralisch zerschlagen, kaum jemand wußte, wie es weitergehen würde. Die Weimarer Republik bildete aber für beide Justizsysteme einen gemeinsamen Bezugspunkt. Während die NS-Justiz die Traditionen politisch einäugiger Rechtsprechung übernahm bzw. verschärfte, versuchten nach 1945 die sozialdemokratischen und „bürgerlichen“ Rechtspolitiker an die Reformansätze der Weimarer Zeit anzuknüpfen. Schließlich aber siegten die kommunistischen Funktionäre, die sich scharf von Weimar abgrenzten. Zusammen genommen, erschweren allein schon diese fundamental unterschiedlichen Ausgangspunkte den Vergleich beider Rechtssysteme ungemein.

Das gleiche gilt für den komparatistischen Blick auf die deutsche Justiz im Zweiten Weltkrieg. Sie wird hier wegen der anderen Rahmenbedingungen nur am Rande behandelt, muß aber analytisch im Auge behalten werden; denn sie zeigt die nahezu unbegrenzte Eskalation einer entfesselten Strafjustiz. In der DDR gab es keine Justiz unter Kriegsbedingungen, vielmehr entschärfte sich die Strafpolitik ab 1961, ohne allerdings jemals annähernd rechtsstaatliche Normen zu erreichen. Zur NS-Kriegsjustiz bestanden grundsätzlich große Unterschiede wegen der erhöhten Gewaltbereitschaft und der subjektiven Legitimität von Gewalt bei den Juristen; hinzu kam die Ausbreitung nationaler und rassistischer Denkmuster. Noch schwieriger wird der Vergleich, wenn man die nationalsozialistische Besatzungsherrschaft berücksichtigt. Im besetzten Osteuropa herrschte ein schrankenloses Regime, dort gehörte der Massenmord zum Alltag. Überall wurden jüdische Juristen ermordet ${ }^{23}$; in Polen und der Sowjetunion drohte allen Juristen dieses Schicksal, weil sie zu den nationalen Eliten gerechnet wurden.

Für die Fragestellung dieser Untersuchung ist die Kriegszeit nicht von grundlegender Bedeutung. Sie konzentriert sich auf die Phase totalitärer Gleichschaltung, die früher ablief. Ihre Wurzeln lagen schon in der Frühentwicklung der späteren Staatsparteien. Die ausgesprochene Justizfeindlichkeit resultierte in der NSBewegung aus der Ablehnung von Verfahrensweisen, oftmals aus Antisemitismus. Demgegenüber schöpften KPD und Teile der SPD ihre grundsätzliche Justizkritik 1945 vor allem aus der politischen und oft unsozialen Rechtsprechung der Weimarer Republik, von der Justizverfolgung im Nationalsozialismus ganz zu schweigen. Die Defizite der Rechtsprechung wurden aber bereits in der Vorgeschichte beider Diktaturen auch von breiteren Kreisen wahrgenommen, in den zwanziger Jahren wie 1946/47 war immer wieder von der "Justizkrise“ die Rede. Aber auch

${ }^{23}$ Vgl. die Ermordung eines jüdischen Landgerichtsdirektors i.R. 1937 im KZ Sachsenhausen, Gruchmann, Justiz im Dritten Reich, S. 650. 
in späteren Phasen übten die Regimespitzen noch erhebliche Kritik an den Gerichten; bekannt ist Hitlers öffentliche Juristenschelte von 1942, die er allerdings intern wieder zurücknahm ${ }^{24}$.

Beiden Diktaturen gemeinsam war die Leitfunktion einer totalitären Ideologie, im Dritten Reich schon sehr früh, in der DDR offen erst 1952. So unterschiedlich beide Ideologien auch waren, so beanspruchte doch jede den umfassenden Zugriff auf Gesellschaft und Institutionen. Das mußte sich unweigerlich auch auf das Rechtsdenken auswirken. So findet man im NS-Recht wie im staatlichen Sozialismus ständig den Topos vom "Volk“ bzw. der Nähe der Justiz zu diesem. In der SBZ war dies zunächst noch kaum mit totalitären Ideologemen verbunden, sondern vielmehr eine Mixtur aus einer Begrifflichkeit der Jahre vor 1933, der Notsituation der Nachkriegszeit und begrenzten sowjetischen Anleihen. Im Dritten Reich hingegen war der Volks-Begriff von Anfang an rassistisch aufgeladen. Mit der Ideologisierung des Rechts gewann hier wie dort der Gedanke an Raum, die Verwirklichung der gesellschaftlichen Utopien würde zum Verschwinden der Kriminalität führen. Im Dritten Reich erreichte die Entfaltung der Kriminalbiologie, also die rassistische Lehre von der Erblichkeit krimineller Veranlagung, ihren Höhepunkt. Die Kriminologie der frühen DDR rechnete dagegen die Tendenz zum Verbrechen eher sozialen Herkunftsmerkmalen zu, vor allem aber gesellschaftlichen Zusammenhängen. So sollte die DDR-Justiz im voraus lokale "Kriminalitäts-Schwerpunkte" entdecken und exemplarisch hart bestrafen. Im Dritten Reich führte die "präventive Verbrechensbekämpfung“ zur Einweisung von 70-80000 Personen in Konzentrationslager ${ }^{25}$. In beiden Rechtssystemen grassierte der charismatische Führerkult, wenn auch die Stalin-Vergottung der Jahre bis 1955 später in der DDR durch das „Amtscharisma“ der SED hilfsweise ersetzt werden mußte.

Der Anspruch der Staatsführung, zumindest in der Theorie ein totales Eingriffsrecht in das System zu haben, hatte für die Verfahrensstruktur des Rechts erhebliche Folgen. Wurden im Dritten Reich große Teile der Weimarer Verfassung außer Kraft gesetzt, so galt in der SBZ zunächst ein Besatzungsrecht eigener Legitimität. Aber auch die neuen Verfassungen der Länder und dann der DDR wurden nach der Staatsgründung 1949 in ihren substantiellen Teilen ausgehöhlt. Der Gesetzgebung blieb das gleiche Schicksal nicht erspart; die Parlamente gerieten zur Staffage. An die Stelle der Gesetze traten zunehmend Durchführungsverordnungen bzw. Runderlasse, oftmals geheime Regelungen. So blieben die formalen Grundlagen für die Tätigkeit des MfS anfangs fast noch geheimer als die der Gestapo in ihren ersten Jahren.

Unter den Juristen vor und nach 1945 wurde heftig über große Reformprojekte gestritten. Knüpften diese in den ersten Nachkriegsjahren noch an die Liberalisierungsbestrebungen der Weimarer Republik an, so rückten in der DDR wie im Nationalsozialismus bald die neuen Staatsziele und die neue gesellschaftliche Wirklichkeit ins Zentrum der Diskussion. Während es in der DDR Jahrzehnte dauerte, bis grundlegende Neukodifikationen in Kraft traten, scheiterten sie im

24 Vgl. Angermund, Deutsche Richterschaft, S. $248 \mathrm{ff}$.

25 Wagner, Volksgemeinschaft ohne Verbrecher, S. 9. 
Dritten Reich in erster Linie an dessen kurzer Lebensdauer, aber auch am Unwillen zu weiterer gesetzlicher Bindung.

Die DDR-Juristen machten zusehends Anleihen bei sowjetischen Konzeptionen, wohingegen die Nationalsozialisten letztendlich keine neue Rechtstheorie entwickelten. Was übrig blieb, waren Gesetze, um Verfolgungsmaßnahmen leichter durchzusetzen und zu legitimieren. Die Rechtsstaatlichkeit der Weimarer Republik wurde seit 1933 demontiert und - trotz ersten Versuchen der Wiederanknüpfung - in der DDR nicht wieder aufgebaut. Die politisch relevante Gesetzgebung des Nationalsozialismus zeigte Parallelen zur DDR vor allem dort, wo es um Nützlichkeitserwägungen des Regimes ging, so beim Handelsschutzgesetz, vor allem aber bei der Bekämpfung von Kritik am Regime; hier war es „Heimtücke“, dort "Boykotthetze“, bei beiden Hoch- bzw. Landesverrat. Freilich machte die Rechtsanwendung in Ostdeutschland ab 1949 einen Wandel durch: Schließlich ging das politische Strafrecht noch auf die legitimen Setzungen der Alliierten zurück, neonazistische Propaganda zu verhindern und die neuen Institutionen zu schützen. Diese Ambivalenz fehlte dem politischen Strafrecht ab 1933; es war ausschließlich gegen die Demokratie gewendet. Das rassistische Sonderrecht des NS-Staates fand in der DDR überhaupt keine Entsprechung26. Eine Spezifik der SED-Diktatur waren hingegen die zahlreichen Gesetze und Erlasse zur Bevorzugung der Staatswirtschaft und zur Enteignung von Unternehmern und Bauern ab einer bestimmten Betriebsgröße, die von 1948 an ergingen. Ausgeprägt waren in beiden Diktaturen solche Gesetze, die die Wirtschaft und damit die Allgemeinheit vorgeblich schützen sollten, aber von der jeweiligen Ideologie durchdrungen waren.

\section{b. Der Justizapparat und seine Tätigkeit im Vergleich}

Will man nun die Struktur und die Tätigkeit der Justiz beider Systeme vergleichen, so würde die Provinz Brandenburg im Dritten Reich den analytisch besten Vergleichspartner abgeben. Hier herrschten ähnliche strukturelle Voraussetzungen wie nach 1945, auch wenn man den Verlust der Neumark berücksichtigt.

Ein direkter Brandenburg-Vergleich für die Zeit bis 1949 müßte als Pendant zu Justiz und Polizei der NS-Zeit die sowjetischen Militärtribunale und das MGB heranziehen. Doch schon die oberflächliche Parallelisierung der Lager, so etwa bei der Betrachtung von Sachsenhausen in den Jahren von 1936 bis 1950, kann fehlgehen. Völlig ohne Parallele stehen aber die spezifischen NS-Mordaktionen da, so der Massenmord an den Kranken besonders im Alten Zuchthaus Brandenburg oder die Deportation der brandenburgischen Juden in den Tod ${ }^{27}$. In Brandenburg begann der Massenmord an den deutschen Juden, als jüdische Anstaltsinsassen ab Juni 1940 nach Brandenburg/Havel transportiert und dort im Gas erstickt wurden.

26 Dazu grundlegend: Majer, Fremdvölkische.

27 Vgl. Demps, Die Provinz Brandenburg in der NS-Zeit, S. 654 ff.; Hübener, Brandenburgische Heil- und Pflegeanstalten, S. $241 \mathrm{ff}$. 
Die Beteiligung der Justiz an diesen Verbrechen war vielfältig. Schon frühzeitig blockierte die Justizführung die Verfolgung von NS-Straftaten, besonders in den Konzentrationslagern ${ }^{28} .1941$ wurde der Massenmord an Kranken von allen Oberlandesgerichtspräsidenten und Generalstaatsanwälten juristisch abgesegnet. Wer offen Informationen über die Massenmorde im Osten verbreitete, konnte wegen "Heimtücke“ von den Sondergerichten belangt werden ${ }^{29}$. Geradezu symbolischen Charakter für die Unterschiedlichkeit beider Diktaturen hat der Fall des Potsdamer Amtsgerichtsrats Erhard Wetzel, der an der Ausarbeitung von Mordplänen in riesigen Dimensionen beteiligt war ${ }^{30}$. Wie der Zufall es wollte, arbeitete am selben Gericht ein profilierter Antinazi, Lothar Kreyßig. Der Amtsgerichtsrat war einer der wenigen Juristen, die gegen die nationalsozialistischen Massenverbrechen, insbesondere an Kranken, protestiert hatten ${ }^{31}$. So wie Wetzel einen Extremfall repräsentiert, so blieb auch Kreyßig in einer hoffnungslosen Außenseiterposition. Erstaunlich ist immerhin, daß letzterer bis Ende 1940 auf seinem Posten blieb, obwohl ihm schon 1935 mit der Entlassung gedroht worden war; ein langwieriges Entlassungsverfahren endete aber erst 1942. In der DDR wurden oppositionelle Richter in der Regel sofort entlassen.

Wie in allen anderen Regionen auch, so haben brandenburgische Juristen bis 1945 zahllose Menschen aus politischen oder „rassischen“ Gründen zum Tode verurteilt ${ }^{32}$, sei es an Gerichten in Brandenburg selbst oder an den Sondergerichten in Polen. Zu Haftstrafen Verurteilte wurden oftmals der Gestapo übergeben und kamen in Konzentrationslagern zu Tode. In der SBZ gab es solche Verbrechen nicht, auch hatte die deutsche Justiz keinerlei Interventionsmöglichkeit in das sowjetische Lagersystem. Allerdings wurden Mißhandlungen durch MfSAngehörige, auch mit Todesfolge, anscheinend von den Gerichten der DDR nur selten geahndet.

Geht man nun auf das Dritte Reich der Vorkriegszeit zurück bzw. die DDR ab 1949 und beschränkt den Vergleich nicht nur auf Brandenburg, so weisen die Entwicklungen etwas größere Ähnlichkeit auf ${ }^{33}$. Nur in der Frühphase lief die Gesamtstruktur der Justizverwaltung bei beiden Diktaturen in unterschiedliche Richtungen: Zwar entfaltete das preußische Justizministerium unter dem Nationalsozialisten und ehemaligen Justizobermeister Hans Kerrl für kurze Zeit eine eminent eigenständige Politik ${ }^{34}$; diese zielte inhaltlich aber in nahezu entgegengesetzte Richtung wie die von Hoeniger und Stargardt. Während 1933/34 die

28 Vgl. den Abbruch der Ermittlungen der Potsdamer Staatsanwaltschaft wegen der Ermordung Kurt von Schleichers am 30. 6. 1934, Gruchmann, Justiz im Dritten Reich, S. 443-445.

29 Vgl. Kramer, OLG-Präsidenten und Generalstaatsanwälte; Dörner, Justiz und Judenmord.

30 Vgl. Bundesarchiv Dahlwitz-Hoppegarten, ZD I 4239, Personalakte Wetzel; BLHA, Rep. 240 Potsdam, Nr. 44, Bl. 169, Rassenpolitisches Amt der NSDAP an LG Potsdam, 20. 8. 1941; Aly/ Heim, Vordenker der Vernichtung, S. $412 \mathrm{ff}$.

31 Gruchmann, Ein unbequemer Amtsrichter im Dritten Reich; Willems, Lothar Kreyssig, S. $89 \mathrm{ff}$. Kreyssig erhielt 1945 das Angebot, wieder in den Justizdienst zu gehen. Er trat jedoch in das Magdeburger Konsistorium ein, ebenda, S. 167. Vgl. auch Weiß, Lothar Kreyssig, S. $160 \mathrm{ff}$.

32 Liste von KPD-Opfern aus dem Bezirk Frankfurt/Oder in: Wir waren damals 19, S. 29-36.

33 Vgl. den Faktorenkatalog bei Rottleuthner, Zur Steuerung der Justiz im Nationalsozialismus und in der DDR.

${ }^{34}$ Kerrl wollte das Preußische zum Reichsjustizministerium erheben, Gruchmann, Justiz im Dritten Reich, S. 100. 
Länderjustizverwaltungen dann in der „Verreichlichung“ weitgehend ausgehebelt wurden, ist in der SBZ bis 1948 eine Föderalisierung zu beobachten, in Brandenburg - als Provinz - sogar in nie gekanntem Ausmaß. Ab 1948 wendete sich jedoch das Blatt, schubweise wurde der Landesjustizverwaltung bis 1952 jede Eigenständigkeit genommen. Im Vergleich gesehen, wurde in der DDR eine höhere Homogenisierung der Justizverwaltung von der SED-Spitze angestrebt und durchgesetzt als im Nationalsozialismus. Bei letzterem blieben regionale Unterschiede durchaus noch bestehen, knüpfte doch die NS-Justiz an den traditionellen Apparat, größtenteils das alte Personal und das hergebrachte Justizmilieu an. Die SED hingegen wollte den völligen Austausch und Umbau.

In der systematischen Einflußnahme setzte die NS-Führung vor allem auf das Reichsjustizministerium. Dieses war zwar nicht rein nationalsozialistisch besetzt, dort war aber das Spitzenpersonal weit weniger liberaldemokratisch eingestellt als die Gruppe um Schiffer bis 1948. Die Anleitung der Justiz im Nationalsozialismus ging den an sich traditionellen Weg vom Ministerium zu den Oberlandesgerichten und den Generalstaatsanwaltschaften. In der DDR war dies nur eine Säule eines stärker regulierten - Anleitungssystems. Beiden Rechtssystemen gemein war die Aufwertung der Staatsanwaltschaft zum entscheidenden Akteur in politischen Strafsachen, ansatzweise auch in Zivilsachen ${ }^{35}$. In der DDR ging man noch weiter, dort wurde die gesamte Staatsanwaltschaft 1951 komplett ausgegliedert; die Bedeutung der Oberlandesgerichte nahm immer mehr ab, für die Steuerung sprangen ab 1951/52 das Oberste Gericht und die Justizverwaltungsstellen ein. Insgesamt hielt sich also der institutionelle Umbau der Justiz unter dem Nationalsozialismus in Grenzen. Vielmehr wurden neue Gerichtssysteme nur im Krieg in den besetzten Gebieten etabliert. Überhaupt deutet die Kontinuität des regulären Justizapparates vom Kaiserreich bis zur Bundesrepublik darauf hin, daß dieser institutionelle Rahmen nur ein Faktor unter vielen für eine spezifische Diktaturjustiz war.

Im Gegensatz zum Obersten Gericht der DDR, das mit SED-loyalen Juristen völlig neu aus der Taufe gehoben wurde, stand die Rechtsprechung des Reichsgerichts in der Kontinuität der Weimarer Republik. Gerade bei Prozessen gegen Kommunisten konnte sie sich deshalb problemlos der Diktatur anpassen ${ }^{36}$. Die Leitrechtsprechung hat in beiden Fällen - Oberstes Gericht und Reichsgericht die politischen Ansprüche der Machthaber erfüllt, wenn auch in unterschiedlichem Ausmaß. Während das Oberste Gericht zur echten Leitinstanz wurde, die das Signal zu Prozeßwellen setzte und ständig Auslegungsrichtlinien verbreitete, war das Reichsgericht kein zentraler Bestandteil der Justizpolitik. Vielmehr übernahm der Volksgerichtshof diese Aufgabe in der politischen Strafjustiz ${ }^{37}$.

Grundlage jeglicher Justizssteuerung in der Diktatur ist das Berichtswesen. Die Mechanismen der Anleitung waren im Dritten Reich hingegen nur indirekter Natur. Deshalb kam der nationalsozialistischen Gesetzgebung in diesem Zusammenhang ein höherer Stellenwert zu als der der DDR: Ergänzt durch die Aktivität der

35 Rüping, Staatsanwaltschaft, S. $23 \mathrm{ff}$.

36 Vgl. Zarusky, Einleitung, S. 20.

37 Vgl. Wrobel, Anfechtung der „Rassenmischehe“. 
Gestapo, konnte damit relativ leicht eine Selbststeuerung des Systems erreicht werden. Die genaue Beachtung der Verfahrensregeln und der gesetzlichen Grundlagen ist selbst für den Volksgerichtshof über weite Strecken kennzeichnend gewesen ${ }^{38}$.

Neben der Rechtssetzung galten im Nationalsozialismus seit 1936 auch allgemeine Anforderungen wie die „Leitsätze über Stellung und Aufgaben des Richters", die die Nichtanwendung von NS-feindlichen Gesetzen vorsahen und dem „Führerbefehl“ Gesetzeschrakter zusprachen. Ein regelrechtes Netzwerk der Steuerung etablierte sich erst spät und nur regional, vor allem in Hamburg mit dem "System Rothenberger": Hier gab es enge Absprachen der Partei mit den Richtern und eine interventionistische Personalpolitik. Rothenbergers weitergehende Vorstellungen von Justizsteuerung, wie er sie in seiner Denkschrift von 1942 niederlegte, wurden - bis auf die von ihm vorgesehene gute Bezahlung der Richter - in der DDR faktisch verwirklicht ${ }^{39}$.

In der SBZ/DDR rückte zwar nicht allein das Justizministerium, dafür aber die gesamte Justizverwaltung in ihren unterschiedlichen Formen in eine Schlüsselposition bei der Steuerung der Rechtsprechung. Innerhalb der Gerichte erscheint die Justizlenkung im Dritten Reich ähnlich wie in der DDR, vor allem durch die Aufwertung der Staatsanwaltschaft als Lenkungsorgan. Sie ist grundsätzlich weisungsgebunden; instrumentalisiert wurde dies nach 1933 und nach 1947. Insbesondere an die Staatsanwälte bei den Sondergerichten erging eine Reihe allgemeiner und fallbezogener Weisungen ${ }^{40}$, in der DDR an alle. Allerdings setzte sich vor 1945 eine Praxis wie in der DDR, die „Strafe nach Antrag“, nicht durch.

Erst im Zweiten Weltkrieg mit seinen spezifischen Rahmenbedingungen expandierten die Steuerungsversuche der NS-Führung gegenüber der Justiz, so 1942 mit der Einführung von sogenannten Vor- und Nachschauen und der Versendung der Richterbriefe, einem eher schwachen Anleitungsinstrument. Doch selbst unter den Bedingungen des Krieges wurde kein Steuerungssystem wie später in der DDR erreicht. Die deutsche Justiz im „Altreich“ bestand im Kern unverändert weiter.

Mehr noch als in der Kontinuität der Institutionen lag ein fundamentaler Unterschied beider Rechtssysteme in der Kontinuität des Personals. Wurde ab 1933 nur ein Bruchteil der Richter ausgetauscht, so erfolgte von 1945 bis 1955 in der SBZ/DDR ein völliger, nahezu zweimaliger Wechsel. Von den 10000 Richtern im Reich wurden bis 1935370 entlassen, in Preußen 97 Richter und Staatsanwälte. Allerdings war die Zahl der entlassenen höheren Beamten größer; in Preußen mußten 643 Juristen aus dieser Kategorie wegen ihrer jüdischen Herkunft gehen. Manche Richter jüdischer Herkunft waren unmittelbar nach der Machtübernahme von SA-Männern in den Gerichten zusammengeschlagen worden. Den Entlassungen der Jahre nach 1933 fehlte jegliche Legitimität, sie richteten sich fast ausschließlich gegen Juden und Anhänger der Weimarer Demokratie. Über die Kategorien des Berufsbeamtengesetzes hinaus waren 1933 am meisten noch die

38 Vgl. Marxen, Volksgerichtshof, S. 30.

39 Bästlein, Vom hanseatischen Richtertum, S. 144.

40 Rüping, Staatsanwaltschaft, S. $29 \mathrm{ff}$. 
Oberlandesgerichtspräsidenten und die Leiter der Staatsanwaltschaften von Entlassung, Versetzung oder Herabstufung bedroht $t^{41}$. In der Provinz Brandenburg wechselte der preußische Justizminister Kerrl des weiteren fast alle Landgerichtspräsidenten aus ${ }^{42}$. Dabei kamen natürlich meist andere langjährig tätige Juristen zum Zuge, da - im Gegensatz zur DDR mit ihren Volksrichtern - kein anderes Personal verfügbar war; arbeitslose Studienabsolventen mit Sympathien für den Nationalsozialismus hatten 1933 beste Einstellungschancen. In der SBZ erfolgte auf Anordnung der sowjetischen Besatzungsmacht dagegen ein radikaler Schnitt. Das Spitzenpersonal war $1945 \mathrm{zu}$ einem erheblichen Teil kompromittiert; bestimmte Juristen, die besonders belasteten Kategorien zugerechnet wurden, landeten sogar in den Lagern des NKWD.

Auch die Personalpolitik der Justizverwaltungen gestaltete sich im Dritten Reich zurückhaltender als in der frühen DDR. Eine Zentralisierung fand dabei nur ganz begrenzt statt, vielmehr hatten die Oberlandesgerichts-Bezirke weiter großen Spielraum. Seit 1935/36 galten politische Kriterien für die Beförderungen und die Beurteilungen; darüber hinaus hatten die Richter und Staatsanwälte aber relativ wenig Unannehmlichkeiten zu befürchten. Absetzungen waren selten und an ein langwieriges Verfahren gebunden. Selbst wenn ein Staatsanwalt amtsenthoben war, was seit 1937 grundsätzlich möglich war, konnte er oftmals als Richter unterkommen.

Trotz anderslautender Deklamationen verblieb die nationalsozialistische Personalpolitik in konservativen Bahnen. Die soziale Zusammensetzung des Justizapparates änderte sich kaum; dagegen wurden Frauen zusehends aus ihren Posten gedrängt, seit 1936 hatten sie keine Chance mehr auf eine Planstelle ${ }^{43}$. Da auf die Machtergreifung 1933 keine drastische Entlassungswelle folgte, stellte sich auch die Frage nach schneller Gestellung von Ersatz nicht. Vielmehr gab es genügend arbeitslose Assessoren, die um Anstellung nachsuchten ${ }^{44}$. Zwar hatte es schon in der Weimarer Zeit Überlegungen zur Schulung von Volksrichtern, also Personen ohne juristischen Abschluß, gegeben. Unter anderen politischen Vorzeichen kam diese Vorstellung im Krieg erneut ins Spiel, insbesondere angesichts der Personalknappheit ${ }^{45}$; verwirklicht wurde sie jedoch nicht.

Ähnlich wie in der SBZ/DDR kam es jedoch zum Einsatz von Rechtsanwälten im höheren Justizdienst, allerdings erst im Zweiten Weltkrieg. Sie gelangten sogar vorzugsweise als Staatsanwälte an die Sondergerichte im besetzten Osteuropa, wo sie an der verheerenden Urteilspraxis mitwirkten. Zahlenmäßig blieb ihr Anteil an Richtern und Staatsanwälten jedoch sehr gering ${ }^{46}$.

Mit der Struktur des Personals hängt die Frage der politischen Konformität zusammen. Der Eintritt der Juristen in die jeweilige Staatspartei zeigte in etwa den gleichen zeitlichen Verlauf, wenn man auch die SED des Jahres 1946 nicht mit der NSDAP von 1934 gleichsetzen kann. Im Jahre 1938 hatten $54 \%$ aller Richter und

\footnotetext{
41 Vgl. Morsey, Politische Gesinnungsprüfung, S. $221 \mathrm{f}$.

42 Gruchmann, Justiz im Dritten Reich, S. 229.

43 Rüping, Staatsanwaltschaft, S. $46 \mathrm{ff}$.

44 Angermund, Deutsche Richterschaft, S. $21 \mathrm{ff}$.

45 Feth, Volksrichter, S. 356f.; Angermund, Deutsche Richterschaft, S. 264.

46 Douma, Rechtsanwälte als Staatsdiener.
} 
Staatsanwälte ein Mitgliedsbuch der NSDAP, zum Teil erlangt durch korporative Übertritte. Der Grad der Mitgliedschaft in der jeweiligen Staatspartei war jedoch auf längere Sicht in der DDR höher; dort hatte er auch eine größere Bedeutung für den einzelnen: Die SED-Mitglieder mußten sich insbesondere 1951 einer politischen Überprüfung unterziehen lassen. Innerhalb der Gerichte waren die Justizangestellten mit SED-Parteibuch gehalten, an den Veranstaltungen der Betriebsparteiorganisation teilzunehmen. Die Mitgliedschaft in der NSDAP zeigte dagegen nur einen Indikator für die Übereinstimmung mit den Zielen des NS-Staates und für das Karrierestreben an. Viele Richter, die der NSDAP distanziert gegenüberstanden und ihr nicht beitraten, haben nichtsdestotrotz Terrorurteile en masse verhängt. Ein eindeutiger Zusammenhang zwischen NSDAP-Mitgliedschaft und Teilnahme an Justizverfolgungen läßt sich bei Richtern im allgemeinen nicht nachweisen ${ }^{47}$. Tendenziell gilt dies eher für die SED-Mitgliedschaft in der Zeit, als diese noch einen brauchbaren statistischen Indikator abgab; in den politischen Strafkammern saßen ab 1950 nur noch SED-Richter.

Unterschiedlich sind auch Ausbildung und Sozialisation des Rechtspersonals beider Systeme. Die Ausbildung der Juristen, die im Dritten Reich tätig waren, datierte meist noch aus Zeiten des Kaiserreichs oder der Weimarer Republik; die Juristen der DDR, die noch $1955 \mathrm{im}$ Amt waren, hatten in den allermeisten Fällen ihre Ausbildung nach 1945 erhalten. Eine Zentralisierung der juristischen Fachausbildung forcierten beide Systeme. Die Praxis war jedoch grundverschieden, wenn man die DDR mit ihrer Dauerschulung in den fünfziger Jahren betrachtet.

Im Vergleich zur DDR-Justiz waren fachliche und politische Schulung der Juristen unter dem Nationalsozialismus eher gering entwickelt. Die juristische Fortbildung war bei Volljuristen auch gar nicht in dem Maße nötig wie bei den Volksrichtern. Wo es sie dennoch gab, beschränkte sie sich auf „fachwissenschaftliche Wochen" oder die Lektüre der juristischen Zeitschriften. Eine Mischung aus Fortbildung und Indoktrination bot das Referendarlager „Hans Kerrl“; der NSRechtswahrerbund organisierte für seine Mitglieder "Kameradschaftsabende“ und Wochenendschulungen. Deren Bedeutung ist aber eher als gering zu veranschlagen; statt inhaltlicher Ausrichtung wurde hier mehr das Gemeinschaftsbewußtsein gefördert. Zudem schränkte man die Schulung bei Kriegsbeginn wieder ein ${ }^{48}$.

Politischem Druck von außen sah sich das Justizpersonal unter dem Nationalsozialismus vor allem in den ersten Jahren bis 1935 ausgesetzt; dies konnte bis zum SA-Terror in Gerichten reichen. Ein Dauerproblem stellten freilich die Interventionen aller möglichen Parteistellen dar ${ }^{49}$. In der SBZ/DDR nahm der politi-

47 Niermann, Durchsetzung, S. 376; Warmbrunn, Strafgerichtsbarkeit, S. 474.

48 Majer, Fremdvölkische, S. 629 f.

49 Vgl. Weinkauff, Die deutsche Justiz, S. $113 \mathrm{ff}$. So war etwa ein Gerichtsassessor am Amtsgericht Neuruppin erheblichen Anfeindungen ausgesetzt, als er einer Beleidigungsklage von Otto Dibelius gegen einen Pastor der „Deutschen Christen“ recht gab. Der Richter mußte nicht nur während der ganzen Zeit des Nationalsozialismus, sondern auch nach 1945 in Schleswig-Holstein um seine planmäßige Anstellung kämpfen; Schorn, Richter im Dritten Reich, S. 565 ff.; Godau-Schüttke, Ich habe nur dem Recht gedient, S. $195 \mathrm{ff}$. Ein Richter des AG Oranienburg wurde hart von der SS attackiert, als er sich bei der Obduktion eines im KZ Sachsenhausen ermordeten Häftlings weigerte, den Lagerarzt beizuziehen; Gruchmann, Justiz im Dritten Reich, S. $653 \mathrm{f}$. 
sche Druck von 1948 bis 1952 konstant zu, obwohl dort ein weitgehender Personalaustausch stattgefunden hatte. Beiden Systemen gemeinsam waren konstante Attacken der Parteipresse auf „unerwünschte“ Urteile und Richter; freilich ließen auch sie mit längerer Regime-Dauer nach.

Grundsätzlich waren Partei-Instanzen an der Personalpolitik zu beteiligen, so gab es ab 1935 Regelanfragen beim Stellvertreter des Führers ${ }^{50}$. Letztendlich entschieden aber die Oberlandesgerichte über Versetzungen usw., entsprechende Verlangen von NSDAP-Gruppen hatten kaum eine Aussicht auf Erfolg. Überhaupt war der Anteil rein politischer Versetzungen von Juristen im Dritten Reich recht gering. Ganz anders im Fall der SED. Entfernungen oder Versetzungen von Juristen auf Wunsch des ZK oder der Landes-/Bezirksleitungen wurden umgesetzt, insbesondere wenn der Betreffende aus der SED ausgeschlossen worden war.

Diese doch recht gravierenden Differenzen zweier Justizapparate in diktatorischen Systemen zeigen deutlich, wie es um den Handlungsspielraum der Juristen bestellt war. Im Dritten Reich agierten fast nur „Profis“ 51 , die zwar Attacken aus der NSDAP, letztendlich aber kaum berufliche Konsequenzen zu befürchten hatten. In der DDR dagegen waren die Volksrichter als halbe Dilettanten schon wegen ihrer Wissensdefizite von der Anleitung durch Justizverwaltung und Staatspartei abhängig. Allerdings war die Generation der Volksrichter, die seit Ende 1949 die Schulen verließ, auch von sich aus zur Anpassung ans Regime bereit. Insgesamt war die Steuerung in der DDR straffer und systematischer, die Sanktionsmittel waren härter. Kurzum: Die Handlungsspielräume der Richter unter dem Nationalsozialismus erscheinen größer. Zugleich war ein höherer Anteil und natürlich eine bedeutendere Zahl von Richtern im Nationalsozialismus an politischen Verfahren beteiligt (etwa jeder Dritte) als in der DDR (etwa jeder Vierte) ${ }^{52}$. Gerade unter diesem Aspekt wirft die brachiale Strafpolitik der NSJustiz ein um so erschreckenderes Licht auf die Juristen.

Allerdings haben viele Richter in den Jahren des Dritten Reichs ihren Handlungsspielraum auch dosiert genutzt, um allzu harte justizpolitische Vorgaben abzumildern; das trifft sogar auf die frühen Jahren des Volksgerichtshofs zu. Die Bandbreite der politischen Orientierung unter den Richtern konnte auch nach 1933 von DDP bis NSDAP reichen ${ }^{53}$. Insbesondere an den regulären Kammern der Landgerichte und an den Amtsgerichten war die Rechtsprechung nicht einheitlich politisch ausgerichtet. In geringerem Maße gilt dies auch für die Amtsbzw. Kreisgerichte der DDR. Geradezu ein experimenteller Idealfall wäre ein Vergleich der Tätigkeit von Richtern, die aus der DDR in die Bundesrepublik flüchteten und dort wieder bei Gericht arbeiten konnten, mit ihren dortigen Kollegen, die den Systemwechsel vom Nationalsozialismus mitgemacht hatten. Dabei

50 Ebenda, S. $207 \mathrm{f}$.

51 Davon unberührt bleibt die Feststellung, daß im Zweiten Weltkrieg ein Prozeß der Deprofessionalisierung in den juristischen Berufen in Gang kam, vgl. Jarausch, Unfree Professions, S. $172 \mathrm{ff}$

52 Niermann, Die nordrhein-westfälische Justiz, S. 748; für DDR eigene Schätzung auf Grund der vorliegenden Personalangaben.

53 Vgl. Stein-Stegemann, In der Rechtsabteilung, S. 202 ff.; Warmbrunn, Personalprofil der Richter, S. 173. 
könnte klarwerden, welch enorme Bedeutung das politische System und die Struktur der Justiz für das Verhalten der Richter haben.

Diesen Systembedingungen stellten sich nur wenige entgegen. Minimal war die Zahl der aktiven Juristen, die man dem Widerstand im Dritten Reich zurechnen kann. Dazu fehlten meist die biographischen Voraussetzungen und - nach den „Säuberungen“ von 1933 - auch jeglicher Rückhalt im eigenen Milieu ${ }^{54}$. In der DDR hingegen arbeitete eine Reihe von Justizfunktionären heimlich mit dem UfJ zusammen. Zugleich bot sich den Juristen der DDR lange die Möglichkeit der Flucht in die Bundesrepublik mit der Aussicht, dort wieder auf einen vergleichbaren Posten zu gelangen 55 .

Insgesamt entsteht der Eindruck, daß die Staatspartei der DDR viel größere Anstrengungen unternahm, um die Konformität des Justizpersonals zu erreichen. Das weist auf das Konsens-Defizit der frühen DDR-Gesellschaft hin. Selbst die alten Volljuristen ohne NSDAP-Mitgliedsbuch wurden als unzuverlässig entlassen, viele der frühen Volksrichter machten die Radikalisierung ab 1948 nicht mit. Erst ab 1953, als es in der Bevölkerung die massivsten Widerstände gegen das SED-Regime gab, zeigte sich die neue Juristen-Elite weitgehend konform.

Die Rolle der jeweiligen Staatsparteien in der Justiz hing sehr stark von deren institutioneller Struktur ab. Allein die SED war bis in die fünfziger Jahre vollständig ausländischen, nämlich sowjetischen Vorgaben unterworfen. Während die Einheitspartei allmählich einen regelrechten Staatsführungsapparat in den ZKAbteilungen und bei den territorialen Parteileitungen entwickelte, war die NSDAP bis 1939 institutionell weniger bedeutsam, sie „vernutzte“ gleichsam den Staatsapparat parasitär ${ }^{56}$. Cum grano salis erscheint der vielzitierte „Doppelstaat“ also eher in der DDR als im Dritten Reich bestanden zu haben. Allerdings war Mitte der fünfziger Jahre kaum noch ein traditioneller Rechtsapparat - also ein klassischer „Normenstaat“ - vorhanden; das Personal hatte man nahezu komplett ausgewechselt, die formalen Regelungen standen oftmals nur auf dem Papier ${ }^{57}$.

Sowohl die Landes-/Bezirksleitungen der SED wie die Gauleitungen der NSDAP haben auf die Justiz Einfluß genommen; beide hatten ein Interventionsrecht bei Ernennungen. Allein in der DDR entwickelte sich in den fünfziger Jahren ein festes Regelsystem, das weit über die Kontrolle der Urteile hinausging. Grundlage dafür war vor allem die Berichterstattung lokaler und regionaler Parteistellen nach oben, die in der DDR schon bald genau geregelt wurde, im Dritten Reich aber erst ab 1941. Aus den nationalsozialistischen Gau- und Kreisleitungen hingegen stammten immer wieder einzelne, oftmals voluntaristische Interventionen $^{58}$. Hin und wieder kam es zu offenen Konflikten zwischen Gauleitern und führenden Juristen, die zur Absetzung von Oberlandesgerichtspräsidenten oder zur Entlassung von Generalstaatsanwälten führen konnten. Erst 1942 gab es Ver-

54 Vgl. Angermund, Deutsche Richterschaft, S. 7 f.

55 Vgl. Albin, Richterlicher Widerstand, S. $46 \mathrm{ff}$.

56 Vgl. Mommsen, Nationalsozialismus und Stalinismus, S. $474 \mathrm{f}$.

57 Vgl. Werkentin, Politische Strafjustiz, S. 397 f;; und die Kritik von Rottleuthner, Ende der Fassadenforschung, S. 59.

58 Beispielsweise beschwerte sich der Gauleiter der „Kurmark“, Kube, über ein Urteil des AG Lukkenwalde, ohne allerdings mit seinem Ansinnen durchzudringen; Gruchmann, Justiz im Dritten Reich, S. 662. 
suche, die Rechtsprechung mit dem Parteiapparat systematisch zu koordinieren, was aus der vorgeschriebenen Beteiligung der Gauleiter am Gnadenverfahren deutlich wird59. Berüchtigt sind schließlich die Eingriffe der Staatsführer in die Justiz, durch Hitler vor allem seit 1939. In der DDR wurden sie durch ein geregeltes Verfahren der Vorlage von der ZK-Abteilung vorbereitet. Insgesamt ergibt sich für die NSDAP also eher der Eindruck spontaner Intervention. Die eigentliche Steuerung lief über das Reichsjustizministerium und seine nachgeordneten Behörden. In der Personalpolitik und in der Justizsteuerung entwickelte sich die Gleichschaltung in der DDR radikaler und schneller als im Dritten Reich; dazu bedurfte es auch nicht des beschleunigenden Faktors Krieg. SMAD und SED setzten ihren Willen zur Neu-Konstruktion weitgehend durch.

Die institutionelle Umbildung der politischen Justiz im Dritten Reich weist gewisse Ähnlichkeiten zur Entwicklung in der SBZ/DDR auf. Ursprünglich stammt die Einrichtung der Sondergerichte noch aus der Weimarer Zeit; so gab es bereits 1919-1924 Sondergerichte gegen Schwarzhandel60. Die bayerischen Volksgerichte, die - im Ausnahmezustand geschaffen - im gleichen Zeitraum tätig waren, zeigten alsbald Auswüchse politischer Justiz. Formell setzte der NS-Staat mit der Bildung von Sondergerichten die Spezialjustiz zur Bekämpfung von Ausschreitungen fort, die es seit 1931 gab.

Auch die Sonderjustiz der DDR - die es laut Verfassung gar nicht geben durfte - knüpfte an allgemein legitimierte Ausnahmeregelungen an, nämlich den Befehl 201 der sowjetischen Besatzungsmacht. Der Bruch der Kontinuität in der Rechtsprechung war 1933 klarer als 1947. An allen Oberlandesgerichten wurden Sondergerichte für Verfahren auf der Basis von Reichstagsbrand- und „Heimtücke“Verordnung geschaffen. Die Expansion der Kammern auf die Landgerichte erfolgte weitgehend erst 1940, so etwa beim LG Frankfurt/Oder'11. Ein Vergleich von Sondergerichten und 201-Kammern zeigt zunächst eine Reihe von Parallelen. So bestimmte bei beiden zunächst die Geheimpolizei und dann das Gericht den Umfang der Beweisaufnahme, der Strafrahmen war nicht genau festgelegt. Allerdings gab es gegen die Entscheidungen der Sondergerichte in der NS-Zeit keine Rechtsmittel, bei den 201er-Verfahren dagegen bis zu einem gewissen Grade. Auffällig ist die unterschiedliche Personalbesetzung an den Ausnahmegerichten: Setzte die SED in den 201er-Kammern vor allem junge Volksrichter mit SED-Parteibuch ein, so arbeiteten an den Sondergerichten bis Kriegsbeginn in erster Linie erfahrenere Richter, die oftmals nicht NSDAP-Mitglied waren. Im Krieg verlagerte sich der Schwerpunkt der gesamten Strafrechtsprechung von den Landgerichten auf die Sondergerichte ${ }^{62}$; in der DDR kam es dazu nie. Die Sondergerichte in den besetzten Gebieten ab 1940 fanden überhaupt keine Entsprechung, sie warfen im Schnellverfahren meist Todeurteile aus. Durchaus parallel entwickelten sich anfangs der 1934 geschaffene Volksgerichtshof, faktisch eine Art Sondergericht des Reichsgerichts, und die politischen Kammern des Obersten Gerichts der DDR. Im Krieg, besonders ab 1942, geriet der Volksgerichtshof aber zu einem

\footnotetext{
59 Majer, Fremdvölkische, S. 628 f., 636f.; Bästlein, Vom hanseatischen Richtertum, S. 102.

60 Wassermann, Justiz als Mythos, S. 95.

61 Dörner, „Heimtücke“, S. 34 ff.; Wassermann, Justiz als Mythos, S. 98.

62 Gruchmann, Justiz im Dritten Reich, S. 953; Niermann, Durchsetzung, S. 376.
} 
Mordinstrument des NS-Staates, hinter dessen Tätigkeit das Oberste Gericht weit zurückblieb63.

Unter dem Nationalsozialismus bestanden die Verwaltungsgerichte weiter, während sie in der DDR nach kümmerlichen Ansätzen bald wieder in der Versenkung verschwanden. Im Dritten Reich waren sie Gegenstand einer Dauerdebatte, die von den Verteidigern der Verwaltungsgerichte nur deshalb geführt werden konnte, weil deren Instanzen sich kaum mehr mit dem Individualrechtsschutz beschäftigten und immer mehr NS-freundliche Urteile fällten. Während die traditionellen Kompetenzen zusehends ausgehöhlt wurden, dienten die Verwaltungsgerichte im Krieg bald nur noch zur "Verwaltungsvereinfachung“. Immerhin konnte die Vorgängerinstitution des brandenburgischen Verwaltungsgerichtshofs, das Preußische Oberverwaltungsgericht, durchaus eine Zeitlang auf rechtsstaatliche Normen pochen. Insgesamt erwiesen sich die Verwaltungsgerichte aber für die NS-Führung nicht als derart einschränkend, daß man sie abgeschafft hätte ${ }^{64}$. In der SBZ/DDR strebte die SED einen Umbau der Verwaltung mit neuem Spitzenpersonal an; da wurde die Gelegenheit genutzt, die Verwaltungsgerichte gleich beim Neuaufbau wirkungslos zu machen. Im NS-System gab es hingegen keine Einrichtung, die den Kontrollkommissionen kommunistischer Staaten vergleichbar wäre. Sie waren wohl auch nicht nötig, da der Nationalsozialismus weitgehend auf die Kooperation des Staatsapparates bauen konnte.

Von fundamentaler Bedeutung für die Justiz in allen totalitären Diktaturen ist die Polizei. Schon das reguläre Hilfsorgan der Staatsanwaltschaften, die Kriminalpolizei, veränderte sich im Dritten Reich wie in der SBZ gegenüber der Weimarer Republik. Der Nationalsozialismus konnte allerdings - im Gegensatz zur SED auf die weitgehende Personalkontinuität unter den Kriminalern setzen. Neben neuen Verfahren wie der Vorbeugungshaft waren es besonders die Aufgabenfelder, die neu definiert wurden. Zwar wurden der Kriminalpolizei politische Ermittlungen 1937 entzogen; im Rahmen einer "rassistischen Generalprävention“, wie sie ab 1937 auf die Agenda gesetzt wurde, war die Kripo aber von zentraler Bedeutung bei der Verfolgung der Sinti und Roma, die schon ab 1938 in den Massenmord in Konzentrationslagern mündete. Diese Aufgabenteilung zwischen Kripo und Gestapo erweiterte sich dann im Krieg. Im besetzten Osteuropa waren Kriminalpolizisten bei nahezu allen Massenverbrechen involviert ${ }^{65}$.

Angesichts der Verbrechen der NS-Polizei und im Hinblick auf eine Gleichschaltung setzte die Kriminalpolizei der SBZ hingegen nahezu vollständig auf neues Personal; deshalb hatte sie lange mit Fluktuation und mangelnder Qualifikation zu kämpfen. Auch ihr Arbeitsgebiet bildete zunächst die normale Kriminalität, sie war am Rande in die "Gegnerbekämpfung" eingeschaltet und erhielt schließlich Aufgaben beim "Aufbau des Sozialismus“. Allerdings ist ihre Rolle im Verfolgungsapparat immer randständig geblieben ${ }^{66}$.

Schon ähnlicher entwickelten sich das MfS ab 1950 auf der einen Seite und der Gestapo/Sicherheitsdienst-Apparat bis 1937/38 auf der anderen. Beide waren die

${ }^{63}$ Vgl. Wagner, Volksgerichtshof, S. $796 \mathrm{ff}$.

${ }_{64}$ Stolleis, Verwaltungsgerichtsbarkeit, bes. S. $208 \mathrm{f}$.

65 Vgl. Wagner, Volksgemeinschaft ohne Verbrecher, S. $201 \mathrm{f}$., $254 \mathrm{ff}$.

66 Vgl. Das Arbeitsgebiet 1 der Kriminalpolizei. 
zentralen Apparate zur „Gegnerbekämpfung“, übernahmen die Ermittlungen in den meisten politischen Verfahren und versuchten die Bevölkerung genauso wie den Justizapparat mittels Spitzeln oder auf der Basis von Denunziationen zu überwachen. In beiden Fällen bestand eine Informationspflicht der Justiz an die Geheimpolizei in "politischen" Ermittlungsverfahren ${ }^{67}$. Ähnlichkeiten beider Geheimpolizeien konnten auch die Opfer ihrer Ermittlungsverfahren spüren, insbesondere bei den brutalen Verhören und in der Behandlung in Polizeigefängnissen. Immerhin löste beim MfS im Laufe der fünfziger Jahre der psychische Druck den physischen allmählich ab. Rechtlos blieben alle Delinquenten ${ }^{68}$.

Allerdings gab es auch gravierende Unterschiede in Struktur und Personal. Der wichtigste ist sicherlich die Führungsfunktion sowjetischer Berater im MfS, die sich bis 1952 auf nahezu alle Tätigkeiten erstreckte. Die Kommissariate 5 wie das MfS griffen auf Polizisten zurück, die frühestens 1945 eingestellt worden waren. Wie bei der Kriminalpolizei des Dritten Reiches kam auch der größte Teil des Gestapo-Personals aus der Polizei der Weimarer Republik; der Sicherheitsdienst wurde zwar neu aufgebaut, seine Funktionäre hatten jedoch oftmals ein (Jura-) Studium hinter sich. Früher als die Kriminalpolizei entwickelten Gestapo/SD um 1937 ein rassistisches Paradigma mit fatalen Folgen. Während die Gestapo immer mehr Juden verhaftete, arbeitete der SD zu dieser Zeit bereits an "Gesamtlösungen“ in der Judenverfolgung. Das MfS suchte zwar den vermeintlichen „Klassengegner“, entwickelte aber nie monströse Planungen zu seiner physischen Vernichtung. Der gravierendste Unterschied beider Geheimpolizeien war aber sicherlich das Schutzhaftverfahren der Gestapo, das sich ähnlich nur beim NKWD/MGB wiederfindet, nicht jedoch beim MfS. Mit Beginn des Zweiten Weltkrieges war die Gestapo nicht nur ermächtigt, Justizurteile durch Mord zu „korrigieren“, sondern fügte dem Schutzhaftverfahren noch den - ohne jegliches formales Verfahren durchgeführten - Massenmord durch Erschießung oder Deportation zur Vernichtung hinzu. Das Schutzhaftverfahren beruhte auf Ideen, die schon vor dem Nationalsozialismus entwickelt worden waren. Diese präventive Verhaftung fiel auch 1933 anfangs in den Bereich der Justiz, viele „Schutzhäftlinge“ saßen in regulären Gefängnissen ein. Doch nach anfänglichen Auseinandersetzungen zwischen Justiz und politischer Polizei setzte die Gestapo 1934 ihre alleinige Kompetenz in der „präventiven Verbrechensbekämpfung“ durch. Damit war die Justiz zu einem erheblichen Teil ausgehebelt worden. Sie fand sich jedoch bald mit dieser Aufgabenteilung $a b$, ja manche Behörden wie die Generalstaatsanwälte arbeiteten problemlos mit der Gestapo zusammen.

Zwischen DDR-Justiz und MfS gab es zwar hin und wieder Reibereien, ein echter Kompetenzkonflikt blieb allerdings aus. Dazu gab es auch viel weniger Anlaß als in den ersten Jahren der NS-Herrschaft; schließlich entschieden bis Anfang der fünfziger Jahre die sowjetischen Behörden, wer welche Aufgaben wahrzuneh-

67 Majer, Fremdvölkische, S. 646f. Zur Stapostelle Potsdam vgl. Hinze, Vom Schutzmann zum Schreibtischmörder.

68 Vgl. auch die diesbezügliche Äußerung des DVdI-Abteilungsleiters Schönherr, die Gestapo sei Vorbild für K 5, Henke/Engelmann, Aktenlage, S. 230. 
men hatte. Letztendlich war die politische Polizei in beiden Systemen der justiziellen Kontrolle entzogen, in beiden spielte sich eine Kooperation ein ${ }^{69}$.

Von zentraler Bedeutung für die Bewertung der Justiz in Diktaturen sind die politischen Prozesse. Deutsche Gerichte verurteilten Gegner der jeweils herrschenden Regime ab 1933 sofort, in der SBZ erst Mitte 1949. Zu den NS-Prozessen, die ab dieser Zeit zum Sprungbrett für Unterdrückungsmaßnahmen wurden, fand sich natürlich keine Entsprechung im Dritten Reich. Die Abrechnung mit der "Systemzeit" der Weimarer Republik richtete sich gegen Unschuldige, sie lief zum größten Teil über SA-Terror oder über die Schutzhaft-Verfahren ab. Schon ab 1935/36 richtete sich die politische Justiz des NS-Staates nicht mehr nur gegen vermeintliche politische "Gegner", immer mehr sickerte das rassistische Paradigma in die Rechtsprechung ein. Für die Jahre ab 1937/38 rücken deshalb die Parallelen in der NS-Rechtsprechung zur politischen Justiz der DDR allmählich in den Hintergrund.

Schon vor dem Krieg gehörte die Rassenpolitik zum Alltag des deutschen Justizsystems im Nationalsozialismus. Mit der Einrichtung der Erbgesundheitsgerichte, in Potsdam ab 1935, konnten Richter Zwangssterilisierungen verhängen. Allerdings war es in der SBZ durchaus umstritten, ob es sich bei allen Sterilisierungen im Dritten Reich um Unrechtsmaßnahmen handelte. Vom Jahre 1938 an waren Gerichte befugt, ebenso wie das Reichssippenamt, über die Einstufung der „rassischen“ Herkunft zu entscheiden. Für die Betroffenen konnte dies katastrophale Folgen haben. Seit 1936 waren Urteile gegen Juden wegen „Rassenschande“, also außerehelicher sexueller Beziehungen zu Nichtjuden, an der Tagesordnung 70 . Der Rassismus drang im Laufe der dreißiger Jahre nicht nur ins Strafrecht, sondern auch in die anderen Rechtsbereiche ein: So konnten nichtjüdische Ehepartner ihre "Rassenmischehe" anfechten; im Arbeits- und Zivilrecht wurden Juden und andere Minderheiten systematisch benachteiligt und schließlich von Rechtsmitteln ausgeschlossen ${ }^{71}$.

Die inzwischen häufig anzutreffende Parallelisierung von „Rassenverfolgung“ und "Klassenverfolgung“ überdeckt also zahlreiche tiefgreifende Unterschiede. Während sich im Dritten Reich die Rechtsprechung eindeutig bis hinein zum Justizmord von rassistischen Mustern leiten ließ, trat der Rechtsapparat der DDR zwar mit dem Anspruch einer Justiz für eine Klasse an, realisierte ihn letztendlich jedoch nur begrenzt. Vor allem aber fehlte es der DDR-Justiz an der Ausschließlichkeit, mit der die Gerichte bis 1945 Juden und „Fremdvölkische“ behandelten. Das bedeutete, daß bestimmte Personengruppen grundsätzlich schlechter gestellt wurden, bei den Juden unentrinnbar bis zum Tod ${ }^{72}$. In der DDR gab es zwar soziale Muster der Benachteiligung vor Gericht, ob diese aber zur Anwendung kamen, hing immer von wechselnden politischen Entscheidungen ab. Gerade spezifische Justizkampagnen wie gegen SED-Abweichler, "Buntmetallschmuggler“ oder „Verbrecher am Volkseigentum“ zeigen, wie leicht diese sozialen Muster durchbrochen werden konnten. Ein Teil der Richter war auch Anfang der fünf-

69 Vgl. Eckert, Gleiche Brüder; Vollnhals, Geheimpolizei, S. $46 \mathrm{ff}$.

$70 \mathrm{Vgl}$. Robinsohn, Justiz als politische Verfolgung, passim.

71 Vgl. ausführlich Rethmeier, Nürnberger Rassegesetze, bes. S. $163 \mathrm{ff}$.

72 Urteile brandenburgischer Gerichte gegen Juden in: Püschel, ...der Angeklagte, S. $46 \mathrm{ff}$. 
ziger Jahre selbst noch bürgerlicher, in Einzelfällen sogar adliger Herkunft. Somit stand die Justiz der DDR letztendlich weniger unter einem sozialen denn unter einem politischen Paradigma.

Das zeigt ebenso die Tendenz kommunistischer Parteien, kampagnenartig gegen eigene Funktionäre vorzugehen. Dies war dem NS-System fremd. Höchstens in eklatanten Fällen der - im Dritten Reich endemischen - Korruption erfolgten Strafverfahren gegen „Hoheitsträger“, die gelegentlich mit Todesurteilen endeten. Die Rolle der Parteigerichtsbarkeit war bei der SED ungleich größer als bei der NSDAP. Die Ermittlungen der Zentralen Partei-Kontrollkommission der SED gingen oftmals gleitend in politische Strafverfahren über.

Vergleicht man das Vorgehen der Justiz beider Regime gegen bestimmte Gruppen, so läßt sich der Umfang politischer Justizverfolgung etwas genauer festmachen. Behält man den Nationalsozialismus bis 1938 als Bezugsgröße, so betraf dies die politischen Gegner des jeweiligen Systems, die natürlich nur zum kleinen Teil identisch waren, aber auch dieselben Organisationen, wie im Falle der Kirchen und der Zeugen Jehovas. Politische Urteile vor allem gegen katholische Geistliche waren im Nationalsozialismus ab Ende 1935 viel ausgeprägter als vergleichsweise die kurze aber heftige Verfolgungswelle der SED gegen die evangelische Kirche Anfang 1953. Im gerichtlichen Vorgehen gegen Zeugen Jehovas erwies sich die Justiz der DDR ab 1950 in den Strafmaßen noch härter als die Gerichte bis $1939^{73}$. Allerdings wird diese Feststellung dadurch relativiert, daß die Inhaftierung aller Verfolgtengruppen in Konzentrationslagern des Nationalsozialismus in der DDR keine Entsprechung mehr fand. Die Internierung durch die sowjetische Geheimpolizei basierte dagegen anfangs auf einem alliiertem Konsens gegen Funktionsträger des Dritten Reiches. Schon bald zeichnete sich aber eine sowjetische Verfolgungspraxis bezüglich politischer Gegner ab, wie es sie ähnlich im nationalsozialistischen KZ-System bis 1938 gegeben hatte. Zahllose Schicksale von Internierten, die vom einen ins andere Lagersystem kamen, dokumentieren dies.

Die Intensität der politischen Strafverfahren läßt sich in etwa an den Statistiken für OLG-Bezirke im Dritten Reich ablesen. So wurden im Bereich des OLG Hamm, dem Gerichtsbezirk mit der härtesten politischen Justiz im Reich, zwischen 1934 und 193812000 Personen allein wegen Hochverrats verurteilt, dazu kamen weit über tausend Verfahren wegen „Heimtücke“. Dies war ein Vielfaches der Verfahren nach KRD 38 und Artikel 6 in Brandenburg von 1950 bis 1954. Selbst auf dem Höhepunkt der Justizrepressionen, im ersten Halbjahr 1953, ergingen in der ganzen DDR nur doppelt so viele Verurteilungen vor I-Senaten wie in Hochverratssachen allein im Raum Hamm im Jahre $1934^{74}$.

${ }^{3}$ Vgl. die Schätzung der. Wachtturm-Gesellschaft, daß im Dritten Reich 6000 Zeugen zu durchschnittlich 2,3 Jahren Haft verurteilt wurden. Im Krieg wurden 250 weitere - meist wegen Kriegsdienstverweigerung - zum Tode verurteilt. Fast 1000 Personen starben in Lagern. Garbe, Zwischen Widerstand und Martyrium, S. 483, 488.

74 Niermann, Durchsetzung, S. 169, 252; SAPMO, DY 30/IV 2/13/409, MdJ an Rechtsabt. des Hohen Kommissars, 28. 7. 1953. Die in der Literatur hin und wieder auftauchende Zahl von 78000 politischen Verurteilungen in der DDR allein 1950 (z. B.: Richter, Entstehung und Transformation, S. 2559) ist wohl eine Verwechslung mit der Gesamtzahl aller Verurteilungen, vgl. Rosenthal/ Lange/Blomeyer, Justiz, S. 31. 
Es ist also nicht zu übersehen, daß die politische Strafjustiz des NS-Staates selbst in den Vorkriegsjahren im allgemeinen härter vorging als die der DDR in den fünfziger Jahren. In Einzelfällen urteilten aber Gerichte der DDR bei vergleichbaren Delikten, insbesondere Kritik an der Staatspartei, mit schärferen Strafen. Das Bild der Justiz im Nationalsozialismus ist vor allem durch die mindestens 40000 Todesurteile geprägt, die sie verhängt hat ${ }^{75}$. Bis 1939 stand die Quantität der Todesurteile durchaus in Kontinuität zur Weimarer Republik; allerdings wurde die Todesstrafe auch immer öfter vollstreckt ${ }^{76}$. 1940/41 begann dann der Justizmassenmord, vorrangig in den besetzten Gebieten. In der DDR lag die Zahl der verhängten Todesurteile bei einigen hundert.

Parallelen zur DDR ergeben sich dagegen im Strafvollzug bei Haftstrafen und natürlich für den einzelnen Betroffenen, bei der Behandlung der Inhaftierten in den dreißiger Jahren auf der einen Seite und in den fünfziger Jahren auf der anderen 77 . Das Gefängniswesen im Dritten Reich verblieb zwar in der Hoheit der Justiz, gerade für politische Häftlinge war dies jedoch nur ein geringer Vorteil. In Justizanstalten saßen nicht nur „Schutzhäftlinge" ein, in einigen Fällen - wie den Emslandlagern - übernahm die Justiz sogar selbst Konzentrationslager in eigene Verwaltung ${ }^{78}$.

Während die Überwachung des politischen Strafvollzuges in beiden Fällen von der Geheimpolizei mitbestimmt wurde, konnte allein die Gestapo die Urteile ordentlicher Gerichte in eklatanter Form aushebeln: durch die Übernahme entlassener Häftlinge in die Konzentrationslager. Dabei spielte die Justiz eine nicht unerhebliche Rolle. Spätestens hier endeten die Parallelen im Strafvollzug, denn mit der Übernahme ins Lager waren die Häftlinge unmittelbar vom Tod bedroht. Die Durchlässigkeit zwischen dem Strafvollzug der Justiz und den Konzentrationslagern ist ein Kennzeichen der NS-Zeit, das der DDR abging ${ }^{79}$. Dem Dritten Reich fehlte hingegen, trotz mehrerer Reichsamnestien in den Jahren 1934 bis 1938, die periodische Korrektur der Abstrafungskampagnen durch breite Haftentlassungen. In der DDR entwickelte sich eine Art Repressions-Amnestie-Rythmus, der zunächst von sowjetischer Seite diktiert wurde. Bestimmte Gruppen politischer Häftlinge blieben davon jedoch ausgenommen.

Die Schwankungen und die Unsicherheit in der gesamten Strafpolitik der DDR beruhten nicht zum geringen Teil auf der schwachen Verankerung des SEDRegimes in der Bevölkerung. Die harte politische Justiz und viele Wirtschaftsstrafverfahren konnten in der Öffentlichkeit kaum vermittelt werden. Ob die Juristen überhaupt noch als regionale Elite anerkannt wurden, ist fraglich. In der NS-Zeit kam der Justiz in der Bevölkerung hingegen immer noch eine relativ hohe Legitimität zu. Im Laufe der dreißiger Jahre fand sich unter den Deutschen eine

75 Rottleuthner, Deutsche Vergangenheiten, S. 485. Diese Zahl umfaßt auch Urteile außerhalb des "Altreichs". Hinzuzurechnen sind die etwa 15000 Häftlinge, die ab Ende 1942 von Thierack an Himmler zur "Vernichtung durch Arbeit" übergeben wurden und fast alle in den Konzentrationslagern zugrunde gingen.

76 Evans, Rituals of Retribution, S. $915 \mathrm{f}$.

77 Vgl. Drobisch, Alltag im Zuchthaus Luckau.

78 Drobisch, Konzentrationslager und Justizhaft, S. 282.

$79 \mathrm{Vgl}$. Drobisch, Konzentrationslager und Justizhaft; und die Beurteilungen und Übergaben aus dem Zuchthaus Luckau: Drobisch, Alltag im Zuchthaus Luckau, S. $269 \mathrm{f}$. 
breite Unterstützung der Ziele des Regimes. Mitverantwortlich dafür waren die vermeintlich sinkende Kriminalität und der professionelle Apparat der Justiz, der sich positiv gegenüber der Gestapo abhob. Die politischen Verfahren gerade wegen Hoch- und Landesverrats kamen den vorherrschenden nationalistischen Denkmustern entgegen. Zunehmend richtete sich die Justizrepression gegen marginalisierte Minderheiten, und schließlich: Die Deutschen hatten noch keine Erfahrungen mit einer Diktatur. Für oppositionelle Kreise galt dies alles natürlich nicht; aber diese waren eben eine kleine Minderheit. Lediglich die Bevorzugung von Funktionären der NSDAP vor Gericht, wie sie unter Druck der Parteidienststellen an der Tagesordnung war, sorgte für einen Ansehensverlust der Justiz im NS-Staat.

Vergleicht man NS- und DDR-Justiz auf regionaler Ebene, also in überschaubaren Zusammenhängen ${ }^{80}$, so erweist sich deren Funktion als recht ähnlich, die Zielvorgaben und - in deren Konsequenz - die sozialen Folgen aber erweisen sich als recht unterschiedlich. Die regionalen Gerichte regelten das allgemeine Rechtsleben wie in allen anderen politischen Systemen auch, solange nicht die Prioritäten des Regimes berührt waren. Diese konnten ideologischer Natur sein, aber auch utilitaristisch. Einen nicht zu unterschätzenden und politisch hochbedeutsamen Teil der Gerichtstätigkeit machten die Strafverfahren gegen echte oder dazu erklärte Gegner des jeweiligen Regimes aus. Zu diesem Zweck existierten gesonderte Strafkammern mit ausgewählter Personalbesetzung, die zugleich gesteigerter Kontrolle unterlagen. So unterschiedlich auch Anleitungsmechanismen, Organisation und Personal im Justizsystem waren, entscheidend war die Durchsetzung der Konformität des Rechtsstabes. Und diese wurde vor allem an den Prioritäten der Staatsparteien gemessen. Im Endeffekt haben beide Staatsparteien ihre Ziele in der Justiz durchgesetzt, im Nationalsozialismus in kurzer Frist, in der SBZ/DDR erst im Laufe von sechs bis zehn Jahren.

\section{c. Die Rezeption der NS-Justiz}

Der Vergleich zwischen der NS-Justiz und der Justiz in der SBZ/DDR stand schon den Zeitgenossen vielfach vor Augen. In der Justizpolitik von SMAD und SED bis Anfang der fünfziger Jahre spielte die Rezeption der Justiz vor 1945 eine herausragende Rolle. Die SED-Funktionäre verfügten - als ehemalige Angeklagte - vielfach über eigene Erfahrungen in diesem Bereich, die Strafverfolgungsbehörden in Brandenburg stellten vereinzelt Ermittlungen wegen NS-Justizverbrechen an; bei den sowjetischen Stellen herrschte dagegen anscheinend eher ein schematisches Bild von nationalsozialistischen „Repressionsorganen“ vor.

Nach der weitgehenden Beseitigung NS-spezifischen Rechts durch die Alliierten waren immer wieder Verfahrensformen in der Diskussion, die aus der NS-Zeit stammten oder während ihr pervertiert wurden. Dies zeigt vor allem die Debatte um die Nichtigkeitsbeschwerde, die allein in Brandenburg sogar denselben $\mathrm{Na}$ men erhielt wie im Dritten Reich. Auch der Begriff der "Schutzhaft“ tauchte hin und wieder in der SBZ/DDR auf, ohne allerdings denselben Inhalt wie im Natio-

80 Vgl. dazu allgemein Lepsius, Plädoyer für eine Soziologisierung, S. $614 \mathrm{f}$. 
nalsozialismus zu bezeichnen. Die brandenburgische Justizverwaltung war sich in dieser Beziehung unsicher: „Es wird empfohlen, bis zur endgültigen Klärung keine Sicherungsverwahrung zu beantragen bzw. zu verhängen." ${ }^{81}$ Vereinzelt gab es aber durchaus Überlegungen, auch präventive Verhaftungen zuzulassen. So begrüßte der Landtagspräsident Otto Meier, daß ein Abgeordneter, der angeblich als Justizangestellter Amtsgeheimnisse verletzt hatte, bereits vor Aufhebung seiner Immunität in „Schutzhaft" genommen worden sei ${ }^{82}$. Häufiger anzutreffen war die Verwendung der Begrifflichkeit vom "gesunden Volksempfinden“, aber ebenso die Kritik daran. Auch hier handelte es sich letztlich um eine umgangssprachliche Terminologie, die nicht erst unter dem Nationalsozialismus gängig, wohl aber unter diesem formalisiert und pervertiert wurde ${ }^{83}$. Angesichts der Beharrungskraft solcher Formeln in ganz Deutschland nach 1945 und der Konjunktur des „Volks"-Begriffs in der SBZ erscheint eher die Kritik an diesen interessant als ihre Weiterverwendung.

Nur in ganz wenigen Einzelfällen ist die - im Dritten Reich eingeführte - „analoge" Rechtsanwendung nachweisbar ${ }^{84}$, obwohl sie verschiedentlich von einzelnen Juristen besonders im Wirtschaftsstrafrecht gefordert wurde. Letztendlich nahm man davon jedoch Abstand85. Insgesamt blieb die Anwendung spezifisch nationalsozialistischer Rechtsfiguren und Normen ein peripheres Phänomen, das von heftigen Debatten begleitet wurde.

Ab 1949 - parallel zur Transformation des Antifaschismus - spielte die NS-Zeit in der Argumentation eine immer geringere Rolle. In dem Bewußtsein, die Diktatur gründlich überwunden zu haben, ging dieser Bezugspunkt den neuen Juristen allmählich verloren; das galt offensichtlich auch für solche Volksrichter, die selbst unter dem Nationalsozialismus gelitten hatten. Die konkrete Kritik an der NS-Justiz wich nun der Überzeugung, die Schaffung des neuen Gesamtsystems Sozialismus werde alle undemokratischen Entwicklungen beseitigen, selbst wenn sie von offensichtlicher Repression begleitet war. Mitte der fünfziger Jahre wurden alle Relikte der NS-Justiz nur noch in der Bundesrepublik lokalisiert.

Will man nun ein Resümee dieses Diktaturvergleichs ziehen, der an einigen Faktoren exemplifiziert wurde, so bleibt festzustellen: Die Rahmenbedingungen der zwei Systeme unterschieden sich fundamental. Nicht zuletzt verstand sich die Justiz der DDR als positives Gegenstück zu ihrer Vorgängerin. Im Gefolge der Weimarer Justiz konnte das NS-Regime auf das alte Personal bauen und die politische Justiz in weitgehendem Konsens mit diesem durchsetzen. Nach 1945 kamen völlig neue Juristen, die erst auf die Staatsideologie hin geschult werden mußten und bis weit in die fünfziger Jahre genauer "Anleitung und Kontrolle“

81 BLHA, Rep. 240 Potsdam, Nr. 9, Bl. 160a-160e, Rderl. Abt. Justiz Prov.verw. Nr. 81, 12. 2. 1946; vgl. einen Fall in Thüringen: Weber, Rechtsstaat Thüringen, S. 125.

82 Stenographische Berichte des Landtages, 60. Sitzung, 5. 12. 1949, S. 2.

83 Vgl. BLHA, Rep. 212, Nr. 612, Bericht über Schöffenschulung LG Eberswalde am 10. 10. 1950.

84 BLHA Rep. 212, Nr. 178, Bl. 88-94, Bericht Besichtigung AG Brandenburg (Alscher) am 25. 4. 1949: Strafvollstreckung in Analogie; das Vorgehen wurde moniert.

85 BLHA, Rep. 240 Potsdam, Nr. 53, Bl. 528b, Protokoll der Richtertagung am 28. 4. 1948; BLHA, Rep. 212, Nr. 803, Bl. 242, 297, Stargardt an GStA, 10. 10. 1949; Rdschr. MdJ der DDR, 12. 12. 1949. Vgl. Schöneburg, Strafrecht und Staatssozialismus, S. 174. 
unterworfen wurden. Somit erscheint die deutsche Justiz der sowjetischen Besatzungszone, also bis Mitte 1949, von der des NS-Staates gründlich verschieden.

Einige Parallelen zur NS-Vorkriegsjustiz ergaben sich zunehmend nach der Gründung der DDR, seit 1949/50, so in der Konformität des Rechtsstabes, in der Entwicklung einer totalitären Rechtsideologie, im Abbau formaler Sicherungen, in der Verfolgung von Systemgegnern und in der Strafpraxis bei den Gefängnisstrafen. Doch schon ab 1937 entwickelte die NS-Justiz zahlreiche Züge, die sich nach dem Krieg nicht mehr wiederfinden. Für eine vergleichende globale Gesamtbetrachtung der Rechtssysteme im "Dritten Reich“ und der DDR muß jedoch sowohl die Kriegszeit des Dritten Reiches als auch die Justiz der DDR ab den sechziger Jahren berücksichtigt werden. Deshalb erweist sich als entscheidend, daß die Justiz im Nationalsozialismus zu einem Teil der Maschinerie des Massenmordes vor allem an Minderheiten und Ausländern wurde. Die wichtigsten Verfolgungswerkzeuge des NS-Staates waren aber zunehmend die Polizei und die Besatzungsverwaltungen, und nicht mehr die Justiz. Insofern wies die NS-Justiz weit mehr Parallelen mit ihrem Pendant im sowjetischen Stalinismus auf, und eher weniger mit der Entwicklung in der DDR. Kein Zweifel kann jedoch daran bestehen, daß die Justiz in beiden Systemen zum Instrument der Diktatur degradiert wurde.

\section{Leitbild Sowjetjustiz}

Während die Justiz im Dritten Reich anfangs die negative Folie für die Entwicklung in der SBZ abgab, sich aber einige Parallelen zu ihr herauskristallisierten, wurde die Justiz der Sowjetunion gleichzeitig immer mehr zum Leitbild für die DDR stilisiert. Deshalb soll an dieser Stelle die Entwicklung in der Hegemonialmacht unter zwei Aspekten analysiert werden: Inwieweit entwickelten sich in der Sowjetunion gleiche Funktionsmechanismen wie in der DDR, und inwieweit kann man von einer Sowjetisierung oder gar Stalinisierung der DDR-Justiz sprechen?

Verglichen mit der Justiz im Nationalsozialismus, sind die entsprechenden Kenntnisse über die Sowjetunion von 1917 bis 1956 gering. Allerdings gibt es bereits eine an Überblicksdarstellungen reiche Literatur, sei es aus der Ostrechtsforschung, sei es aus der Rechtsgeschichte ${ }^{86}$. In der modernen Stalinismus-Historiographie seit den siebziger Jahren sind eine Reihe von Arbeiten zur Justiz vorgelegt worden. Deren Ergebnisse konnten in den letzten Jahren durch die Nutzung von Archivakten vertieft werden, insbesondere im Bereich der Strafjustiz ${ }^{87}$. Für die hier interessierende Fragestellung ergeben sich allerdings zwei Defizite: Die unmittelbare Nachkriegszeit ist nur rudimentär einbezogen worden ${ }^{88}$, und es gibt nur wenige westliche Regionalstudien, die auch die Justizentwicklung behan-

86 Maurach, Handbuch der Sowjetverfassung, S. 272-325; Kucherov, The Organs of Soviet Administration of Justice; Schittenhelm, Strafe und Sanktionssystem.

87 Solomon, Soviet Criminal Justice.

88 Ebenda, S. 337 ff.; jetzt vor allem Boterbloem, Life and Death, S. 152-170. 
deln ${ }^{89}$. Gerade in Fragen der Entscheidungsfindung, der Personalpolitik und der Anleitung/Kontrolle auf unterster Ebene sind die Informationen immer noch spärlich. Kaum zu überblicken ist hingegen die Vielzahl neuerer Arbeiten aus den GUS-Staaten zur stalinistischen Repression auf regionaler Ebene, welche oft die Gerichtstätigkeit thematisieren ${ }^{90}$. So muß eine vergleichende Untersuchung auf der Auswertung der Literatur zu verschiedenen Themenbereichen basieren.

\section{a. Entwicklung und Rabmenbedingungen der Justiz in der Sowjetunion}

Die erste grundlegende Frage beim Vergleich der frühen DDR-Justiz mit der sowjetischen lautet: Mit welcher Phase der sowjetischen Entwicklung soll verglichen werden? Selbst Wilhelm Pieck notierte von einem Gespräch mit sowjetischen Politikern: „Erfabrungen SU aus welcher Zeit? ob 1925, 1935 oder 51“91. Die Vielgestaltigkeit und fast permanente Umgestaltung des Rechtssystems stellt die Komparatistik vor große Probleme. Abhilfe können hier nur forschungspragmatische Entscheidungen schaffen, nämlich ein gedrängter Vergleich der Entwicklungsprozesse: Dabei entsprächen die Jahre 1945/46 in der SBZ einer Revolutionszeit, die Zeit bis etwa 1951 einer "Neuen Ökonomischen Politik“; danach kämen Stalinismus bzw. natürlich die synchrone Nachkriegszeit. Ähnlich war auch die Selbstwahrnehmung bei manchen kommunistischen Justizfunktionären der DDR.

Schon die Vorgeschichte beider Justizsysteme wies mehr Unterschiede als Gemeinsamkeiten auf. Zwar waren beide aus dem Krieg, nur das sowjetische aber aus einer Revolution geboren. Die jeweils vorgefundenen Justizsysteme unterschieden sich 1917 und 1945 beträchtlich; in Rußland fehlte eine konfliktorische Rechtskultur, besonders im Verhältnis zwischen Herrschaft und Gesellschaft. In den Jahren 1917 bis 1921 machte die russische KP eine utopische Phase unter Bedingungen des Bürgerkriegs durch, in der ein totaler Schnitt mit jeder Vergangenheit intendiert war. 1945 hingegen stand in der SBZ zunächst die Rückkehr zur Weimarer Justiz auf der Tagesordnung. Zuerst die Februarrevolution von 1917, dann aber vor allem die Standgerichte der Bolschewiki, die neuen Volksgerichte und Revolutionstribunale brachen völlig mit dem zaristischen Justizsystem; zusammen mit der „Außerordentlichen Kommission“, sprich: Tscheka, die selbständig Verhaftungen und Tötungen vornahm, sorgten sie für den revolutionären Terror. Staats- und Rechtsanwaltschaft waren zeitweise abgeschafft; Richter wurden zunächst gewählt, dann von den Räten bestimmt; es galten ausschließlich Dekrete der Revolution ${ }^{92}$. Diese weitgehende De-Regulierung des Rechtssystems hat es in der SBZ nur in embryonalen Ansätzen gegeben; dort existierten „revolutionäre Gerichte" lediglich kurze Zeit und an wenigen Orten, sie hatten kaum weitreichende Kompetenzen. Eher schon verbreiteten die sowjetischen Militärtri-

89 Bahnbrechend: Fainsod, Smolensk Under Soviet Rule, S. 173-192.

90 Beispielsweise: Leningradskij martirolog, S. $5 \mathrm{ff}$.

91 Pieck-Notiz über eine Besprechung in Karlshorst am 23.5. 1951, Badstübner/Loth, Wilhelm Pieck, S. 368. Aus der Notiz geht der Urheber des Zitats nicht eindeutig hervor, wahrscheinlich ist es Tschuikow. Hervorhebungen in der Vorlage.

92 Altrichter, Staat und Revolution, S. $137 \mathrm{ff}$.; für die Jahre bis 1925 im Detail: Hazard, Settling Disputes. 
bunale und Internierungen die Atmosphäre von Verfahrenslosigkeit und Massenrepression. Letztendlich sorgte aber vor allem der Bürgerkrieg bis 1921 für eine radikale Ausnahmesituation, die sich trotz einiger Parallelen von der Lage in der SBZ gründlich unterschied.

Die Justizentwicklung der sowjetischen Besatzungszone, also bis 1949, erscheint am ehesten vergleichbar mit der Phase der Neuen Ökonomischen Politik in der Sowjetunion, die der nachfolgenden DDR mit dem Spätstalinismus bzw. der Konstellation Mitte der fünfziger Jahre. Soweit man nicht den synchronen Vergleich vorzieht, bieten sich für die NEP-Zeit viele strukturelle Parallelen zur SBZ/DDR-Justiz, insbesondere für die wenigen Jahre nach den schweren Kirchenverfolgungen, die bis 1923 angedauert haben ${ }^{93}$. Die NEP-Ära war ähnlich wie die Jahre der SBZ von einer gemischten ökonomischen Verfassung gekennzeichnet, die von der KP jedoch als Übergangsphänomen gesehen wurde. In diesen Jahren sieht man in der Sowjetunion eine teilweise Rückkehr zum „bürgerlichen" Rechtssystem, einen starken Rechtsapparat unter dem Volkskommissariat für Justiz, das jedoch den Strafvollzug abgeben mußte. Ähnlich wie in der SBZ existierten neben Reformbemühungen weiter permanente Repressionsmaßnahmen, wenn auch nicht in dem Ausmaß wie im Bürgerkrieg oder im Stalinismus. So galten in den Jahren von 1921 bis 1926 relativ milde Strafnormen. Zur gleichen Zeit setzte die OGPU allerdings ihre außergerichtlichen Massenmorde fort ${ }^{94}$. Schon in den zwanziger Jahren war der Grad der Parteimitgliedschaft unter den Juristen erheblich, 1928 hatte man eine Totalerfassung der Staatsanwälte und die KP-Zugehörigkeit bei $86 \%$ aller Richter erreicht. Gleichzeitig nahm der Bildungsstand der Juristen immer weiter ab, noch weitaus drastischer als in der frühen DDR: 1936 hatten 50\% der Justizjuristen keinerlei juristische Ausbildung. Auch die Rotation unter sowjetischen Richtern in den zwanziger und dreißiger Jahren war noch größer als selbst in der SBZ/DDR bis Mitte der fünfziger Jahre95.

Mit dem Beginn des Stalinismus, also der Zeit ab 1928/29, ging die Zeit der Ambivalenz im sowjetischen Recht zu Ende. Die Strafnormen wurden sukzessive verschärft, besonders 1932 und 1934. Gleichzeitig stieg die Zahl der Verurteilungen explosionsartig, sie erreichten mit 2,3 Mio. im Jahre 1933 ihren Höhepunkt. Die Verfahren wurden immer formloser und willkürlicher; tendenziell kehrte man zur Phase des "Rechtsnihilismus" in Revolution und Bürgerkrieg zurück ${ }^{96}$.

Viel bedeutsamer aber war, daß die Kollektivierung für den Tod von Millionen Menschen, vor allem Bauern und ihren Familien, stand. Zwar verloren die Massendeportationen ab 1934 an Bedeutung, und eine stärkere Förmlichkeit wurde wieder durchgesetzt. Doch sorgten die neuen Strafgesetze für ein Hochschnellen der Verurteilungszahlen. Die schon bei Tscheka und OGPU vorhandenen Sondergerichte erhielten nun immer mehr Kompetenzen. Ab Mitte 1937 war ihre Aufgabe nur noch blanker Massenmord. Im Gegensatz zu den Richtern spielten die Staatsanwälte im "Großen Terror" eine erhebliche Rolle. Die Staatsanwaltschaften mußten immer noch die Haftbefehle sanktionieren, ihre Vertreter saßen

$93 \mathrm{Vgl}$. Solomon, Soviet Criminal Justice, S. $49 \mathrm{ff}$.

94 Vgl. Werth, Ein Staat, S. 152, 904.

95 Solomon, Soviet Criminal Justice, S. 34-38; Rittersporn, Soviet Officialdom, S. 213.

96 Ebenda, S. 221 ff.; Sharlet, Stalinism, S. 163 ff. 
in den Trojki, Dreierkollegien, die Abertausende zum Tode verurteilten. Allerdings konnte sich das Schicksal alsbald auch gegen Juristen selbst wenden ${ }^{97}$. Besonders 1938 waren sie von NKWD-Verfahren bedroht. Etwa die Hälfte aller Richter und Staatsanwälte wurde entlassen, davon die meisten verhaftet. Hunderte Juristen mußten als angebliche „Konterrevolutionäre“ sterben ${ }^{98}$. Das Justizsystem benötigte Jahre bis zu seiner voller Rekonstruktion, in den Westgebieten noch verzögert durch die Zerstörungen des Krieges.

Tatsächlich erscheint ein Vergleich der Nachkriegsphasen am sinnvollsten. Zwar hatte die Sowjetunion 1944 bereits eine 27jährige Geschichte bolschewistischer Justizpolitik hinter sich, so daß von einem Prozeß der „Gleichschaltung“ also nicht mehr die Rede sein kann; eine Reihe von Rahmenbedingungen war jedoch ähnlich wie in der SBZ/DDR. Die wichtigste von ihnen ist - neben der simplen Synchronität - zweifellos das stalinistische Herrschaftssystem und seine Einschränkung ab 1953; beides wirkte in vermittelter Form auch auf Ostdeutschland ein. Beide Systeme hatten mit der Bewältigung der Kriegsfolgen zu kämpfen, insbesondere der exorbitanten Kriminalität99. In der Sowjetunion wie in der DDR mündete die Justizentwicklung im Laufe der fünfziger Jahre in einen stabilen Apparat, der danach nur noch graduell verändert wurde.

Dennoch gab es bei den Rahmenbedingungen auch von 1945 bis Mitte der fünfziger Jahre erhebliche Unterschiede. Noch immer herrschte das stalinistische Terrorregime, das insbesondere in den Lagern auch nach dem Krieg noch unermeßliche Opfer forderte. Selbst nach Stalins Tod kam es zu Massentötungen an Lagerinsassen bei der Niederschlagung von Revolten.

Unmittelbar nach dem Krieg entwickelten sich zur gleichen Zeit rudimentäre Ansätze für Rechtsreformen. So wurde 1946 in der - allerdings ergebnislosen Diskussion um eine neue Verfassung der Sowjetunion die Abschaffung der Sondergerichte aus der Kriegszeit vorgeschlagen ${ }^{100}$. Die Beschwerden der Staatsanwaltschaft gegen willkürliche Verhaftungen, die es vereinzelt schon in den dreißiger Jahren gegeben hatte, bekamen nun mehr Gewicht. Der Generalstaatsanwalt Gorschenin monierte auch, daß in der SBZ Zehntausende ohne Sanktion durch Staatsanwälte verhaftet worden seien ${ }^{101}$.

Doch 1947/48 verdüsterte sich das Bild wieder, und zwar schneller als in der SBZ. In der Folge der drakonischen Diebstahl-Gesetze vom Juni 1947 und der Massendeportationen in den Westgebieten erhöhte sich die Zahl der Gulag-Insassen sprunghaft. Entsprechende Strafbestimmungen hatte es bereits seit 1932 gegeben, jedoch noch nicht in der Schärfe. 1952 flossen sie dann teilweise in das Volkseigentumsschutzgesetz der DDR ein. Erst nach Stalins Tod kamen Rechtsreformen in Gang, die diesen Namen auch verdienten. Das wirkte sich unter anderem dadurch auf die DDR aus, daß ein am sowjetischen Vorbild orientiertes StGB 1953 scheiterte.

\footnotetext{
${ }^{77}$ Solomon, Soviet Criminal Justice, S. 237, $244 \mathrm{ff}$.; Fallstudie auf Aktenbasis: Kotkin, Magnetic Mountain, S. 335-340.

$98 \mathrm{Vgl}$. Schertwy repressij, S. 78-91.

99 Boterbloem, Life and Death, S. 157; Kuromiya, Freedom and Terror, S. 301.

100 Subkowa, Obschtschestwo i reformy, S. 51.

101 Foitzik, Sicherheitsapparat der SMAD, S. 127.
} 


\section{b. Struktureller Vergleich}

Will man die regionale Justiz in der DDR und der Sowjetunion im Vergleich analysieren, so stellt sich zunächst die Frage nach der adäquaten Vergleichseinheit: Republik oder Oblast? Oblasti entsprechen von der Größenordnung am ehesten den Ländern, glichen aber als reine Verwaltungseinheit eher den Bezirken, wo es kaum föderale Traditionen und keine föderalen Strukturen gab ${ }^{102}$. Eine regional unterschiedliche Rechtsentwicklung konnte sich nach 1917 nur dort entfalten, wo die Bolschewiki noch nicht die Macht erobert hatten. In der Sowjetunion, wie sie nach 1922 existierte, sind unterschiedliche Ausprägungen der Justiz in regionaler und lokaler Perspektive vor allem auf die mangelnde Durchsetzungskraft der Zentrale und weniger auf föderale Wurzeln zurückzuführen.

Wegen der schieren Größe des Landes waren der Zentralisierung in der Sowjetunion jedoch immer gewisse Grenzen gesetzt. So blieben die Aufgaben meist zwischen Justizministerien der Republiken und dem Unionsjustizministerium verteilt; letzteres existierte gar nur von 1936 bis 1956. Ebenso erlangten Oberstes Gericht und Generalstaatsanwaltschaft erst 1936 die Aufsicht über die nachgeordneten Stellen ${ }^{103}$. Es war weniger das Ministerium als das Oberste Gericht, das mit 60 Richtern die Rechtsprechung bis hinunter zu Volksgerichten überwachte. Die politische Strafpraxis lief in dieser Zeit natürlich am Justizsystem weitgehend vorbei.

Das Ministerium war in erster Linie für die Personalpolitik zuständig; als regionalen Unterbau errichtete es 1938 die Justizverwaltungsstellen, die die Verwaltungsaufgaben der Oblastgerichte übernahmen. Etwas Vergleichbares etablierte sich in der DDR 1952. Der DDR verwandt war auch die vergleichsweise geringe politische Bedeutung des Justizministeriums innerhalb der obersten Führungsriege. Die Politbüros beider Staatsparteien griffen in die Justiz nach Gutdünken ein; in der Sowjetunion scheinen diese Interventionen aber sprunghafter und weniger formell geregelt gewesen zu sein ${ }^{104}$. Im Gegensatz zur DDR bahnte sich in der Sowjetunion bereits eine regelrechte Parteijustiz an. Die Zentrale ParteiKontrollkommission der KPdSU verfügte seit 1950 sogar über ein eigenes Untersuchungsgefängnis ${ }^{105}$.

Entscheidend für den Zugriff der Staatspartei auf die Justiz waren jedoch die regionalen Parteiapparate. Die Oblast-Komitees der KPdSU mit etwa 120 Funktionären, hier die Vergleichseinheit für Landes- und Bezirksleitungen, haben sich - nach Jahren des Terrors auch in der Partei - in den fünfziger Jahren allmählich stabilisiert. In den Oblast-Komitees hatte die Partei - wie die SED - keine eigene Justizabteilung, dieses Ressort fiel ab 1948 in die Abteilung für den Staatsapparat. Etwas instabiler waren die Rajon-Parteikomitees, in denen eine sehr starke Fluk-

102 Die Oblast Kalinin mit ca. 1,8 Mio. Einwohnern verfügte etwa über 200 Angestellte der Staatsanwaltschaft, Boterbloem, Life and Death, S. 163.

${ }_{103}$ Zum folgenden: Solomon, Soviet Criminal Justice, S. $275 \mathrm{ff}$.

104 Fitzpatrick, Stalin's Peasants, S. 301 f., allerdings mit einem Beispiel von 1937. Stärker formalisiert war die Arbeit der sog. Gerichtskommission beim Politbüro, die die Listen von Erschießungsopfern vorlegte.

105 Nekrasow, Trinadzat schelesnych narkomow, S. $287 \mathrm{f}$. 
tuation herrschte ${ }^{106}$. Schon in den zwanziger Jahren war die Intervention von Parteiinstanzen in einzelne Verfahren ein strukturelles Problem gewesen ${ }^{107}$. Zeitweise ging diese Funktion allerdings an das NKWD über, das 1937/38 das Justizsystem unangefochten dominierte.

Die regionalen Richter und Staatsanwälte standen auf der Kadernomenklatur der Oblast-Komitees, die darauf achteten, daß Kandidaten mit KP-Parteibuch und „richtiger sozialer Herkunft“ auf diese Posten gelangten ${ }^{108}$. Im Grunde konnten Funktionäre der Rajon-Komitees die Auswahl der Richter an den Volksgerichten mitbestimmen und gegebenenfalls deren Entlassung erwirken, genauso wie es die Oblastkomitees auf ihrer Stufe taten ${ }^{109}$. Demgegenüber waren direkte Interventionen in Verfahren seltener. Die Parteiorganisationen aller Ebenen versuchten immer wieder, für angeklagte KP-Funktionäre einzuschreiten, die meist der Unterschlagung beschuldigt waren. Seit 1954 startete Chruschtschow deshalb verschiedene Kampagnen gegen willkürliche Interventionen der regionalen Parteiapparate in die Justiz. Diese erwiesen sich allerdings als zweischneidig, weil Chruschtschow zugleich eine Regeneration der Parteiorgane als Führungsinstanzen betrieb. In der Konsequenz erfolgten keine schriftlichen Interventionen mehr, sondern mündliche "Ratschläge" vorrangig an Staatsanwälte110. In der DDR dauerte es noch eine Weile, bis die Bezirks- und Kreisleitungen eine derart starke Stellung in der Justiz hatten, eigentlich erst in der zweiten Hälfte der fünfziger Jahre. Zu dieser Zeit bildete sich auch ein Konsensverhalten zwischen Parteifunktionären und den Justizjuristen aus, letztere waren zumeist Parteimitglied. Insofern glichen sich die Interventionspraktiken in der DDR und in der Sowjetunion an.

Der Zugriff der pseudodemokratischen Räte auf die Justiz war in der DDR bis Mitte der fünfziger Jahre nur in sehr begrenztem Umfang möglich. Ganz anders in der Sowjetunion: Schon seit den zwanziger Jahren hatten die Räte erhebliche Interventionsmöglichkeiten, weil sie für Finanzierung und Ausstattung der Justizbehörden zuständig waren. Auf Dauer hatte dies zur Folge, daß die Verwaltung glaubte, in Verfahren eingreifen zu können, die sie für relevant hielt. Auch diese Erscheinungen wurden in den fünfziger Jahren durch Chruschtschows Kampagne nur ansatzweise eingedämmt. Der beste Weg zur Abwehr von Interventionen war für die Juristen immer noch die Beschwerde beim Vorgesetzten des Intervenierenden 111 .

Freilich bestand im allgemeinen eher Konsens zwischen lokaler Partei, Räten und Gerichten. Das sowjetische Justizpersonal der Nachkriegszeit war bereits vollständig im sozialistischen Staat sozialisiert worden. Dennoch fehlte es bei der Mehrheit an einer Erfahrung von Kontinuität im Rechtssystem. Erst nach dem Krieg waren dafür die Voraussetzungen geschaffen; ab 1946 ordnete die KPdSU eine bessere Ausbildung der Justizjuristen an. Bis dahin war der Einsatz von

\footnotetext{
106 Vgl. Fainsod, Wie Rußland regiert wird, S. 258 ff.; Hough, Soviet Prefects, S. 17.

107 Vgl. Solomon, Local Political Power.

108 Fainsod, Smolensk, S. 178.

109 Solomon, Soviet Politicians, S. 4 f.

$1: 0$ Gorlizki, Political Reform, S. 261 ff.; Solomon, Soviet Politicians, S. 13.

$111 \mathrm{Vgl}$. Solomon, Soviet Criminal Justice, S. $287 \mathrm{ff}$., $396 \mathrm{f}$.
} 
Volksrichtern nach den Lücken, die die Zeit des "Großen Terrors" gerissen hatte, noch einmal expandiert. Zahlreiche juristische Institute wurden eingerichtet, einige Jahre nach Kriegsende stieg der Anteil der Juristen mit entsprechender höherer Bildung. 1957 konnten $55 \%$ aller Richter einen solchen Abschluß vorweisen, den sie meist im Fernstudium erworben hatten ${ }^{112}$. In der DDR erfolgte diese Entwicklung mit zeitlicher Verzögerung; allerdings waren die Ausgangsbedingungen hier besser, da bis Anfang der fünfziger Jahre noch eine Reihe von Volljuristen tätig waren.

Die Mechanismen der Kaderpolitik in der DDR wurden, ebenso wie die Einrichtung der Justizverwaltungsstellen, vom sowjetischen Vorbild übernommen. In etwa gleich waren auch Bezahlung und Sozialprestige, wenn auch letzteres in der DDR noch stark an den traditionellen Justizjuristen gemessen wurde. Das Schulungssystem, wie es sich in der Justiz der DDR in den fünfziger Jahren entwickelte, orientierte sich zweifellos an sowjetischen Vorbildern.

Die überragenden sowjetischen Juristen waren die Staatsanwälte. Seit der Wiedereinrichtung der Staatsanwaltschaft 1922 wurde ihre Position systematisch ausgebaut und schließlich 1936 von der übrigen Justiz abgekoppelt. Die Prokuratura hatte entscheidenden Anteil an der Überwachung der Kollektivierung und war als einziges Justizorgan systematisch am "Großen Terror" beteiligt. Obwohl viele Staatsanwälte selbst in den Strudel der Massenmorde gerissen wurden, blieb die Institution erhalten ${ }^{113}$. In der DDR wurde, insbesondere mit der Aufwertung von 1951/52, formal ein ähnlicher Weg gegangen. Die sogenannte GesetzlichkeitsAufsicht der Staatsanwaltschaft für alle Bereiche in ihrem Bezirk entwickelte sich aber nur kümmerlich. Vielmehr hatte sie es noch bis 1953 mit der Konkurrenz der Kontrollkommissionen zu tun; aber auch sonst konnten sich die Staatsanwälte nur schwer daran gewöhnen, umfassende regionale Kontrolle zu betreiben ${ }^{114}$.

Die sowjetischen Verteidiger konnten sich seit 1922 in Kollegien organisieren, bis 1930 waren aber auch Einzelrechtsanwälte zugelassen ${ }^{115}$. Die Kollegien der DDR entstanden erst ab 1953 und brauchten ebenfalls einige Zeit, bis sie die Arbeit der Verteidiger monopolisieren konnten. Im Unterschied zur Sowjetunion der Nachkriegszeit arbeiteten in der DDR immer noch zum allergrößten Teil „bürgerliche“ Rechtsanwälte, die nicht nur eine klassische Universitätsausbildung vorweisen konnten, sondern auch grundsätzlich eher kritisch zum SED-Regime eingestellt waren. Die Fluchtzahlen aus dieser Berufsgruppe sprechen hier eine deutliche Sprache.

Der Instanzenzug und die Rechtsprechung waren in der Sowjetunion etwas anders strukturiert als in der DDR. So beschäftigten sich die Oblastgerichte kaum mehr mit Fällen erster Instanz, sogar Tötungsdelikte kamen vor die Volksgerichte ${ }^{116}$. Dies widersprach der deutschen Rechtstradition; anscheinend wollte auch die SED brisantere Fälle nicht an den Kreisgerichten verhandeln lassen.

112 Rittersporn, Soviet Officialdom, S. 230.

113 Solomon, Soviet Criminal Justice, S. $140 \mathrm{ff} ., 174 \mathrm{ff}$.

114 Vgl. Müller, Gerichtsverfassungsrecht, S. $236 \mathrm{ff}$.

115 Huskey, Russian Lawyers, S. $150 \mathrm{ff}$.

116 Rabe, Justiz, S. 1561. 
Die Rolle der sowjetischen Kontrollkommission in der Justiz ist noch nicht hinreichend erforscht, hatte aber ohne Zweifel Vorbildcharakter für die deutsche ZKK unter Fritz Lange. Ursprünglich existierte in der Sowjetunion eine gemeinsame Kontrollkommission für Staat und Partei zusammen mit der Arbeiter- und Bauerninspektion. Erst 1934 wurde die Staatskontrolle eigenständig und 1940 zum Volkskommissariat bzw. Ministerium erhoben. Seit dem Krieg leiteten die berüchtigten Stalinisten Lew Mechlis und Wsewolod Merkulow dieses Ressort ${ }^{117}$. Auffällig war hier die enge personelle Verflechtung mit der Geheimpolizei, die es in der SBZ/DDR in dieser Form nicht gab. Auch die funktionale Bedeutung der sowjetischen Kontrollkommission dieser Zeit war eine andere als die der ZKK. $\mathrm{Da}$ die Gleichschaltung der Justiz in der Sowjetunion zu diesem Zeitpunkt längst abgeschlossen war, mußte die Staatskontrolle nicht als Quasi-Ersatz einspringen. Durchgreifende Justizkontrollen sind bisher lediglich aus den Jahren 1927 bis 1930 bekannt. Spätere Interventionen zielten oftmals gar auf die Abmilderung von harten Urteilen ${ }^{118}$. Allerdings sind die Kenntnisse über die Arbeit der Kontrollkommissionen ab 1935 spärlich; auf jeden Fall hatten sie das Recht, Verfahren einzuleiten. Bis zu einem gewissen Grade wurde die Funktion der Kontrollkommissionen in den dreißiger Jahren von den Staatsanwaltschaften übernommen, insbesondere seit letztere 1936 aus der Justizverwaltung ausgegliedert waren ${ }^{119}$. Eine ähnliche Umverteilung läßt sich auch 1952/53 in der DDR beobachten.

Ohne Zweifel war die Repression durch Gerichte und Geheimpolizei in der Sowjetunion bis in die fünfziger Jahre erheblich härter als in der DDR. Allein in den Jahren des "Großen Terrors" 1937/38 wurden in jeder Oblast zwischen 5000 und 10000 Menschen von den Trojki in Pseudoverfahren formal zum Tode verurteilt und vom NKWD ermordet. In den Republik-Zentren und anderen Großstädten gingen die Opferzahlen dieser Massenmorde jeweils in die Zehntausende ${ }^{120}$.

Während die NKWD-Trojki Ende 1938 abgeschafft worden, bestanden auch weiterhin die sogenannten Miliz-Trojki für Strafen bis zu fünf Jahren und die Sonderkollegien des NKWD/MWD in Moskau und bei den Republikministerien. Diese Ferntribunale verhängten zumeist Haftstrafen, konnten bis zum Herbst 1945 aber auch Todesurteile aussprechen. Insgesamt haben Pseudogerichte der Geheimpolizei von 1945 bis 1953 noch 626000 Verurteilungen ausgesprochen, wenn auch die Zahlen mit den Jahren immer mehr abnahmen ${ }^{121}$. Alle diese Sonderinstitutionen fanden keine deutsche Entsprechung in der DDR.

$\mathrm{Ab}$ Kriegsende wiesen die Strukturen politischer Justiz in der Sowjetunion eine Reihe von Parallelen zur SBZ/DDR auf: Auch auf sowjetischem Territorium fiel ein großer Teil der Bestrafungen in die Kompetenz der Militär- bzw. NKWD-Tribunale, insbesondere die massenhaften Verfahren wegen echter oder angeblicher Kollaboration. Ebenso ist eine Zunahme der Verfahren gegen Jugendliche zu be-

117 Vgl. Korschichina, Sowjetskoje gossudarstwo, S. 336f., 388.

118 Solomon, Soviet Criminal Justice, S. 50 ff., 107 ff.; Fainsod, Smolensk, S. 185 f.; vgl. den Auftrag des Politbüros an die ZKK zur Überprüfung des Obersten Gerichts der RSFSR, 5. 11. 1935, Stalinskoje politbjuro, S. $65 \mathrm{f}$.

119 Ginsburgs, Soviet Procuracy, S. $55 \mathrm{f}$.

120 Vgl. die laufend publizierten Opferlisten für einzelne Städte, z. B. Leningradskij martirolog, S. 50.

121 Solomon, Soviet Criminal Justice, S. 245; Rossi, Gulag Handbook, S. 274, 276; Keep, Last of the Empires, S. 15. 
obachten, auch wegen angeblicher Bildung von Untergrundgruppen ${ }^{122}$. In den annektierten Westgebieten der Sowjetunion waren NKWD-Verfahren und Massendeportationen angeblicher Oppositioneller an der Tagesordnung. Die Parallele zur SBZ liegt hier natürlich im dortigen Vorgehen des MGB und der Militärtribunale, nicht bei der deutschen Justiz.

Die Repressionswelle in der Sowjetunion, die ab Mitte 1947 anrollte, stellte freilich die Vorgänge in der SBZ/DDR in den Schatten. So konnten ab Anfang 1948 solche Häftlinge, die während des „Großen Terrors“ zu zehn Jahren Lagerhaft verurteilt worden waren und nun entlassen wurden bzw. zur Entlassung anstanden, im administrativen Verfahren einfach erneut verurteilt bzw. ihre Haftzeit verdoppelt werden ${ }^{123}$. Zahlenmäßig eher gering nehmen sich dagegen die bekannten politischen Massenbestrafungen ab 1948 aus, wie die AntikosmopolitismusKampagne oder gegen KP-Funktionäre gerichtete Aktionen wie die „Leningrader Affäre" oder die "mingrelische Affäre", deren Opfer meist in Exekutionsanlagen endeten ${ }^{124}$.

Die sowjetischen Verfahren wegen NS-Verbrechen oder Kollaboration machten 1944 bis 1946 einen erheblichen Teil aller Strafprozesse aus ${ }^{125}$. Die Sowjetunion und ihre Einwohner waren durch die deutsche Besatzung und die Massenverbrechen schwerstens geschädigt worden. Sieht man vom Problem der Kollaborations-Prozesse ab, verliefen die NS-Verfahren in der Sowjetunion und der Sowjetzone ziemlich parallel. Dies lag zunächst in der Logik der Sache, da die sowjetischen Militärtribunale diese Verfahren bis 1946 auch in Deutschland führten. Ab 1948 zeichnete sich überall eine zunehmende politische Instrumentalisierung der NS-Verfahren ab, besonders solcher gegen deutsche Kriegsgefangene. Zu diesem Zeitpunkt wurden fast nur noch Pauschalvorwürfe verhandelt; die Verurteilungen dienten dazu, die Kriegsgefangenen als politisches Faustpfand länger in Haft halten zu können ${ }^{126}$. Zu Beginn der fünfziger Jahre ging die Zahl der Verfahren drastisch zurück. Somit zeigen sich bei den NS-Verfahren auffällige Ähnlichkeiten beider Justizsysteme.

Zahlenmäßig noch bedeutsamer als Verfahren wegen Teilnahme an NS-Verbrechen waren nach dem Krieg Prozesse wegen pauschaler Kollaborationsvorwürfe. Insbesondere im Baltikum und in der Ukraine dürften die geheimen Schnell-Verurteilungen gegen Personen, die im Verdacht standen, in irgendeiner Beziehung zur deutschen Besatzung gestanden zu haben, die Zahl der Hunderttausend überstiegen haben ${ }^{127}$. Hinzuzurechnen sind Bestrafungen von Rotarmisten, die aus deutscher Kriegsgefangenschaft zurückgekehrt waren und denen man denselben Vorwurf machte; seit 1952 ergingen durchweg Urteile zu 25 Jahren Lagerhaft ${ }^{128}$.

${ }^{122}$ Subkowa, Obschtschestwo i reformy, S. $72 \mathrm{ff}$.; Iwanowa, Gulag, S. $74 \mathrm{ff}$.

${ }^{123}$ Ebenda, S. 67.

124 Vgl. Subkowa, Kaderpolitik und Säuberungen, S. $213 \mathrm{f}$.

125 Genaue Statistiken liegen bisher nicht vor. Anhand der Zahl der in den letzten Jahren nicht Rehabilitierten läßt sich jedoch die Größenordnung der Zahl der Angeklagten schätzen, die tatsächlich wegen Beteiligung an NS-Verbrechen verfolgt worden waren.

126 Vgl. Zeidler, Stalinjustiz; allerdings standen auch nach 1948 noch schwerstbelastete NS-Täter in der Sowjetunion vor Gericht. Etwa 20-25\% der Verurteilten wurde nach 1991 die Rehabilitierung verweigert.

127 Kuromiya, Freedom and Terror, S. $284 \mathrm{ff} ., 299 \mathrm{f}$.

128 Iwanowa, Gulag, S. 57. 
Alle diese Verfahren konnte es in der SBZ/DDR nicht geben, sieht man von den Militärverfahren gegen Sowjetbürger auf deutschem Gebiet ab.

Aber auch die Kriminalisierung nicht-politischer Taten verschärfte sich erdrutschartig ab Ende 1946. Es läßt sich eine Tendenz feststellen, die von der vorwiegend politischen Verfolgung bis etwa 1946 wegführte zur Kriminalisierung wegen "normaler" Vergehen. Das zeigen die Massenbestrafungen auf der Basis der „Volkseigentums“-Erlasse von 1947, die vor allem die fast völlig entrechteten Kolchos-Bauern betrafen. Noch 1952 ergingen 180000 Verurteilungen wegen Diebstahl von Staatseigentum; zwei Jahre später waren es 113000 Fälle. Bis 1953 kamen etwa 1,3 Mio. Menschen deshalb zur Verurteilung ${ }^{129}$. Damit lagen die Verurteilungsziffern in der DDR - in Relation zur Bevölkerungszahl - lediglich 1952/ 53 zeitweise höher, als das Volkseigentumsschutzgesetz mit aller Härte praktiziert wurde ${ }^{130}$.

Im Vergleich zur DDR noch erheblich drakonischer gestaltete sich das stalinistische Arbeitsstrafrecht, das bis 1956 galt. Seit 1940 wurden Disziplinverstöße oftmals mit Lagerhaft geahndet; die abschreckenden Urteile ließen zwar bei Kriegsende nach und wurden 1951 weiter eingedämmt. Doch noch 1947/48 machte der Vorwurf des „Bummelantentums“ bei manchen Volksgerichten die Mehrzahl der Verfahren aus ${ }^{131}$. In der SBZ konnten ab 1946 solche Verstöße zwar unter Umständen, etwa in Sowjetischen Aktiengesellschaften, ebenfalls zu Haft führen; im allgemeinen blieb es in der DDR aber beim Entzug der Lebensmittelkarten oder bei Geldstrafen, wenn nicht überhaupt die Konfliktkommissionen diese Fälle auf außergerichtlichem Wege bereinigten. Ebenso wie in der DDR schwankten auch die sowjetischen Richter zwischen einem Unterlaufen der drakonischen Bestimmungen einerseits und überharten Urteilen andererseits. Doch in den Strafbestimmungen, im Ausmaß der Aburteilungen und im Strafvollzug bestanden immer noch deutliche Differenzen ${ }^{132}$.

Die bereits mehrfach erwähnte Aussetzung der Todesstrafe von 1947 bis Anfang 1950 war von einer massiven Zunahme der Einweisung in Lager und der dortigen Haftdauer begleitet; im Gulag blieben die Todesraten hoch. Schon nach Wiedereinführung der Todesstrafe für politische Verbrechen wurden allein bis 1953 etwa 4000 Personen hingerichtet ${ }^{133}$. Auch hier zeigt sich der enorme quantitative Unterschied zur DDR.

Der sowjetische Strafvollzug wurde frühzeitig auf Gefängnisse und Lager verteilt, von 1930 bis 1956 mit eindeutigem Schwergewicht auf den Lagern. Gleichzeitig kam er seit 1922 aus dem Justizbereich in die Hoheit der Geheimpolizei; erst 1953 übernahm das Justizministerium den Gulag für fast ein Jahr, um ihn dann 1954 an das (vom KGB getrennte) Innenministerium abzugeben ${ }^{134}$. Damit war

129 Werth/Moullec, Rapports secrets, S. 53; Werth, Ein Staat, S. 258 f.

130 Werkentin, Politische Strafjustiz, S. $69 \mathrm{ff}$.

131 Solomon, Soviet Criminal Justice, S. $301 \mathrm{ff} ., 423 \mathrm{ff}$.

132 Ebenda, S. $432 \mathrm{ff}$.

133 Iwanowa, Gulag, S. 74. Erst Chruschtschow dehnte die Todesstrafe auch wieder auf Mord (1954) und schwere Wirtschaftsverbrechen aus.

134 Stettner, Archipel Gulag, S. 57; Lubjanka, S. 137; Iwanowa, Gulag, S. 78. Die Speziallager wurden nicht an das MdJ abgegeben. 
zwar administrativ derselbe Stand wie in der DDR erreicht, die Wirklichkeit des Vollzugs sah jedoch anders aus.

Nach den momentan vorliegenden - möglicherweise unvollständigen - Statistiken stieg die Zahl der Lagerhäftlinge 1948 auf über eine Million und erreichte erst 1952/53 einen Höhepunkt mit 1,7 Mio. Menschen ${ }^{135}$. Das deutet nicht nur die Verhärtung der Strafpolitik an, sondern zeigt auch, daß - selbst anteilig gerechnet - verglichen mit den Zahlen der SBZ/DDR ein Vielfaches an Häftlingen einsaß. Mit Ausnahme der besonders harten Katorga- und Speziallager glichen die Lebensbedingungen im sowjetischen Lagersystem zwar denen in den Speziallagern auf dem Boden der SBZ (die seit 1948 auch organisatorisch zum Gulag gehörten), kaum jedoch denen in den DDR-Gefängnissen. Zudem lag selbst in den sowjetischen Gefängnissen die Todesrate weit über deutschen Verhältnissen. Eine in der DDR unbekannte Form des "Strafvollzugs" war die Verbannung in Sondersiedlungen, von der vor allem Familien von "Kulaken“ oder kollektiv bestrafte Nationalitäten betroffen waren. Doch gab es hier einen nahezu fließenden Übergang zu den Justizbestrafungen. So wurden 1948 Zehntausende Bauern deportiert, die ihr Arbeitssoll auf den Kolchosen angeblich nicht erfüllt hatten. Die Justiz schaltete man dabei gar nicht erst ein ${ }^{136}$. Seit November 1948 konnten alle Personen, die aus den Sondersiedlungen geflüchtet waren, zu 20 Jahren Lagerhaft verurteilt werden. Innerhalb eines Jahres ereilte an die 10000 Menschen dieses Schicksal ${ }^{137}$.

Die periodischen Amnestien, die in den meisten kommunistischen Systemen verkündet wurden, fielen in der Zeit des Stalinismus, also bis 1953, minimal aus ${ }^{138}$. Die vorzeitigen Entlassungen aus dem Gulag zogen sich ab 1954 über mehrere Jahre hin; erst Ende der fünfziger Jahre war ein der DDR vergleichbarer Häftlingsstand erreicht und das Gefängnissystem übernahm den Strafvollzug wieder teilweise. Allerdings verschwand die Welt der Lager in der Sowjetunion damit nicht. Noch Ende der fünfziger Jahre waren dort 900000 Gefangene interniert, davon 2/3 mit offensichtlich überhöhten Strafen. Die Zahl der politischen Häftlinge wird mit 11000 angegeben ${ }^{139}$. Erst zu diesem Zeitpunkt waren quantitativ ähnliche Dimensionen wie in der DDR erreicht.

Dagegen wies die Rezeption der Justiz durch die sowjetische Bevölkerung bis in die fünfziger Jahre markante Unterschiede zur DDR auf. Dabei ist in Rechnung zu stellen, daß es nach dem Krieg kaum noch jemanden gab, der jemals etwas anderes gekannt hatte als das Sowjetsystem oder über genauere Kenntnis anderer Länder verfügte, von den Rotarmisten einmal abgesehen. Somit lebten die Sowjetbürger in einem fast hermetisch geschlossenen System, das sie zu einem erheblichen Maß prägte. Das bedeutet nicht, daß die Rechtsprechung widerspruchslos hingenommen wurde. Vielmehr waren es die Bürger gewohnt, ihre Kritik an ein-

135 Keep, Last of the Empires, S. 13. Die Zahl der Insassen von Strafkolonien, die meist ohne Urteil deportiert worden waren, sank im gleichen Zeitraum von über einer Mio. auf 740000. Dazu kommen noch Millionen Einwohner sogenannter Sondersiedlungen. Kritik an diesen Zahlen bei Stettner, Archipel Gulag, S. 383 ff.

136 Iwanowa, Gulag, S. 63.

137 Ebenda, S. 68.

138 Solomon, Soviet Criminal Justice, S. $421 \mathrm{f}$.

139 Werth, Ein Staat, S. 282 f. 
zelnen Maßnahmen und Urteilen in Beschwerden zu formulieren, sei es pauschal an die Staatsführung oder an die zuständigen Beschwerdestellen, die Kontrollkommission oder die Justizbehörden. Mit der massenhaften Zunahme des Unrechts Anfang der dreißiger Jahre vervielfachten sich auch die Beschwerdebriefe. Die Arbeiter- und Bauerninspektion erhielt 192943000 Beschwerden, die Staatsanwaltschaften aller Ebenen wurden seit Beginn der Dreißiger mit Eingaben regelrecht überhäuft. 1935 mußte das Justizministerium eine eigene Beschwerdeabteilung einrichten. Die Beschwerden konnten zu einer zweischneidigen Sache werden, gerade Mitte der dreißiger Jahre führten sie oftmals zu Verfahren gegen den Absender; mancher Briefschreiber aus der Nachkriegszeit fand sich in einer psychiatrischen Anstalt wieder ${ }^{140}$. In der DDR entwickelte sich das Beschwerdewesen erst allmählich. Dort war die Mehrheit der Bevölkerung gegen das SEDRegime eingestellt; sie hatte auch ganz andere Möglichkeiten, Protest gegen Justizwillkür vorzubringen. Dennoch glichen sich auch in diesem Bereich die Verhältnisse - spätestens in den sechziger Jahren - langsam an die sowjetischen an.

Ein großer Teil der Beschwerden war allerdings nicht allein gegen Rechtsverletzungen gerichtet, sondern enthielt Beschuldigungen, die angezeigte Personen, egal ob belastet oder unschuldig, in die Hände des Terrorapparates spielten. Nach neueren Forschungen war der Umfang der Denunziationen in der Sowjetunion aber geringer als bisher angenommen, selbst in der Zeit des "Großen Terrors" ${ }^{\text {1411. }}$. Einiges deutet darauf hin, daß die Mehrheit der sowjetischen Bevölkerung den Unrechtscharakter des Regimes nicht so wahrnahm wie Außenstehende. So herrschte bei vielen durchaus Angst vor den Rückkehrern aus dem Gulag ab 1954, da man eine erhebliche Zunahme der Kriminalität befürchtete.

Insgesamt zeigt sich, daß die sowjetische Entwicklung zwar ab 1952 das organisatorische Vorbild und die politischen Muster für die Abläufe der regionalen Justiz in der DDR abgab, eine Reihe deutscher Spezifika aber Bestand hatten. Von größerer Bedeutung ist jedoch, daß in der Sowjetunion bis 1954 ungleich härtere Massenverfolgungen abliefen als selbst nach der 2. Parteikonferenz in der DDR. Die sowjetische Justiz hatte ab 1947 wieder erheblichen Anteil an politischer Repression, wenn sie auch erst ab 1953 ihre vollen Kompetenzen wieder erlangte. Berücksichtigt man ferner, daß die Sowjetunion zu diesem Zeitpunkt ihre gesellschaftliche Umwälzung schon hinter sich hatte, so erscheint die sowjetische Entwicklung noch weit gewalttätiger. Als in der DDR ab 1962 vergleichbare strukturelle Voraussetzungen geschaffen waren, nämlich Vollkollektivierung und Verstaatlichung, nahmen die politischen Verfolgungen bei weitem kein solches Ausmaß mehr an. Die Rahmenbedingungen beider Entwicklungen unterschieden sich doch erheblich.

140 Alexopoulos, Exposing Illegality, S. $174 \mathrm{ff}$.; Romanovskij, Zur Anatomie des Spätstalinismus, S. 33.

141 Fitzpatrick/Gellately, Introduction, S. 758; qualitative Analyse bei Kozlov, Denunciation. 


\section{c. Sowjetisierung oder Stalinisierung?}

In der Frage des Verhältnisses zwischen sowjetischer politischer Ordnung und DDR-System gibt es inzwischen eine vielfältige Begrifflichkeit: Sie reicht von der These vom ubiquitären Stalinismus in der SBZ/DDR über die Stalinisierung, von der Differenzierung zwischen sowjetischer Einflußnahme und Sowjetisierung bis hin zur "sowjetischen Überlagerung“. Sowjetisierung wird hier verstanden als formale Übernahme aktueller sowjetischer Leitbilder, institutioneller Formen und Verfahren. Insofern geht es nicht um sowjetische Einflußnahme ${ }^{142}$; es steht außer Zweifel, daß diese für die Jahre bis etwa 1951 von erheblicher Bedeutung für den Gang der Justizgeschichte war.

$\mathrm{Zu}$ fragen ist zunächst einmal danach, wie denn die Sowjetisierung überhaupt praktisch zustande kam. Nur wenige Juristen gelangten aus dem sowjetischen Exil oder der dortigen Kriegsgefangenschaft in die SBZ. In der DJV war es Fritz Löwenthal, der detaillierte Kenntnisse der Sowjetjustiz aus Moskau mitbrachte. In Brandenburg sind lediglich einige Antifa-Kader unter den Volksrichtern zu verzeichnen. Von den deutschen Juristen wurde die Sowjetjustiz anfangs nur schwach rezipiert ${ }^{143}$ : Kaum jemand hatte Russisch-Kenntnisse; in der SBZ waren nur wenige Übersetzungen sowjetischer juristischer Literatur greifbar. Erst Anfang der fünfziger Jahre begann sich dies zu ändern. Mit dem Jahr 1951 sind deutliche Zeichen einer Sowjetisierung von Rechtswissenschaft und Jurastudium zu sehen. Vorträge über die Sowjetjustiz gehörten nun zur Schulung ${ }^{144}$, die „Neue Justiz“ brachte ab 1950 regelmäßig Artikel zur Sowjetunion, Übersetzungen wie die von Wyschinskis Gerichtsreden erreichten hohe Auflagen. Dennoch bleibt selbst für diese Zeit anzumerken, daß hier lediglich ein Propaganda-Bild von der Sowjetjustiz transportiert wurde. Hin und wieder schien aber die Realität des Sowjetsystems auch in Publikationen durch ${ }^{145}$.

Entscheidende Anstöße zu einer Sowjetisierung konnten zunächst also nur von SMAD und SMA kommen, wo zahlreiche sowjetische Juristen arbeiteten. Vom sowjetischen Strafvollzug hatten selbst die Rechtsoffiziere wenig Kenntnisse, da er nicht in den Händen der Justiz lag ${ }^{146}$. Die ersten Jahre sowjetischer Rechtspolitik in Deutschland zeigen, daß überhaupt nur wenige Versatzstücke vom sowjetischen Vorbild eingeflossen sind: so die „Beispielprozesse“, die Justizveranstaltungen, die Ausgliederung von Transportstaatsanwaltschaften und die Bildung von Kontrollkommissionen. Ab 1948 wurde nicht nur die Einflußnahme sowjetischer Rechtsoffiziere systematisiert, auch die Inhalte ihrer Politik ließen deutlichere Sowjetisierungstendenzen erkennen - vor allem die Durchsetzung und Transfor-

142 Vgl. Lemke, Einleitung, S. 12-15.

143 Vgl. beispielsweise die verharmlosende Darstellung des NKWD und der Sowjetjustiz aus dem Jahre 1947 in Kurella, Ich lebe in Moskau, S. 106-116.

$144 \mathrm{Vgl}$. Wentker, Errichtung und Transformation, S. 614f. Beispielsweise BLHA, Rep. 212, Nr. 295, Protokoll Richtertagung in Eberswalde 17.10. 1950; BLHA, Rep. 679, Nr. 74, Arbeitsplan der JVSt. Frankfurt für das IV. Quartal 1952.

145 Beispielsweise erwähnte Hermann Klenner 1953 die Massenerschießungen an Weißgardisten ab September 1918, Klenner, Formen, S. 42. Und man kann annehmen, daß den Juristen in der DDR Wyschinskis Haßtiraden gegenüber politischen Angeklagten bekannt waren: „Die tollwütigen Hunde müssen allesamt erschossen werden." Wyschinski, Gerichtsreden, S. 542.

146 Vgl. Oleschinski, Strafvollzug, S. 68. 
mation des Volksrichter-Experiments, das in seinen Anfängen beide Traditionen in sich trug: die deutsche und die sowjetische.

Wie aufgesetzt manche dieser Modelle wirkten, zeigte das Debakel des nach sowjetischem Vorbild veranstalteten "Justizwettbewerbs" 1950/51. In diesen Kontext fallen auch die zahlreichen importierten Rituale, die sich im Alltag der Juristen immer mehr festsetzten. Nur schwer konnte man sich mit der formalisierten "Selbstkritik“ anfreunden, schon eher mit den zahllosen neuen Bezeichnungen wie "Instrukteure“ oder "Justizbrigade“, die ausufernden "Pläne“ usw. ${ }^{147}$ Aber erst die neue Generation von Volksrichtern, die eine starke Loyalität zur SED - und damit implizit auch zur Sowjetunion - spürte, adaptierte diese Formen immer mehr.

Innerhalb der Justizverwaltung war die Angleichung an die Sowjetunion durchaus als Problem präsent. Im Rechtsausschuß der SED blickte man neidvoll nach Osten: „In Rußland hat man eine Justiz, die absolut auf den Staatsgedanken abgestellt ist und mit der Staatspolitik absolut konform geht. Wir wissen aber nicht, wie unsere Justiz sich entwickelt." 148 Allerdings war man sich nicht darüber im klaren, ob die DDR eine genauso lange Frist benötigen würde, um den zeitgenössischen Stand des Vorbildes zu erreichen ${ }^{149}$.

Konkrete Eindrücke von der sowjetischen Justiz konnten ostdeutsche Juristen erst durch Delegationsreisen gewinnen, so Hilde Benjamin im Jahre 1949. Gezielt zur Vorbereitung der Justizreform unternahm eine Gruppe von Spitzenjuristen 1952 eine Reise in die Sowjetunion. Dabei wurden exemplarisch bestimmte Typen von Gerichten und Justizverwaltungen besichtigt, um sowjetische Vorbilder kennenzulernen und in der DDR zu übernehmen ${ }^{150}$. Dennoch liefen auch die Umstellungen 1952 unter dem Rubrum „schöpferische Anwendung der Leninschen Sowjettheorie" 151 , also durchaus mit eigenen Spielräumen.

Tendenzen einer Sowjetisierung der Justiz kann man in der SBZ ab 1948/49 beobachten, sie brachen mit den Umorganisationen des Jahres 1952 durch. Dennoch kann auch nach dieser Zeit nicht von einer Kopie des sowjetischen Modells gesprochen werden: Zunächst war die gesellschaftliche und wirtschaftliche Verfassung der DDR in den fünfziger Jahren eine andere als die in der Sowjetunion. Besonders die Existenz eines nicht-kollektivierten Bauerntums hatte für die Strafpraxis Bedeutung. Im Grunde glichen sich beide Justizsysteme einander erst ab 1954 richtig an; man könnte überspitzt fast von einer Konvergenz sprechen. Auf sowjetischer Seite wurde der Einfluß der allmächtigen Geheimpolizei zurückgeschnitten und das Lagersystem reduziert und reformiert. Mit den Kampagnen für Gesetzlichkeit wurden in den Prozessen die Verfahrensregeln stärker beachtet. Die völlige Entrechtung der Bauern wurde zurückgenommen. In der DDR wiederum etablierte sich ein Justizsystem, das nicht nur äußerlich, sondern auch im

147 Vgl. Danyel, Politische Rituale, S. 70.

148 SAPMO, DY 30/IV 2/13/405, B1.39, Protokoll der Tagung des Ausschusses für Rechtsfragen beim ZS der SED 21./22. 6. 1947 (Geyer).

149 Vgl. BA, DP-11 VA 131, Bl. 40, Vermerk MdJ der DDR/HA II (Bö.), 8. 1. 1951.

150 Breithaupt, Rechtswissenschaftliche Biographie, S. 191; Wentker, Errichtung und Transformation, S. 616 ff.; SAPMO, DY 30/IV 2/13/448, Material zur sowjetischen Justiz, 1952.

151 Entwicklung des Arbeiter- und Bauernstaates, S. 28. 
Hinblick auf die internen Funktionsmechanismen erhebliche Anleihen beim sowjetischen Vorbild machte.

Dennoch blieb es immer bei gewissen Phasenverschiebungen zwischen der Justizentwicklung beider Staaten. Nicht alle Wendungen der sowjetischen Justizpolitik wurden nachvollzogen. So gab es in der SBZ/DDR keine zeitweise Abschaffung der Todesstrafe, die Straffreiheit des Schwangerschaftsabbruchs machte die DDR 1955 nicht mit152. Selbst für die siebziger Jahre schätzte FriedrichChristian Schroeder, daß maximal 15\% der Strafrechtsvorschriften der DDR mit denen der Sowjetunion übereinstimmten ${ }^{153}$. So bleibt die scheinbar paradoxe Feststellung: Als die sowjetischen Machthaber die absolute Kontrolle hatten, gab es aus politischen Gründen bis 1948 keine Sowjetisierung, danach folgte eine Phase deutscher Orientierung am sowjetischen Vorbild, das aber nie ganz kopiert wurde.

Über die Frage nach der Sowjetisierung hinaus ergibt sich das Problem, ob die Justiz in der DDR nicht nur sowjetisiert, sondern auch stalinisiert war. Orientiert man sich an einem trennscharfen und deswegen engeren Begriff von Stalinismus, so ist dies zu verneinen. Mit Stalinismus ist das sowjetische Gesellschafts- und Herrschaftssystem von 1928/29 bis 1953/56 gemeint, mit einer komplett verstaatlichten Wirtschaft, nahezu permanenten Massenverbrechen an der Bevölkerung, mit einem riesigen Lagersystem und der Kanonisierung einer nationalistischen Feindideologie ${ }^{154}$. Ein erweiterter Stalinismus-Begriff hingegen ist kaum vom Leninismus abzugrenzen und wäre deshalb auf nahezu jedes kommunistische System anwendbar ${ }^{155}$.

Dennoch gibt es eine Reihe von Tendenzen, die die DDR im Justizsektor mit der Sowjetunion unter Stalin gemeinsam hat. Da ist an vorderster Stelle der StalinKult, wie er ab Ende 1949 auch die DDR beherrschte. Die Spionage- und Geheimhaltungshysterie ab 1952/53 entsprach in vielem der politischen Mentalität in der Sowjetunion seit Ende der zwanziger Jahre, in Grenzen gilt dies auch für die extrem harte Strafpolitik ab Ende 1950. Dem Stalinismus ähnlich erscheint auch die spezifische Mischung von nach außen propagierter „Klassenjustiz“ einerseits und tatsächlich ökonomisch orientierter Massenbestrafung von Bauern und Arbeitern andererseits. Das meint vor allem die Rechtsetzung und „Rechtsprechung“ zum Schutz der Staatswirtschaft. Auch einige organisatorische Veränderungen waren in der Sowjetunion erst unter Stalin vorgenommen worden, so die Abkoppelung der Staatsanwaltschaft vom Gerichtssystem. Die Prozesse in Waldheim tragen deutlich das Signum des Stalinismus, sie waren eine Fortsetzung der Militärverfahren auf deutscher Ebene.

152 Schittenhelm, Strafe und Sanktionssystem, S. 198.

${ }^{153}$ Schroeder, Strafrecht des realen Sozialismus, S. 194. Allerdings sieht er im Sanktionssystem große Ähnlichkeiten.

154 Eine ausführliche Definition würde den Rahmen dieser Arbeit sprengen. Die empirisch fundierte Diskussion des Begriffs steht noch am Anfang, vgl. Weber, Stalinismus, mit einem weiteren und einem engeren Begriff, wie er hier verwandt wird; Gill, What is Stalinism. Durch die neue Debatte um die mentale Dimension des Stalinismus ist eine Präzisierung zu erwarten: Vgl. Kotkin, Magnetic Mountain, S. $355 \mathrm{ff}$.

155 Das ist auch das Problem in der Diskussion in: Rechtswissenschaft in der DDR, S. $16 \mathrm{ff}$. 
Diese stalinistischen Tendenzen haben das ostdeutsche Justizsystem aber nie so geprägt, daß man insgesamt von stalinistischer Justiz sprechen könnte. Drei der eklatentesten Merkmale stalinistischer Justizpolitik, die Sonderjustiz der Geheimpolizei, die von Massenmorden begleiteten Kampagnen und der spezifische Strafvollzug im Lagersystem, fehlten der DDR. Auch kam eine systematische Rezeption der stalinistischen Theorien in der Justiz der DDR erst nach Stalin zustande. Die Stabilisierung der Justiz, wie sie in der Sowjetunion unter Stalin ab 1945 erreicht wurde, erfolgte in der DDR erst nach dessen Tod. Stark vereinfachend ließe sich formulieren, die brandenburgische Justiz sprang aus einer NEP-Phase in eine nachstalinistische Zeit. Selbst die Kollektivierungswellen in der DDR hatten andere Folgen für die Justiz und für die Bauern als in der Sowjetunion.

Was Sowjetisierung und Übertragung des stalinistischen Rechtssystems in Reinkultur bedeuteten, läßt sich mit einem Blick auf die westlichen Gebiete erkennen, die 1940/44 von der Sowjetunion annektiert waren. Hier fand in kürzester Zeit ein radikaler Bruch durch vollständige Anpassung der Organisation, Import von Spitzenpersonal und Anpassung an alle Gesetze, Verfahrensformen und Strafpolitik statt ${ }^{156}$. Davon kann in der SBZ/DDR nur teilweise und nur langfristig die Rede sein.

Die Prägung der DDR-Justiz durch die Sowjetunion war stark, kam aber nur vermittelt zustande. Vor allem die Leitideen und die institutionelle bzw. personelle Struktur zeigen deutliche Züge der Sowjetisierung. Vieles, was den Zeitgenossen als aktuelles Vorbild erschien, war faktisch in der stalinistischen Sowjetunion ausgehebelt worden. Wie verschlungen die Sowjetisierung des Rechtssystems in der DDR vor sich ging, zeigt schließlich ein Vergleich mit anderen Sektoren. Während in der SED-Parteiorganisation und - durch die Strukturunterschiede begrenzt - in der Wirtschaft eine Imitation nach außen hin weniger Schwierigkeiten machte, war eine Nachahmung im Strafsystem problematischer. Die stalinistische Repression kam zwar via NKWD/MGB und Militärtribunale auch in die SBZ, hatte aber auch verheerende Folgen für das Image der SED. Das MfS und seine Vorläufer erhielten das sowjetische Vorbild - abgeschirmt von der Öffentlichkeit - durch die sowjetischen Instrukteure vermittelt, in der Justiz war das kaum der Fall. Zudem stand die Justiz lange nicht an prominenter Stelle auf der Agenda der SED-Politik, Transformationsprozesse wurden erst vergleichsweise spät vorangetrieben. So blieben erhebliche Unterschiede zur Strafpolitik in der Sowjetunion, die erst auf lange Sicht abgebaut wurden. In der zweiten Hälfte der fünfziger Jahre glichen sich sowjetische und ostdeutsche Justiz immer mehr an, formal nach östlichem Vorbild, inhaltlich trafen sie sich aber eher in der Mitte. Das war keine gewollte Annäherung der Sowjetunion an ostdeutsche Verhältnisse, sondern Folge der politischen Veränderungen in der Sowjetunion selbst. Dieses Phänomen beschränkte sich nicht auf die DDR, sondern war in vielen Staaten des Ostblocks zu beobachten. 


\section{Justiz in der „Volksdemokratie“: Parallelfall Polen?}

Die Spezifika der ostdeutschen Justizentwicklung lassen sich nicht allein am vermeintlichen „Schreckbild“ Nationalsozialismus und am Vorbild Sowjetunion herausarbeiten. Vielmehr erscheint es sinnvoll, einen Vergleich mit den osteuropäischen Ländern zu unternehmen, die wie die Gebiete zwischen Elbe und Oder erst 1944/45 in den sowjetischen Machtbereich gerieten. Um den Besonderheiten des deutschen Weges unter sowjetischer Hegemonie nachzuspüren, soll im folgenden die polnische Justizentwicklung ab 1944 vergleichend beleuchtet werden. Das Beispiel Polen bietet sich deshalb an, weil die Literatur dem Verfasser sprachlich zugänglich ist und - ähnlich wie zur tschechoslowakischen Entwicklung - der allgemeine Forschungsstand rasant voranschreitet.

Die Justizgeschichte der Volksrepublik Polen steht momentan in der ersten Phase ihrer Erforschung. Zwar veröffentlichte ein Exilverlag eine kurze Gesamtdarstellung zum Thema, die aber noch nicht aus Akten gearbeitet werden konnte ${ }^{157}$. Inzwischen liegen Monographien und Editionen zu einigen Teilbereichen der Justizgeschichte vor, so besonders zur bedeutsamen Entwicklung der Militärjustiz bis 1956158 und zu deren massenhaften Todesurteilen ${ }^{159}$. Darüber hinaus sind eine Reihe von Prozessen dokumentiert, insbesondere solche gegen NS-Verbrecher, zuletzt auch die Verfahren wegen des antijüdischen Pogroms in Kielce $1946^{160}$. Es existiert aber weder eine moderne Gesamtdarstellung noch eine Regionalstudie zur Justiz ${ }^{161}$. Vielmehr ist man darauf angewiesen, die zeitgenössischen - normativen und verharmlosenden - Veröffentlichungen aus Polen und die reichhaltige neuere Literatur zu anderen Bereichen der Innenpolitik auszuwerten. Als sehr nützlich erwies sich auch die Nutzung der zeitgenössischen westlichen Ostrechtsforschung. In der zeitgeschichtlichen Osteuropa-Historiographie spielt das Thema jedoch nur eine periphere Rolle ${ }^{162}$. Wie im Fall Sowjetunion erweist es sich, daß formelle Strukturen und Ereignisabläufe relativ gut zu rekonstruieren sind, weniger aber die Entscheidungsprozesse und die Personalpolitik. Deshalb sind dem Vergleich von polnischer und ostdeutscher Justiz in der Nachkriegszeit Grenzen gesetzt.

\section{a. Rabmenbedingungen der Justizpraxis in Polen nach 1944}

Dieser Vergleich muß vorweg eine Reihe von grundlegenden Rahmenbedingungen berücksichtigen, die die polnische und die ostdeutsche Entwicklung unterschieden. Diese resultieren alle mehr oder weniger aus dem Krieg: 1. Polen hatte

157 Rzepliński, Sądownictwo PRL (mit Schwerpunkt auf den siebziger und achtziger Jahren); Szarycz, Sędziowe i sądy; vgl. als Einführung in die Forschung: Mohnhaupt/Schönfeldt, Normdurchsetzung; Świdlicki, Procesy.

158 Poksiński, „TUN“ Tatar-Utniki-Nowicki; ders., My sędziowe.

159 Turlejska, Te pokolenia; Bombicki, Zbrodnie prawa.

$160 \mathrm{Vgl}$. Antyżydowskie wydarzenia.

161 Vgl. aber die Sammelbände Prawo okresu stalinowskiego; Prawo karne w okresie stalinizmu der "Studia Iuridica“.

162 "Ausnahme (für die Zeit bis 1947): Micgiel, Coercion, besonders S. 104 ff.; ders., Frenzy and Ferocity. 
als alliierter Staat keine formelle Besatzungsmacht; 2. in diesem Zusammenhang besaßen die Westalliierten vergleichsweise wenig Einfluß auf die Vorgänge in Polen; 3. die territoriale Westverschiebung und die damit einhergehende Vertreibung der Deutschen wirkte sich auch in der Justiz aus; 4. der Untergrundkampf gegen die deutsche Besatzung schlug ab 1944 in einen Bürgerkrieg - von manchen Historikern auch „Bruderkrieg“ genannt - zwischen kommunistischer Regierung und antikommunistischem Widerstand um.

Ferner ist in Rechnung zu stellen, daß der Krieg in Polen andere Folgen für die Rechtskultur und die politische Kultur als in Deutschland hatte, da die polnische Justiz durch die deutsche Besatzung weitgehend vernichtet worden war. Lediglich auf der untersten Ebene, in sogenannten Burggerichten, gab es noch eine polnische Rechtsprechung, deren Urteile zumeist auch nach 1944 noch Bestand hatten. Alle wichtigen Verfahren wurden vor den rassistischen deutschen Sondergerichten geführt. Im Untergrund versuchte besonders die bürgerliche Widerstandsbewegung, eine Gegen-Justiz zu etablieren, die sich weitgehend mit der Bestrafung von Kollaborateuren beschäftigte ${ }^{163}$. Folgenreich für die Nachkriegsentwicklung war die Vernichtungspolitik der deutschen Besatzungsmacht gegen die polnischen Juristen, die als Teil der Eliten Opfer von Massenmorden wurden. Etwa $57 \%$ der Rechtsanwälte und 22\% der Richter und Staatsanwälte starben bei Mordaktionen oder kamen in den Kriegswirren um. Auch von den Überlebenden kamen nach Kriegsende nicht mehr alle in die Justiz zurück ${ }^{164}$.

So war die traditionelle polnische Justiz im Vergleich zur deutschen 1945 nicht diskreditiert. Der polnische Ministerpräsident Józef Cyrankiewicz war selbst studierter Jurist. Der Justizminister wurde in Polen zunächst 1944/45 von der Bauernpartei Stronnictwo Ludowe gestellt, dann hatte elf Jahre lang der Sozialist bzw. „Kryptokommunist“ Henryk Światowski das Amt inne. Sein Stellvertreter bzw. Unterstaatssekretär Leon Chajn kam zwar ebenfalls aus einer späteren Blockpartei, war in den dreißiger Jahren aber KP-Mitglied gewesen und zum Parteiübertritt delegiert worden. Chajn war faktisch die Schlüsselfigur im Justizministerium ${ }^{165}$. Auch dem Obersten Gericht saß nicht ein Einheitssozialist, sondern ein Angehöriger einer Blockpartei vor. Die Personalkonstellation an der Spitze gestaltete sich somit ähnlich wie in der DDR bis 1953.

Voraussetzung für die Gleichschaltung der Justiz in Polen war die Bildung neuer politischer Institutionen, die explizit jede Kontinuität zum politischen Vorkriegssystem negierten ${ }^{166}$. Ebenso wie in der SBZ agierten diese Institutionen auf der Basis sowjetischer Vollmachten. Der kommunistisch dominierte Landesnationalrat, das polnische Ersatzparlament, leitete schon im Sommer 1944 die Transformation des Rechtssystems ein. So wurde frühzeitig vereinbart, daß alle entdeckten Untergrundkämpfer an die Sowjetunion ausgeliefert werden konnten.

163 Vgl. Gondek, Polska karząca, S. $57 \mathrm{ff}$.

164 Rzepliński, Sądownictwo PRL, S. 26; Geilke, Die neueste Entwicklung, S. 37; Kersten, Między wyzwoleniem, S. 10. Vor allem die Juden unter den Rechtsanwälten waren ermordet worden. Einige Juristen waren 1940 in die Sowjetunion deportiert worden.

165 Mołdawa, Ludzie władzy, S. 340; Rzepliński, Sądownictwo PRL, S. 27.

166 Vgl. Diepenthal, Drei Volksdemokratien. 
In den Jahren bis 1946 folgte eine Reihe von Ausnahmegesetzen, die zunächst gegen NS-Täter und Kollaborateure gerichtet waren. Schon im November 1945 bot ein drakonischer Erlaß über Staatsverbrechen weitere rechtliche Handhabe zur Verfolgung der antikommunistischen Opposition. Die sogenannte „kleine Verfassung" vom Februar 1947 hob die Gewaltenteilung auf - fast exakt zur gleichen Zeit, wie dies auch die Länderverfassungen der SBZ taten. Seit 1944 dominierten in der polnischen Strafpolitik repressive Einzelmaßnahmen, aber es wurde noch kein neues Rechtssystem geschaffen. Vielmehr existierten - wie in der SBZ - bis 1947 nebeneinander sowohl Unterdrückung durch Sonderjustiz als auch eine gewisse Pluralität unter den Parteien.

Erst ab 1949 schlug in der Gesetzgebung ein Prozeß der Sowjetisierung durch, insbesondere mit der Einführung des materiellen Rechtsbegriffs ab 1949 oder der Kategorie der "Gesellschaftsgefährlichkeit" ${ }^{167}$. Das polnische „Friedensschutzgesetz" wurde im Dezember 1950 nur zwei Wochen nach seinem Pendant in der DDR erlassen ${ }^{168}$; die Dekrete zum Schutz des Staatseigentums ${ }^{169}$ kamen aber erst ein halbes Jahr nach dem „Volkseigentumsschutzgesetz“ der DDR.

Die Umwälzung der Eigentums- und Zivilrechtsordnung verlief in Polen ähnlich wie in der SBZ, so kam noch 1944 die Bodenreform und 1946 die Beschlagnahme der wichtigsten Industrieunternehmen. Beides geschah zu einem großen Teil auf Kosten der vertriebenen Deutschen; die vergleichsweise wenigen enteigneten polnischen Unternehmer bekamen eine Entschädigung. Allerdings war auch in Polen der Rechtsweg gegen die Enteignungen ausgeschlossen. Staatsbesitz wurde in der Folgezeit rechtlich bevorzugt, ebenso wie man die Rechtsordnung an die beginnende Wirtschaftsplanung anpaßte.

Das Familienrecht mußte im Nachkriegspolen zunächst modernisiert werden, so mit der durchgehenden Einführung der Zivilehe und der Gleichstellung unehelicher Kinder. Ein Familiengesetzbuch, das zusammen mit tschechoslowakischen Juristen nach sowjetischem Vorbild gestaltet wurde, komplettierte diese Regelungen 1950. Damit war nicht nur die Kirche aus dem Familienrecht ausgeschaltet, sondern auch die Regelung innerfamiliärer Angelegenheiten stärker durch den Staat bestimmt. Die meisten Kodifizierungen, die Ähnlichkeit mit denen in der Sowjetunion und der DDR hatten, fielen in das Jahr 1950, so die Einschaltung des Staatsanwaltes in Zivilverfahren, die Einführung der Vertragsgerichte für Streitigkeiten zwischen Staatsunternehmen und das Gesetz über die Arbeitsdisziplin ${ }^{170}$. Einen gewissen Abschluß dieser Sowjetisierung ${ }^{171}$ bildete die polnische Verfassung von 1952, die sich bereits explizit auf das Sowjetvorbild bezog. Doch als Verfassung hatte sie eine ebenso geringe faktische Bedeutung wie die der DDR und der anderen Staaten Osteuropas.

167 Rosenthal/Lange/Blomeyer, Justiz in der Sowjetischen Besatzungszone, S. 34; zur Strafgesetzgebung vgl. vor allem Ziemba, Prawo przeciwko spoleczeństwu.

168 Geilke, Die polnische Strafgesetzgebung, S. $47 \mathrm{f}$.

169 Dekret über die Erhöhung des Schutzes des gesellschaftlichen Eigentums, 4. 3. 1953; Dekret über den Schutz des gesellschaftlichen Eigentums vor kleinen Diebstählen, 4. 3. 1953, Geilke, Die polnische Strafgesetzgebung, S. 35-38.

170 Rzepliński u. a., Law of the Polish People's Republic, S. 25-68; Berutowicz, Recht, S. 85.

$171 \mathrm{Zu}$ den Grenzen des Sowjetisierungsbegriffs im Fall Polen: Foitzik, Sowjetische Hegemonie, S. $36 f$. 


\section{b. Struktur und Tätigkeit der polnischen Justiz}

Versucht man den Vergleich bei den Mittelinstanzen des Rechtsapparates in der DDR und Polen anzusetzen, so stellt sich die Frage nach den Vergleichseinheiten. Föderale Traditionen und Strukturen gab es in Polen kaum, sieht man von Sonderentwicklungen wie den "wiedergewonnenen“ Westgebieten oder den Bürgerkriegsgebieten an der neuen Ostgrenze Polens ab. Erst die Bezirke der DDR entsprachen auch funktional den Wojewodschaften der Volksrepublik, wenn auch letztere weit weniger Bevölkerung hatten. Die Wojewodschaften erhielten allerdings erst im März 1950 eine rein hierarchische Territorialverwaltung mit den sogenannten Nationalräten. Dies war jedoch eine kaum bedeutsame Einrichtung, Anfang der fünfziger Jahre waren sowohl Polen wie auch die DDR zentralisierte Staatswesen.

Betrachtet man die Justiz, so fällt auf, daß in Polen die Kontinuität des höheren Personals erheblich ausgeprägter war als in der SBZ/DDR. Zwar hatten Krieg und Besatzung große Lücken in die Reihen der Juristen geschlagen; auch fielen Richter und Rechtsanwälte, die sich danach in der antikommunistischen Opposition betätigten, oftmals den Massenverhaftungen unter der Intelligenz 1945 zum Opfer ${ }^{172}$. Aber noch für 1953 läßt sich feststellen, daß 30\% der Richter schon in der Vorkriegsjustiz tätig gewesen waren, wenn auch nicht alle bereits als Richter. Der Personalbestand der polnischen Justiz erreichte seine volle Auffüllung erst 1957173 .

Im Gegensatz zur deutschen Entwicklung fiel die juristische Universitätsausbildung im Zweiten Weltkrieg weg. Dafür gab es an den polnischen Universitäten - im Vergleich zur Vorkriegszeit - ab 1945 nur wenige Veränderungen in den juristischen Fakultäten ${ }^{174}$. Im Vergleich zur DDR hatten die sogenannten Kurs-Richter in Polen eine relativ geringe Bedeutung. Jedoch gab es hier signifikante Ausnahmen: So fehlte dem polnischen Generalstaatsanwalt, der ab 1950 amtierte, also eine der wichtigsten Positionen in der Justiz einnahm, die juristische Ausbildung175. Parallel zur SBZ bestand in Polen von 1946 bis 1952 für Personen mit mittlerer Bildung die Möglichkeit, Richterkurse zu besuchen, die zunächst sechs, dann 15 Monate lang dauerten. Allerdings dominierten die Kursrichter das Justizsystem nicht; 1952 endeten die letzten Lehrgänge. Zur Weiterbildung dieser Richter wurde eigens eine Rechtsschule eingerichtet, die bis 1955 den Rang einer Hochschule verliehen bekam ${ }^{176}$. Besonderes Augenmerk richtete die Kommunistische Partei auf die Ausbildung und Auswahl der Staatsanwälte. Sie durchliefen eine sechsmonatige Ausbildung zum „Volksstaatsanwalt“; die Personalauswahl hierfür behielten sich Geheimpolizei und PPR vor ${ }^{177}$.

Die politische Gleichschaltung und Disziplinierung der Richter in der allgemeinen Justiz verlief in etwa parallel zur SBZ, insbesondere ab der zweiten Jahreshälfte 1948. Schon 1946 war die Unabsetzbarkeit der Richter in Polen beseitigt

\footnotetext{
172 Paczkowski, Pół wieku, S. 137.

173 Rzepliński, Sądownictwo PRL, S. $148 \mathrm{f}$.

174 Vgl. Connelly, Stalinistische Vielfalt, S. 94 ff., der allerdings die politische Randständigkeit der allgemeinen Justiz nicht thematisiert.

175 Swidlicki, Political Trials, S. 323.

176 Geilke, Die neueste Entwicklung, S. $38 \mathrm{f}$.

177 Micgiel, Coercion, S. 126 f.; zur Schulung der Militärrichter vgl. Zaborski, Oni skaziwali.
} 
worden ${ }^{178}$. Nach dem Gerichtsverfassungsgesetz von 1950 wurden die Juristen auch formell auf das Staatsziel Sozialismus festgelegt, zwei Jahre später führte die Verfassung die Wahl der Richter ein ${ }^{179}$.

Anfangs waren vergleichsweise wenig Richter in der polnischen Staatspartei organisiert. 1953 gehörten erst 24,8\% der Richter der PZPR an, davon die meisten Kursrichter, 5,3\% waren Mitglieder der Bauern-Blockpartei, 14,7\% der demokratischen Blockpartei. Fünf Jahre später war der Anteil der PZPR-Mitglieder unter den Richtern lediglich auf $30 \%$ gestiegen, erst 1963 verfügte die Mehrzahl dieser Juristen über das Mitgliedsbuch der Staatspartei 180 .

Nach dem Abzug der deutschen Truppen mußte zunächst das alte Gerichtssystem wieder eingerichtet werden; Verwaltungsgerichte wurden dabei a priori weggelassen ${ }^{181}$. Der institutionelle Umbau der polnischen Justiz setzte unmittelbar 1944 mit der Bildung von Sondergerichten für NS-Verbrecher ein. Ein völliger Neuaufbau der gesamten Justiz stand in den deutschen Ostgebieten an. Während die Sonderjustiz immer weiter um sich griff, beschäftigte sich erst wieder im April 1949 ein Beschluß des zentralen Parteienblocks mit der allgemeinen Justiz. Diesem folgte die neue Strafprozeßordnung, die nur noch zwei Instanzen vorsah und die Institution des Untersuchungsrichters einführte. Außerdem wurde nun das Oberste Gericht in die Rechtsetzung einbezogen. Dies geschah in etwa parallel zur Einrichtung eines solchen Organs in der DDR, das seine Leitungsfunktion allerdings erst langsam entwickelte. Die Spitzeninstanzen wirkten sowohl über ihre Rechtsprechung als auch sporadisch über die von ihnen herausgegebenen Richtlinien. Fast zeitgleich, nämlich ein Jahr früher als in der DDR, wurde das polnische Oberste Gericht 1962 zum führenden Justizorgan aufgewertet ${ }^{182}$.

Mit fünf Erlassen erfolgte im Juni/Juli 1950 ein völliger Umbau des Justizwesens, also zwei Jahre früher als in der DDR ${ }^{183}$; damit sollte das polnische Gerichtssystem auch modernisiert werden. Anstatt des alten vierstufigen Gerichtswesens, das noch Ortsgerichte umfaßte, gab es nun drei Typen von Gerichten, die auch der territorialen Verwaltungseinteilung angepaßt waren ${ }^{184}$. Ganz nach sowjetischen Vorbild gestaltete sich die Ausgliederung der Staatsanwaltschaft aus dem Gerichtssystem, die nun auch noch die "Gesetzlichkeitsaufsicht" übernahm. Staatsanwälte konnten sogar „operative Strafen“ verhängen, zwei Monate Inhaftierung ohne Vorlage von Beweismaterial ${ }^{185}$. Als Aufgabe der Gerichte wurde nun explizit der Aufbau des Sozialismus festgeschrieben. Zwar löste man die Richterkurse wieder auf, die Qualifikationen wurden aber allgemein gesenkt. Erst 1957 machte man dies wieder rückgängig. Schließlich waren von den Justizreformen des Jahres 1950 auch die Rechtsanwälte betroffen, die Juristen, die am schwersten unter deutscher Besatzung zu leiden gehabt hatten. Im Juni 1950 erfolgte die Ein-

178 Vgl. Geilke, Entwicklung des polnischen Justizrechts, S. 113; Włodyka, Organizacja sądownictwa, S. 130.

179 Włodyka, Organizacja sądownictwa, S. 208 f.

180 Rzepliński, Sądownictwo PRL, S. 69.

181 Rácz, Courts and Tribunals, S. 84.

182 Berutowicz, Recht, S. 87.

183 Vgl. den Überblick von Geilke, Entwicklung des polnischen Justizrechts, S. 123-126.

184 Włodyka, Organizacja sądownictwa, S. $217 \mathrm{f}$.

185 Paczkowski, Pól wieku, S. 253. 
führung der Anwaltsgenossenschaften, die drei Jahre später - mit erheblichen Anlaufschwierigkeiten - auch in der DDR eingerichtet wurden.

Die Anleitung und Kontrolle der Gerichte verlief grundsätzlich ähnlich wie in der DDR. Dafür war vor allem das Justizministerium mit seiner Abteilung für die Überwachung der Gerichte zuständig. Diese entsandte auch laufend „Visitatoren“, um die Tätigkeit der Wojewodschaftsgerichte zu überprüfen. Regionale Justizverwaltungsstellen gab es in Polen nicht, die unteren Instanzen wurden durch die Wojewodschaftsgerichte überwacht ${ }^{186}$.

Innerhalb des politischen Systems war die polnische Justiz etwas anders gelagert als die in der SBZ/DDR. Grundsätzlich muß man berücksichtigen, daß in Polen keine offizielle sowjetische Besatzungsverwaltung existierte, sieht man von den Kommandanturen auf lokaler Ebene in den Westgebieten ab. Somit fehlte im allgemeinen der direkte Einfluß von Justizoffizieren der Roten Armee. Allerdings war die polnische Justiz "durch die Hintertür" doch erheblichen sowjetischen Interventionen ausgesetzt, auf oberster Ebene durch die Einflußnahme auf das Politbüro von PPR bzw. PZPR, im Rechtsleben mittels der Instrukteure in Geheimpolizei und Militär. Nur vereinzelt ist der Einsatz sowjetischer Berater zu Prozessen nachweisbar, so in den Verfahren gegen den Vorkriegs-Generalstab oder gegen den Bischof Kaczmarek ${ }^{187}$. Es fehlte jedoch der geregelte, offen legitimierte Zugriff sowjetischer Behörden auf das Gerichtssystem, wie es ihn in der SBZ und den Anfangsjahren der DDR gab.

Ebenso wie die Sowjets griff auch das Politbüro der PPR bzw. PZPR in einzelne Ermittlungen ein. Bei spektakulären politischen Verfahren, so etwa gegen die Führer einer Fraktion der Sozialisten, gaben Geheimpolizei und Politbüro den kompletten Regieplan vor ${ }^{188}$. Die Rolle des polnischen ZK-Apparats, insbesondere seiner Abteilung Verwaltung, ist bisher noch nicht untersucht worden ${ }^{189}$. Es ist allerdings zu berücksichtigen, daß für eine breite Steuerungstätigkeit durch die Partei lange Zeit die Voraussetzungen fehlten. Die kommunistische PPR war in der allgemeinen Justiz kaum verankert, nur wenige Juristen waren dort Mitglied; dies änderte sich erst 1948, als durch die Zwangsvereinigung von Kommunisten und Sozialisten mehr Juristen in die neue Partei kamen. Nachweisbar ist die Nomenklaturordnung von 1950, nach der die Verwaltungsabteilung des ZK der PZPR alle Präsidenten bzw. Vizepräsidenten der Wojewodschaftsgerichte und alle entsprechenden Staatsanwälte bestimmen konnte; gemäß der Kaderordnung vom Januar 1954 wurde dies auf alle Richter an Wojewodschaftsgerichten und den Präses des Powiat-/Kreisgerichts ausgedehnt; der Präses des Wojewodschaftgerichts mußte sogar vom Sekretariat des ZK bestätigt werden ${ }^{190}$. Weit ausgeprägter als die anfängliche Kaderpolitik war der informelle Druck der Kommunisten auf die Justiz. Schon 1946 startete die PPR-Presse eine Kampagne gegen Richter, die angeblich zu "weiche“ Urteile verhängten ${ }^{191}$. Die Interventionen der Nationalräte

186 Włodyka, Organizacja sądownictwa, S. $280 \mathrm{f}$.

187 Wostotschnaja Jewropa, S. 750 f. (dort auch entsprechendes Politbüro-Protokoll der KPdSU vom 10.6. 1952), $903 \mathrm{f}$.

188 Vgl. die Politbürositzungen vom 17.4., 21.5. und 16. 9. 1948, Poksiński, My sędziowe, S. 34.

189 Etwas spärlich die Aktenübersicht bei Mohnhaupt/Schönfeldt, Normdurchsetzung, S. 360.

190 Zieliński, Struktura, S. 351; Rzepliński, Sądownictwo PRL, S. 52.

191 Micgiel, Coercion, S. 105. 
und der PZPR, vor allem von deren Wojewodschaftskomitees, gehörten in der ersten Hälfte der fünfziger Jahre zum Justizalltag. Der entscheidende Druck ging aber von den Präsidenten der Wojewodschaftsgerichte aus, die zugleich den besten Überblick über die Rechtsprechung in ihrem Bezirk hatten ${ }^{192}$. Insgesamt zeigen die Anleitungsstrukturen in Polen und in der DDR also einige Parallelen.

Einen ganz anderen Weg als die SED ging die PPR bzw. PZPR bei der justitiellen Verfolgung ihrer Gegner. Diese lief größtenteils nicht im regulären Rechtssystem ab, wie etwa in der Geheimkammer des Warschauer Wojewodschaftsgerichts ${ }^{193}$. Die Masse dieser Verfahren kam vor die Militärjustiz. Die Hauptursache dafür ist im Bürgerkrieg bis Anfang der fünfziger Jahre zu sehen; erst im November 1945 war überhaupt der Kriegszustand in Polen offiziell aufgehoben worden. Die Tätigkeit der Militärgerichte dehnte sich danach - mit der Begründung des Ausnahmezustandes - im November 1945 und im Juni 1946 auch auf politische Beschuldigungen gegen Zivilisten aus; diese fielen damit unter die drakonischen Bestimmungen des Militärstrafgesetzbuches. Bei Zuständigkeitsstreitigkeiten zwischen allgemeinen Gerichten und Militärtribunalen entschieden immer die letzteren ${ }^{194}$. Daneben bestanden kurzzeitig (Februar bis Juli 1946) Standgerichte bei einigen Bezirksgerichten, die faktisch zu einzelnen Einheiten der Armee und der Innentruppen gehörten und mit Militärjuristen besetzt waren. Sie warfen in fast der Hälfte aller Fälle Todesurteile aus ${ }^{195}$. Die Polnische Armee bildete zu diesem Zeitpunkt das wichtigste Machtinstrument von sowjetischen Kräften und Kommunisten in Polen; wie die Armee insgesamt war auch die Militärjustiz hochgradig mit sowjetischen und linientreuen polnischen Kadern besetz $\mathrm{t}^{196}$. Von ihr wurden von 1946 bis 195365000 Personen verurteilt, allein 22500 davon seit 1950, als der Bürgerkrieg schon am Abflauen war ${ }^{197}$.

Die polnische Militärgerichtsbarkeit ist hier als funktionales Äquivalent zu den sowjetischen Militärtribunalen in der SBZ zu sehen. In den Gebieten unter militärischem Ausnahmezustand gab es aber auch in Polen 1944/45 eine Jurisdiktion der Roten Armee ${ }^{198}$; einer der wichtigsten Prozesse gegen die Führung des antikommunistischen Untergrunds fand nicht in Polen, sondern im Juni 1945 in Moskau statt ${ }^{199}$. Diese Verteilung der Gewichte, also das weitgehende Monopol der Militärjustiz bei der politischen Verfolgung, bildet den Hintergrund dafür, daß der polnische Justizapparat nicht so tiefgreifend umgewälzt wurde wie der ostdeutsche.

192 Geilke, Die neueste Entwicklung, S. 51.

193 Richter und StA wurden vom Obersten Gericht, das über eine eigene Geheimsektion verfügte, und der GStA gestellt. Dort standen 1950-1954 626 Personen vor Gericht, Grzeskowiak, Sądy tajne, S. 64-70; Albert, Historia najnowsza, S. 635. Vgl. die Anordnung des MdJ vom 18. 2. 1950, Kochański, Polska, S. 314.

194 Włodyka, Organizacja sądownictwa, S. 147.

195 Turlejska, Te pokolenia, S. 369-372; nach Anweisung des Obersten Militärgerichts vom 16. 4. 1946 sollte dort die Todesstrafe als Regelstrafe ausgesprochen werden, Kochański, Polska, S. 143.

19630 von 288 Justizoffizieren hatten die sowjetische Staatsbürgerschaft, Poksiński, My sędziowe, S. $21 \mathrm{f}$.

197 Eine Analyse der Rechtsprechung 1949/50: Jarosz, Notatka, S. $250 \mathrm{ff}$.

198 Vgl. Gryciuk, Represje NKWD, Band 1, S. 344f., 356 f., 369 f.

199 Vgl. aus der umfangreichen Literatur zu diesem Verfahren besonders: Proces szesnastu. 
Wie in der SBZ so gab es ebenso in Polen Kontrollkommissionen, dort als „Sonderkommission zur Bekämpfung von Mißbräuchen und Wirtschaftssabotage" ${ }^{200}$. In Form und Benennung orientierten sich diese Organe sicher am sowjetischen Vorbild ${ }^{201}$. Die polnische Kommission, die über Untereinheiten auf Wojewodschafts- und Kreisebene verfügte, sollte entsprechend gegen Wirtschaftsverbrecher vorgehen, vor allem Schieber, Spekulanten, oder gegen die Verletzung der Preisstrafbestimmungen. Auch sie hatte erhebliche Rechte im exekutiven und juristischen Bereich, bis hin zur Anklageerhebung. Auf politischer Ebene waren ihre Kompetenzen - noch stärker als in der SBZ - umstritten. Die einflußreiche Bauernpartei konnte sich mit ihren Vorschlägen zur Reduzierung der Kompetenzen jedoch nicht durchsetzen.

Neben diesen Parallelen gab es auch eine Reihe von Unterschieden zur Zentralen Kontrollkommission. Entsprechend der politischen Gesamtentwicklung erfolgte die Bildung der polnischen Kommission schon früh, nämlich Ende 1945. Sie war dem Parlamentspräsidium unterstellt und hochkarätig besetzt; der Vorsitzende Zambrowski gehörte dem Politbüro der PPR an. Zugleich saßen in jeder Abteilung der Kommission auch Juristen, die vom Justizminister delegiert worden waren ${ }^{202}$. Die gravierendste Differenz zur ostdeutschen Entwicklung machte aber die Strafkompetenz der Kommission aus, insbesondere das Recht auf Einweisung zu Zwangsarbeit bis zu zwei Jahren; faktisch erfolgte die Internierung in Zwangsarbeitslagern. Dagegen konnten die Wirtschaftsstrafämter der SBZ/DDR nur Geldbußen verhängen, wenn auch in erheblicher Höhe. Ab 1951 sollten die polnischen Kommissionen nicht nur Wirtschaftsvergehen ahnden, sondern auch "feindliche Propaganda“ oder "Rowdytum", zwei aus der Sowjetunion importierte und äußerst dehnbare Deliktgruppen. Auf dem Höhepunkt dieser Strafpraxis, im Jahre 1952, wurden über 22000 Personen in die Lager gesteckt. Insgesamt verhängte die Kommission über 300000 Personen Strafen, von denen mehr als 84000 in Lagern abgesessen werden mußten ${ }^{203}$. Auch in der Entwicklung der Kontrollkommission zeichneten sich Unterschiede zur SBZ/DDR auf. Mit der Aufwertung der polnischen Staatsanwaltschaft im Jahre 1950 mußte die Sonderkommission ihr Recht auf eigenständige Untersuchungstätigkeit aufgeben, das zuständige Personal wurde den Staatsanwaltschaften unterstellt204. Die Strafkompetenz blieb jedoch bis 1954 und damit etwas länger als die strafrechtlichen Kompetenzen der ZKK in der DDR erhalten. So läßt sich also auch in diesem Bereich von einer repressiveren Entwicklung in Polen sprechen. Ungeklärt ist bisher, inwieweit die polnische Kontrollkommission - wie die ZKK - ins normale Justizleben eingriff. Grundsätzlich hatte sie das Recht, in laufenden Verfahren zu inter-

${ }^{200}$ Zum Folgenden: Jarosz/Wolsza, Komisja Specjalna, in: Biuletyn Głównej Komisji; ausführlich die Dokumentation: diess., Komisja Specjalna (Wybór dokumentów); Kochanowski, Protokoły posiedzień, S. 282-297; vgl. Geilke, Die polnische Strafgesetzgebung, S. 103-106.

$201 \mathrm{Im}$ November 1952 wurde nach sowjetischem Muster auch ein Ministerium für Staatskontrolle gebildet, Mołdawa, Ludzie władzy, S. 105.

202 Kochanowski, Protokoły posiedzień, S. $282 \mathrm{f}$.

${ }_{203}$ Paczkowski, Polen, S. 418; höhere Zahlen bei Micgiel, Frenzy, S. 20.

204 Vgl. die Politbürositzung vom 19.4. 1950, Jarosz/Wolsza, Komisja Specjalna (Wybór dokumentów), S. 51-56. 
venieren oder diese an sich zu ziehen. Da sie über eigene Strafkompetenz verfügte, wurden diese Fragen aber möglicherweise schon „im Vorfeld“ geklärt.

Wirft man einen vergleichenden Blick auf die Geheimpolizei in Volkspolen und in der DDR, so fallen sofort die Größenunterschiede ins Auge. Schon im Mai 1945 hatte das Amt für Sicherheit in Polen 11000 Funktionäre, im Herbst zweieinhalbmal so viele; Anfang 1953 waren es etwa 43000 Mitarbeiter und bis zu 75000 Informanten ${ }^{205}$. Selbst in Relation zur Bevölkerungszahl ist das ein Vielfaches des damaligen MfS-Personals. Die politische Polizei entwickelte sich in Polen viel schneller als in der SBZ, weil Polen formell nicht unter Besatzung stand, NKWD und polnische Kommunisten aber sofort einen Apparat zur Bekämpfung ihrer politischen Gegner bzw. des bewaffneten Untergrunds benötigten. Im Grunde war das polnische Ministerium für öffentliche Sicherheit schon 1944 in Moskau gebildet worden. Im Gegensatz zum MfS konnte die polnische Geheimpolizei ein gewisses Eigengewicht gegenüber der Staatspartei entwickeln, so daß in Polen beider Verhältnis nicht ganz ohne Reibungen blieb.

Der enorme Geheimpolizei-Apparat bildete in gewisser Hinsicht ein Substitut für die nicht vorhandene reguläre Besatzung. Allerdings war er in Polen auch dann noch weitaus größer als in der frühen DDR, wenn man bei letzterem das MGB- und MWD-Personal hinzurechnet. Alle Führungskader der polnischen Geheimpolizei kamen aus dem Moskauer Exil. Neben den Instrukteuren des NKWD/MGB waren bei der Bekämpfung der Untergrundbewegung bis August 1946 NKWD-Truppen eingesetzt, die Polen im Frühjahr 1947 wieder verließen. Die polnische Geheimpolizei unterschied sich in ihrer Vorgehensweise kaum von ihrem Vorbild MGB, sie schreckte auch vor Morden an politischen Gegnern nicht zurück.

Die Ermittlungstätigkeit in politischen Verfahren beim Amt für Sicherheit ist noch wenig erforscht ${ }^{206}$. Obwohl diese Kompetenz bereits seit dem Dezember 1945 bestand, dürften sich die Abläufe ähnlich gestaltet haben wie später beim MfS, da beide Dienste von sowjetischen Instrukteuren aufgebaut worden waren. So existierte eine Ermittlungsabteilung in der als Ministerium für Öffentliche Sicherheit (MBP) firmierenden Geheimpolizei; in politischen Verfahren und Ermittlungen wegen großer Unfälle arbeitete die Geheimpolizei die Anklagen aus. Das MBP verfügte ebenso wie das MfS über eine Sektion zur Überwachung des Justizministeriums ${ }^{207}$. Die Ermittlungsoffiziere des MBP waren frühzeitig mit weitgehenden Kompetenzen ausgestattet ${ }^{208}$. Die Aufsicht der Staatsanwaltschaft über die Geheimpolizisten bestand wie in der DDR nur auf dem Papier. Zwar verlief die Zusammenarbeit mit der Staatsanwaltschaft im allgemeinen reibungslos; Staatsanwälte, die jedoch den Verhaftungswünschen der Geheimpolizei nicht nachkamen, konnten im schlimmsten Fall selbst im Gefängnis landen. Zahlreiche

${ }^{205}$ Paczkowski, Pół wieku, S. 167; Paczkowski, Aparat Bezpieczeństwa, S. 3; Paczkowski, Polen, S. $417 \mathrm{f}$.

206 Vgl. Dominiczak, Organy bezpieczeństwa, S. 58ff.; zur Abteilung, die gegen Funktionäre der KP ermittelte: Paczkowski, Krótki kurs, S. 130-137.

207 Paczkowski, Pół wieku, S. 234, 252; Aparat Bezpieczeństwa, Teil 1, S. 14 f. Zu den Umorganisationen: Kochański, Polska, S. 99.

208 Vgl. Rundschreiben des MBP vom 8. 1. 1947, ebenda, S. 180. 
Richter wurden unter Druck gesetzt oder auf Drängen des Ministeriums für Öffentliche Sicherheit entlassen ${ }^{209}$.

Ganz anders gelagert als in der SBZ und der frühen DDR war die Bedeutung des militärischen Geheimdienstes in Polen, der Hauptverwaltung für Information. Sie ermittelte in politischen Verfahren für die Militärgerichte. Zugleich unterlagen diese Gerichte der Kontrolle durch die Gegenspionage, die über zahlreiche Spitzel unter den Militärjuristen verfügte ${ }^{210}$.

Auch auf dem Feld der Rechtsprechung zeigen sich Gemeinsamkeiten wie Unterschiede der „volksdemokratischen“ Entwicklungen. Die normale Kriminalität lag in Polen niedriger als in der SBZ, bereits 1948 erreichten die polnischen Zahlen wieder Vorkriegswerte. Zum Vergleich: Im Jahre 1947 kamen in Brandenburg 510 Morde zur Ermittlung, in ganz Polen waren es zur gleichen Zeit 2800 Fälle, obwohl die Einwohnerzahl dort zehnmal höher lag. Bei Diebstahlsdelikten war diese Relation noch krasser: In Polen wurden nur doppelt so viele Fälle gemeldet wie allein in Brandenburg211. So gesehen war die Belastung der Justiz zur gleichen Zeit in der SBZ um ein Vielfaches größer.

Ein anderes Bild ergibt sich jedoch bei den politischen Verfahren. Ausgangspunkt für die politische Justiz war in Polen wie in der SBZ die Bestrafung von NSVerbrechern. Zur gleichen Zeit wie in Deutschland wurden in Polen Tausende von NS-Verfahren durchgeführt. Nach momentanem Erkenntnisstand wurden dabei insgesamt etwa 16800 Personen verurteilt, von denen jeder dritte deutscher Staatsbürger war ${ }^{212}$. Für die Ermittlungen war von Anfang an eine Sonderbehörde zuständig, die dem Justizministerium unterstand und die die Vorarbeit für die Staatsanwaltschaften übernahm: die Hauptkommission zur Untersuchung der deutschen Verbrechen ${ }^{213}$. Bereits im November 1944 ergingen erste Urteile. Die meisten dieser Prozesse erfolgten vor eigens etablierten Sondergerichten mit besonderen Straf- und Prozeßnormen wie der fehlenden Berufungsmöglichkeit. Diese Tribunale wurden jedoch nach zwei Jahren wieder aufgelöst, und die NSVerfahren gingen an die ordentlichen Gerichte (in schwersten Fällen an das ebenfalls befristet tätige Oberste Nationaltribunal).

Anders als in den nichtpolitischen Strafverfahren scheint die kommunistische PPR auf die NS-Verfahren einen gewissen Einfluß gehabt zu haben, war aber insgesamt wohl nicht zufrieden mit dem Ergebnis ${ }^{214}$. Die Deutschen, die vor Gericht standen, waren zu einem Drittel aus Zonendeutschland ausgeliefert worden. Diese kamen fast ausschließlich aus den Westzonen, die SMAD überstellte der polnischen Justiz anscheinend nur 69 Beschuldigte215. Die Angeklagten in NSVerfahren standen zum großen Teil wegen schwerster Verbrechen vor Gericht.

${ }^{209}$ Dominiczak, Organy bezpieczeństwa, S. $65 \mathrm{ff}$.

210 Poksiński, My sędziowe, S. 38. Das Spitzelnetz allein des Militärgeheimdienstes war 1953 größer als das in der DDR von MfS und MGB zusammen, Paczkowski, Aparat Bezpieczeństwa, S. 4.

211 BLHA, Rep. 212, Nr. 22, Bl. 8, Übersicht Geschäftsentwicklung 1947; Jakubowski, Milicja Obywatelska, S. 446, 464. Polen hatte 194624 Mio. Einwohner, 1960 fast 30 Mio.

212 Rückerl, NS-Verbrechen vor Gericht, S. 101; die Untersuchung von Wojciechowska, Przestępcy hitlerowscy, S. 23, zum Sondergericht in Tschenstochau läßt allerdings vermuten, daß die Zahlen höher liegen. Dort wurden in 1159 Verfahren 668 Verurteilungen ausgesprochen.

${ }^{213} \mathrm{Vgl}$. Pilichowski, Badanie i ściganie, S. 3-31.

214 Rzepliński, Sądownictwo PRL, S. 26; Micgiel, Coercion, S. 105.

215 Kobierska-Motas, Ekstradycja, Band 1, S. 172. 
Allerdings konnte auch die Zugehörigkeit zu einer kriminellen Organisation wie der SS für eine Haftstrafe ausreichen. Etwas anders verhielt es sich mit den über 10000 Volksdeutschen, gegen die Urteile ergingen. Sie mußten sich oftmals verantworten, weil sie am "rassischen“ Einbürgerungsverfahren der Besatzungsbehörden teilgenommen hatten ${ }^{216}$.

Bei den NS-Verfahren in der SBZ/DDR und in Polen standen annähernd gleich viele Beschuldigte vor Gericht. Angesichts der Tatsache, daß auf dem Gebiet Polens weit mehr und weit schwerere NS-Verbrechen verübt worden waren als auf dem Territorium der SBZ, hieß das, daß in der SBZ vorwiegend kleinere NSTaten, also meist keine Tötungverbrechen, vor Gericht verhandelt wurden. In Polen hingegen gab es keine sowjetischen Militärverfahren in NS-Sachen, und schon gar nichts, was mit den Waldheimer Prozessen vergleichbar wäre.

Spezifisch polnisch war die Verquickung der NS-Verfahren mit der Nationalitätenpolitik gegen die eingesessenen Deutschen. Doch scheint es nicht angebracht, von einer reinen Instrumentalisierung der NS-Verfahren zur Vertreibung der Deutschen zu sprechen. Aktenkundig sind Todesurteile gegen Deutsche in anderen Verfahren, so wegen Waffenbesitzes. Die NS-Prozesse hatten - soweit sich das momentan rekonstruieren läßt - fast durchweg strafrechtliche Substanz und dienten dann nach außen vor allem zur Legitimierung der Maßnahmen gegen andere Deutsche. Die eigentliche Vertreibung lief auf administrativem Wege ab, ähnlich wie die Kollektivbestrafung der Ukrainer 1947 in Südostpolen²17.

Während in der SBZ die Strafen in NS-Verfahren 1949 immer härter wurden, konzentrierten sich die polnischen Verfahren im gleichen Zeitraum nur noch auf wenige schwer belastete Täter. Danach liefen die NS-Prozesse in beiden Staaten parallel aus. Deutsche wurden kaum noch nach Polen ausgeliefert, und schon ab Herbst 1946 zeichnete sich die Integration von polnischen Kollaborateuren, insbesondere Denunzianten ab ${ }^{218}$ - eine Politik, die von nun an dominierte.

Die politischen Verfahren zur Bekämpfung echter oder vermeintlicher Gegner schlossen sich nahtlos an die NS-Prozesse in Polen an. So wurde die bürgerliche Untergrundbewegung alsbald als pronazistisch apostrophiert, obwohl sie im Krieg die stärkste Kraft gegen die deutsche Besatzung gebildet hatte. Während das NKWD in der SBZ eher eine Chimäre bekämpfte, hatte man es in Polen mit einem echten Gegner zu tun ${ }^{219}$. Ebenso wie in der SBZ mußten Jugendliche beständig Angst haben, wegen des Vorwurfs der Untergrundtätigkeit verhaftet zu werden; sogar "Werwolf"-Gruppen waren in den polnischen Westgebieten anscheinend aktiv220.

Im Unterschied zur SBZ schwelte in Polen nicht nur ein Bürgerkrieg, sondern auch eine echte politische Auseinandersetzung zwischen Kommunisten und dem „bürgerlichen Lager“, vor allem der Bauernpartei. Letztere versuchte nicht nur

$216 \mathrm{Vgl}$. Wojciechowska, Przestępcy hitlerowscy, S. $26 \mathrm{ff}$.

217 Vgl. Turlejska, Te pokolenia, S. 322-331. Die umfangreichen Kopien von Verfahrensakten, die ab

1965 im Rahmen der Rechtshilfe in die Bundesrepublik gelangten, ergeben keine Hinweise auf Deliktfabrikation.

218 Turlejska, Te pokolenia, S. 37.

219 Vgl. Micgiel, Coercion, S. $430 \mathrm{ff}$.

220 Paczkowski, Pół wieku, S. 141; Golabek/Tryc, Z genezy powstania i działalności Werwolfu, S. $140 \mathrm{ff}$. 
den Machtaspirationen der PPR Einhalt zu gebieten, sie forderte 1946 auch die Abschaffung der Geheimpolizei und die Freilassung der politischen Häftlinge ${ }^{221}$. Im Verein mit den sowjetischen Stellen verfolgten die Kommunisten ihre Gegner erbarmungslos. Der Herbst 1946 sah einen ersten Höhepunkt des Terrors, mit Massenverhaftungen und organisierten Demonstrationen gegen die Bauernpartei. Selbst vor der Ermordung von deren Funktionären schreckte die Geheimpolizei nicht zurück. 1947 holten die Kommunisten zum Vernichtungsschlag aus; eine Anklage gegen den Parteichef Mikolajczyk war in Vorbereitung. Dieser floh jedoch in den Westen, im Oktober wurde die Partei gleichgeschaltet. Zahlreiche Funktionäre der Bauernpartei wurden Opfer politischer Prozesse, oft als "Spione“ oder wegen Zusammenarbeit mit der Untergrundbewegung verurteilt ${ }^{222}$.

Ähnlich wie die Bauernpartei nahm auch die - hier katholische - Kirche in Polen eine viel stärkere Stellung ein als in der SBZ/DDR. Sowjetische und polnische Kommunisten schlugen früher und schärfer einen Konfrontationskurs ein. Priester, die mit dem antikommunistischen Untergrund zusammenarbeiteten, gerieten als erste in die Mühlen der politischen Justiz 223. Im Frühjahr 1948 begann eine massive Kampagne gegen die katholische Kirche; 1951 folgten Verhaftungen und Schauprozesse gegen Priester, bei denen mehrfach lebenslange Haftstrafen verhängt wurden. Spektakuläre Höhepunkte waren Anfang 1953 der Prozeß gegen Krakauer Priester wegen „Spionage für die USA“ und im September des Jahres die Verhaftung von Kardinal Wyszynski224. Hier ergeben sich zwar zeitliche Parallelen zu einigen Prozessen in der DDR; die Dimensionen der Verfolgung unterschieden sich jedoch, nicht zuletzt aufgrund der deutschlandpolitischen Rücksichen der sowjetischen Führung. Wohl auf sowjetisches Drängen ișt die Repressionswelle gegen die "Zeugen Jehovas“ zustande gekommen, die parallel zu den Verfolgungen in der DDR verlief. 1951 saßen über 2000 Sektenmitglieder in polnischen Gefängnissen 225.

Ganz ähnlich wie in der SBZ/DDR verlief die Kriminalisierung von KP-Funktionären. So gab es auch in Polen relativ wenige Verfahren gegen kommunistische Kader; am ehesten noch gegen Funktionäre der Polnischen Sozialistischen Partei PPS, die die Parteivereinigung ablehnten, und gegen solche Sozialisten, die im antikommunistischen Untergrund tätig waren. Allerdings spielte das Feindbild "Sozialdemokratismus“ keine Rolle, vielmehr nahmen diese Position die „Nationalkommunisten" ein. Obwohl zahlreiche Spitzenfunktionäre wie Gomułka in Haft saßen, blieb der große Schauprozeß à la Slánský aus. Die Bestrafung von KPFunktionären während der Säuberungswellen ab 1950 war in gleichen Formen wie in der DDR, nämlich fast durchweg in Geheimverfahren, verlaufen ${ }^{226}$.

\footnotetext{
221 Paczkowski, Pół wieku, S. 187.

222 Ebenda, S. 201; Albert, Najnowsza historia, S. 561-564.

$223 \mathrm{Vgl}$. Bombicki, Księza przed sądami.

224 Dominiczak, Organy bezpieczeństwa, S. 68, 105 ff.; Dudek, Państwo i kościół, S. 26, 30ff.; Paczkowski, Pół wieku, S. 273-278.

225 Paczkowski, Polen, S. 419.

226 PZPR-Funktionäre kamen offensichtlich nur selten vor Gericht (so Lechowicz und Jaroszewicz 1955), hingegen zahlreiche Generäle und Offiziere der Polnischen Armee, von denen einige zum
} 
Die Wirtschaftsverfahren nahmen in Polen eine schnellere Wendung hin zum offenen Klassenkampf als in der DDR. Schon 1946 verstärkte sich der Druck auf den Privathandel durch steuerliche Benachteiligung und schlechte Belieferung. 1947 riefen die Kommunisten dann die "Schlacht um den Handel“ aus. Die Kontrollkommissionen überprüften 1947/48 über 100000 Betriebe und bestraften bereits tausende Personen wegen Wirtschaftsvergehen, meist sogenannte Verstöße gegen die Staatsmonopole. Ab 1949/50 nahmen die Bestrafungen der Kommissionen einen massenhaften Charakter an, dann vorrangig wegen Spekulationsdelik$\operatorname{ten}^{227}$.

Das strafrechtliche Vorgehen in der Landwirtschaft zeigte in Polen eine eigentümliche Phasenverschiebung gegenüber der Entwicklung in der SBZ/DDR. Zwar setzte in der polnischen Landwirtschaft die Kollektivierung bereits 1948 ein, zu den drakonischen Pflichtablieferungsregelungen der SMAD gab es jedoch keine zeitliche Parallele; die Zwangsablieferung war in Polen vielmehr schon im Sommer 1946 abgeschafft worden. Dennoch erhöhte sich der Druck auf die wohlhabenderen Bauern, vor allem von seiten der Kontrollkommissionen ${ }^{228}$. Erst 1951/52 führte die polnische Staatsführung wieder schrittweise ein Pflichtablieferungssystem ein, das sukzessive bis 1953 verschärft wurde. Dies hing eng mit dem schleppenden Verlauf der Kollektivierung zusammen ${ }^{229}$. Schon 1952 wurden mehrere zehntausend Bauern wegen fehlender Ablieferungsmengen festgenommen. Etwa 500 von ihnen wurden durch die Verwaltung bestraft, 2000 Bauern von Gerichten verurteilt, weitere 1000 mußten in U-Haft. Die Zahl der Verwaltungsstrafen schnellte aber erst im Jahr darauf in die Höhe, sie wurden dann eine Viertelmillion $\mathrm{Mal}$ verhäng $\mathrm{t}^{230}$.

Diese verschiedenen Typen von politischen Verfahren zeigen den gleitenden Übergang von der Bekämpfung einer echten Opposition hin zur Gegnerfabrikation und Instrumentalisierung der Justiz für die Umwälzung der Gesellschaftsordnung. Dies zeichnete sich schon mit den ideologischen Kampagnen des Jahres 1948 ab; zwei Jahre später wurde auch die allgemeine Justiz auf den Aufbau des Sozialismus ausgerichtet. Besonders ab 1951 begann man - wie in der DDR - massenhaft Meinungsäußerungen aus der Bevölkerung zu kriminalisieren, waren sie nun politischer oder nichtpolitischer Natur ${ }^{231}$.

Wie in allen Diktaturen, so wurden auch in Volkspolen die Verhafteten zum großen Teil entrechtet. Besonders die politischen Häftlinge waren bei der Geheimpolizei oder der militärischen Abwehr ständig Mißhandlungen und Erniedrigungen ausgesetzt. Einzelne Gefängnisse galten als regelrechte Folterstätten für Häftlinge aus dem bürgerlichen Untergrund. Sie hatten meist die Todesstrafe zu

Tode verurteilt wurden. Das Verfahren gegen General Tatar u. a. war als Schauprozeß aufgezogen. Vgl. Turlejska, Te pokolenia, S. 387 f.; Poksiński, TUN, besonders S. $127 \mathrm{ff}$.

227 Kersten, Establishment, S. 372 ff.; Kaliński/Landau, Gospodarka Polski, S. 169; Jarosz/Wolsza, Komisja Specjalna (Wybór dokumentów), S. 8 f.; Jakubowski, Milicja Obywatelska, S. 485 f.

228 Paczkowski, Polen, S. 418.

229 Kaliński/Landau, Gospodarka Polski, S. 272 ff.; vgl. Geilke, Die polnische Strafgesetzgebung, S. 120-130; jetzt grundlegend: Jarosz, Polityka władz, bes. S. 187-236.

${ }^{230}$ Paczkowski, Pół wieku, S. 259; Dobieszewski, Polityka kolektywizacji, S. 447. Im September 1954 saßen 7300 Bauern wegen Nichtablieferung ein, Dominiczak, Organy bezpieczeństwa, S. 58.

231 Vgl. Dominiczak, Organy bezpieczeństwa, S. $56 f$. 
fürchten, die in den Jahren nach 1944 inflationär verhängt wurde. Während der dreißiger Jahre hatte es in Polen meist weniger als 20 Todesurteile im Jahr gegeben ${ }^{232}$. Nach derzeitigem Erkenntnisstand verhängten polnische Militär- und Sondergerichte von 1944 bis 1955 etwa 4400 Todesurteile, von denen etwa 3000 zur Vollstreckung kamen233. Die Todesstrafe war nach dem Krieg in Polen anscheinend nicht so delegitimiert wie in Deutschland. Das Regime erwog sogar die Vollziehung von Hinrichtungen vor Publikum; in Einzelfällen wurden Verurteilte öffentlich erhängt ${ }^{234}$. Angesichts der Zahl und der Begründung der vollstreckten Todesurteile muß man eigentlich von Massentötungen sprechen; nicht berücksichtigt ist in diesen Zahlen die unmittelbare Ermordung gefangener Untergrundkämpfer, deren Opferzahl noch weit höher liegt.

Die Kompetenz für den polnischen Strafvollzug ging nicht - wie in der DDR von der Justiz auf die Polizei, sondern schon im Herbst 1944 auf die Geheimpolizei über, die darüber hinaus Zehntausende in ihren Untersuchungsgefängnissen festhielt. Erst 1954 gingen diese Kompetenzen an das - neu gebildete - Innenministerium, um dann ab 1956 wieder im Justizbereich zu ressortieren ${ }^{235}$. Zu den Gefängnissen hinzuzuzählen sind die vielen Lager. Sie gehörten ebenso wie in der $\mathrm{SBZ}$ - bis auf wenige Ausnahmen - nicht zur Justizverwaltung. Vielmehr handelte es sich vor allem um Internierungslager für Deutsche in den Westgebieten, für Untergrundkämpfer oder die Zwangsarbeitslager der Kontrollkommission. Für 1952 wurde die Zahl ihrer Insassen auf 100-150.000 Personen geschätzt ${ }^{236}$. Ähnlich wie in der SBZ unterstand ein Teil des Lagersystems zunächst dem NKWD, wurde dann aber an das polnische Sicherheitsministerium abgegeben. Erst nach der Auflösung der Kontrollkommission war das Lagersystem 1956 an sein Ende gekommen ${ }^{237}$.

Insgesamt kommen Schätzungen über die Zahl der Inhaftierten in den Jahren 1944-1956 auf bis zu zwei Millionen Menschen238. Die Überfüllung der Gefängnisse erreichte ihren Höhepunkt ab Ende 1949 mit um die 100000 Sträflingen, d.h. jeder 250. Einwohner saß hinter Gittern. Eine vergleichbare Zahl gab es in der DDR nur kurzzeitig, nämlich im Mai 1953239. Im Strafvollzugssystem Polens waren bis 1956 weit mehr politische Häftlinge inhaftiert als in der DDR, nach absoluten Zahlen wie auch in Relation zur Bevölkerungsgröße. So saßen in Polen Anfang 194826400 politische Häftlinge ein, das waren $44 \%$ aller Insassen; Mitte 1950 waren es 35200 Personen, die $36 \%$ aller Inhaftierten stellten; und 1952 nicht weniger als 49.500. Damit näherte sich der Anteil politischer Gefangener an allen Häftlingen den Verhältnissen in der DDR an ${ }^{240}$.

232 Micgiel, Frenzy, S. 10.

233 Poksiński, My sędziowe, S. 14.

${ }^{234}$ Vgl. Kochanowski, Protokoły posiedzień, S. 303 f.; Turlejska, Te pokolenia, S. 106.

235 Im einzelnen: Kochański, Polska, S. 31; Dominiczak, Organy bezpieczeństwa, S. 69 ff.; Utrat-Milecki, Więziennictwo, S. 100-103.

236 Wolsza, Obozy pracy, S. 131.

${ }^{237}$ Dominiczak, Organy bezpieczeństwa, S. 75.

${ }^{238}$ Micgiel, Frenzy, S. 2.

${ }^{239}$ Utrat-Milecki, Więziennictwo, S. 116; Werkentin, Politische Strafjustiz, S. 368.

240 Paczkowski, Pół wieku, S. 259; Paczkowski, Polen, S. 419; Werkentin, Politische Strafjustiz, S. 409. 
Amnestien gab es in Polen ebenso wie in allen sozialistischen Systemen in fast periodischen Abständen. Im Nachkriegspolen hatten sie aber eine besondere politische Bedeutung, weil sie eng mit dem Bürgerkrieg verknüpft waren. Den Angehörigen des Untergrundes wurde 1945 und wieder 1947 bei Rückkehr in die Legalität Straffreiheit versprochen, viele von ihnen gerieten dann jedoch ab 1949 in die Mühlen der Militärjustiz. Neben dieser machtpolitischen Komponente verband das Regime mit den Amnestien natürlich auch die Hoffnung, mehr Zustimmung in der Gesellschaft zu finden.

Dies erwies sich jedoch aufgrund des Legitimitätsmangels der kommunistischen Herrschaft als äußerst schwierig. Da die Kommunisten durch reine Usurpation zur Macht gekommen waren ${ }^{241}$, stießen sie - und damit auch die Gleichschaltung der Justiz - auf weitverbreitete Ablehnung. Im Unterschied zur SBZ handelte es sich nicht um ein völkerrechtlich gedecktes Besatzungsregime, und demokratisch legitimiert erschien der Mehrzahl der Polen nicht die kommunistische Regierung in Warschau, sondern die Exilregierung in London. Zum Vergleich: In den fünfziger Jahren sahen viele Einwohner der DDR eine legitime Alternative in der Bundesrepublik.

Für Polen muß man davon ausgehen, daß die schon vor dem Krieg verbreiteten antikommunistischen und die russophoben Strömungen in der Bevölkerung auch in der Desorientierung der unmittelbaren Nachkriegszeit 1944 weiter existierten, wenn nicht sogar zunahmen ${ }^{242}$. Abstimmungsfälschungen und der hohe Grad der Repression vor allem in den östlichen Gebieten verschärften diese Haltungen. Schätzungen sprechen davon, daß mehrere Millionen Polen bis 1955 unmittelbar oder - als Familienangehörige - mittelbar Opfer politischer Verfolgungen wurden $^{243}$. Allerdings wuchs in Teilen der Arbeiterschaft, in den Ansiedlern der neuen Westgebiete und unter der Intelligenz in den fünfziger Jahren eine schmale, aber loyale Basis der Staatspartei heran.

Die Einstellung der Polen zur Justiz der Nachkriegsjahre läßt sich - ähnlich wie in der SBZ/DDR - zur Zeit nur fragmentarisch rekonstruieren. Für die Terrorverfahren der Militärgerichte kann man davon ausgehen, daß sie generell abgelehnt wurden, obwohl man sie geheimzuhalten versuchte. Im Bereich der "normalen“ Justiz lassen sich die gängigen Beschwerdemuster feststellen, die sich kaum von westlichen Rechtssystemen unterschieden ${ }^{244}$. Bei den Unruhen 1956 waren - wie in der DDR 1953 - Polizei, Verwaltungen und Gerichte als Symbole der Herrschaft Ziel physischer Attacken245. Die entscheidende Differenz zwischen der DDR und Polen im Blick auf die Bevölkerung war sicher die Existenz eines anderen deutschen Staates. Von der Bundesrepublik ging nicht nur eine massive Delegitimierung der SED-Diktatur aus, sie bot vor allem eine Fluchtmöglichkeit, welche die Polen in dieser Form nicht hatten.

$24 ! \mathrm{Vgl}$. Lamentowicz, Legitimation, S. $12 \mathrm{ff}$.

242 Vgl. Kersten, Między wyzwoleniem, S. 6.

${ }_{243}$ Micgiel, Frenzy, S. 32.

244 Vgl. die Auswertung von Beschwerden in: Jarosz, Akta Biura Listów, S. 213.

245 Machcewicz, Massenbewegung, S. 23, 26. 


\section{c. Unterschiede und Konvergenz der "Volksdemokratien"}

$\mathrm{Da} \beta$ die Entwicklungen in der SBZ und in Polen trotz der kommunistischen Machtergreifungen zunächst unterschiedlich waren, verstand sich auch für SEDFunktionäre wie Friedrich Ebert noch 1948 von selbst: „Im Unterschied zu den Volksdemokratischen Ländern sind die Bedingungen des Kampfes gegen diese volksfeindlichen Elemente andere." Die Ausgangspositionen beider Systeme wären zu verschieden, so seien in der SBZ die Privatwirtschaft und die "Reaktionäre“ noch stark ${ }^{246}$. Wenn man so will, waren die polnischen Genossen der SED um mehrere Jahre in der Entwicklung voraus; allerdings schrumpfte dieser „Vorsprung" ab 1949/50247.

Eine Rezeption der polnischen Justizentwicklung setzte in der SBZ/DDR erst relativ spät ein, sieht man von der Presseberichterstattung über polnische NSVerfahren gegen Deutsche ab. Immerhin fuhr eine Delegation aus der DDR zur Teilnahme am polnischen Juristenkongreß $1950^{248}$. Später häuften sich solche Kontakte, so etwa zwischen Hilde Benjamin und Marian Muszkat, dem führenden polnischen Parteijuristen ${ }^{249}$. Es trafen sich beispielsweise aber auch Anwälte aus Cottbus 1956 mit polnischen Kollegen. Dabei nahmen sie die konkreten Unterschiede beider Justizsysteme durchaus wahr: „Praktische Hinweise für unsere Arbeit gaben besonders die polnischen Kollegen hinsichtlich der Stellung des Verteidigers im Strafprozeß. Koll. M. hob hervor, daß der Verteidiger in Volkspolen ohne Zugegensein einer Aufsichtsperson mit dem Angeklagten Rücksprache nehmen kann." 250

Im Jahre 1956 kippte die bis dahin weitgehend positive Polen-Rezeption. Nach Chruschtschows Geheimrede fühlte sich Ulbricht noch im Mai 1956 bemüßigt hervorzuheben, daß es in der DDR im Gegensatz zu Polen keine großangelegten Schauprozesse gegen Kommunisten gegeben habe. Von der Liberalisierung beim östlichen Nachbarn ab Oktober 1956 war er freilich entsetzt ${ }^{251}$.

Noch im Jahre 1953 hatte es in Polen - auf dem Oktoberplenum der PZPR nur leichte Anzeichen für einen "Neuen Kurs“ gegeben ${ }^{252}$. Erst im Jahr darauf zeichnete sich eine Krise in den Straforganen ab. Nach der Flucht eines ihrer führenden Funktionäre in den Westen mußte die Geheimpolizei dauernde Reorganisationen über sich ergehen lassen; unter anderem verlor sie die Aufsicht über den Strafvollzug. Gleichzeitig wurde die Kontrollkommission samt ihren Lagern aufgelöst. Im Dezember 1954 rief die Partei eine Kampagne zur Stärkung der „Gesetzlichkeit“ aus, die durchaus positive Folgen hatte ${ }^{253}$; die politischen Verfahren

246 BLHA, Rep. 332, Nr. 13, Bl. 145, Rede Ebert auf LV-Sitzung 7./8. 10. 1948.

247 So auch Rosenthal/Lange/Blomeyer, Justiz in der Sowjetischen Besatzungszone, S. 64.

248 Vgl. SAPMO, DY 30/J IV 2/3/117, Protokoll der Sitzung des kleinen Sekretariats am 26. 6. 1950. Im September wurden polnische Juristen zu Vorträgen eingeladen.

${ }^{249}$ Rottleuthner, Steuerung, S. 25; SAPMO, DY 30/IV 2/13/453, Tagung des Rates der Internationalen Vereinigung Demokratischer Juristen in Warschau, 20.-23. 11. 1950.

250 BA, DP-1 VA 479, Bl. 139-144, Protokoll Mitgliederversammlung RA-Kollegium Cottbus am 28. 1.1956.

251 Engelmann/Schumann, Kurs auf die entwickelte Diktatur, S. 6; vgl. SAPMO, DY 30/IV 2/13/27,

Plan der Sektorenleiterberatung am 16. 1. 1956: Teilnahme am polnischen Juristenkongreß.

${ }_{252} \mathrm{Zu}$ den internen Diskussionen ab März 1953 vgl. Paczkowski, Aparat Bezpieczeństwa, S. 6 ff.

253 Vgl. Albert, Najnowsza historia, S. 690 f.; Paczkowski, Terror, S. 32 f. 
gingen nun von der Militärjustiz auf normale Gerichte über. Im Frühjahr 1956 wurden alle Spitzenfunktionäre der Justiz ausgewechselt. Den eigentlichen politischen Bruch brachte jedoch der „polnische Oktober“ 1956. In weit größerem Ausmaß als in der DDR entwickelte sich eine Entstalinisierung mit einer Amnestie, Rehabilitierungen und der Entschärfung der Repression. Die Gerichte pochten nun wieder stärker auf ihre Unabhängigkeit von der Staatspartei. Die polnische Staatsführung erreichte sogar, daß sowjetische Soldaten, die in Polen Verbrechen verübten, vor polnische Gerichte gestellt werden konnten - in der DDR undenkbar254.

Allerdings blieb eine Bestrafung der Verantwortlichen für die Repressionen weitgehend aus. Ab 1955 wurden lediglich mehrere Funktionäre der Geheimpolizei vor Gericht gestellt, darunter zahlreiche aus der Ermittlungsabteilung255. Freilich war damit weder die einheitliche Ausrichtung der Justiz noch die politische Verfolgung durch die Gerichte beendet. Vielmehr wurde das Repressionssystem auf Proportionen heruntergeschnitten, wie sie ähnlich in der DDR erst später, ab den sechziger Jahren, vorherrschten.

Ein Vergleich der Justizentwicklung in Polen und Ostdeutschland bis Mitte der fünfziger Jahre ergibt trotz der gemeinsamen stalinistischen Hegemonie doch markante Unterschiede ${ }^{256}$. Offensichtlich zählte für Sowjets und Kommunisten nicht das Verfahren, sondern vor allem das Ergebnis. Schon der zeitversetzte Prozeß der kommunistischen Machtergreifung gestaltete sich recht unterschiedlich. Während die Sowjets ihrer spezifisch antipolnischen Politik keine außenpolitischen Hemmungen auferlegten, wurde die kommunistische Gleichschaltung durch den Kampf gegen eine massive Opposition unter den Bedingungen eines Bürgerkriegs durchgesetzt. Die SBZ beerbte ein völlig niedergeschlagenes System, die Entwicklung blieb jedoch durch gesamtdeutsche Rücksichten beeinflußt. Zwar gab es in der polnischen Justiz eine größere personelle Kontinuität, aber die Tätigkeit der Justizjuristen wurde durch die Militärjustiz ausgehebelt. Letztere und die polnische Geheimpolizei bildeten das funktionale Äquivalent für NKWD und sowjetische Militärtribunale in der SBZ. In Polen konnte es keine echte sowjetische Besatzung geben, dafür aber ein penetriertes System. Trotzdem war dort die politische Rechtsprechung erheblich brutaler als in der SBZ/DDR bis 1953. Der Ausnahmezustand bot die Handhabe für die massenhaften Todesurteile. Im Gegensatz zur SBZ/DDR entwickelte sich eine frühzeitige und stärkere Stalinisierung der Justiz in zwei Stufen: ab 1945/46 mit der Sondergerichtsbarkeit, die stark der sowjetischen Sonderjustiz ähnelte; ab 1949 im allgemeinen Rechtssystem. Merkmale für diese Stalinisierung waren die Durchdringung der einheimischen Militärjustiz mit sowjetischem Personal, die Dominanz der Geheimpolizei, massenhafte Justiztötungen bis hin zu Wyschinski-Imitationen einzelner Ankläger im Gerichtssaal257. Auf dieses Niveau sank die DDR-Justiz nicht.

${ }^{254}$ Mastny, We are in a Bind, S. 231.

255 Paczkowski, Pół wieku, S. 293 ff.; Geilke, Die neueste Entwicklung, S. 50 f.

256 Mit ähnlichen Ergebnissen für die Hochschulpolitik: Connelly, Stalinistische Vielfalt, S. $102 \mathrm{ff}$.

257 So ein Militärstaatsanwalt im Verfahren gegen einen General 1952, Albert, Najnowsza historia, S. 634 . 
Erst ab 1952/53 ist eine allmähliche Konvergenz zu verzeichnen, die 2. Parteikonferenz der SED propagierte für die DDR offen dieselbe Zielorientierung wie die anderen "Volksdemokratien" vor ihr. Während die DDR-Justiz nun zunehmend repressiver agierte, ging die polnische Justiz allmählich wieder vom Ausnahmezustand ab. Nach 1955 deutete sich erneut ein gewisses Auseinanderfallen der Entwicklungen an: In Polen kam es zu einer echten Entstalinisierung, sogar die Kollektivierung wurde rückgängig gemacht; die DDR verschloß sich dieser Entwicklung. Dennoch war in Polen kein Ende der politischen Justiz erreicht, besonders ab 1958 wurden wieder spektakuläre Prozesse gegen Systemgegner inszeniert. Beide Staaten strebten zur „sozialistischen Normalität“ der sechziger Jahre. So blieb auf mittlere Sicht die paradoxe Entwicklung, daß die sozialistischen Staaten zunehmend ihre eigenen Wege gingen, sich die Justizsysteme beider Länder hingegen eher noch anglichen.

\section{Gemeinsame Strukturen}

Im Vergleich der vier hier behandelten Justizsysteme werden nicht nur Gemeinsamkeiten und Unterschiede recht deutlich, sondern auch Universalia der Justiz in der Diktatur. Zunächst ist die Bedeutung der Synchronität für die Analyse zu betonen. Regime der Zeit nach 1945 waren auch Regime nach Massenmord und Weltkrieg. Zwar konnte sich diese Erkenntnis in der Sowjetunion erst ab 1953 langsam verbreiten; in Deutschland und Polen war die "totalitäre Erfahrung" nach dem Krieg aber präsent. Auch diese Perspektive unterschied die SBZ und „Volkspolen“ vom Nationalsozialismus und Stalinismus bis 1945.

\section{a. Zielsetzung}

Der Legitimationsanspruch der totalitären Diktaturen beruhte neben charismatischen Elementen zum großen Teil auf dem "geschichtlichem Auftrag“, der sich in der jeweiligen Staatsdoktrin manifestierte. Das Rechtswesen konnte dadurch nur teilweise legitimiert werden und leitete daraus den Anspruch auf Konformität mit dem System und die Verpflichtung zur Niederhaltung politischer Gegner und angeblicher Saboteure ab. Weiterhin legitimierte sich die Justiz - wie in allen Staaten - durch die Bekämpfung der normalen Kriminalität und die Regelung der sozialen Beziehungen, sei es im Wirtschaftsleben oder im Familienrecht.

Die Besonderheit der Rechtsideologien totalitärer Staaten liegt aber im Anspruch, die Justiz zu Zwecken einer gesellschaftlichen Umwälzung zu instrumentalisieren, ein Anspruch, der massenhaftes Unrecht zur Folge hatte. Nationalsozialismus und Bolschewismus erklärten in bestimmten Phasen die physische Ausrottung ihrer - selbst definierten - Gegner zum offenen Ziel. Diese Aggressivität findet sich zumindest ansatzweise im polnischen Bürgerkrieg wieder, kaum aber in der DDR.

Darüber hinaus erwarten totalitären Diktaturen die Beseitigung jeglicher Kriminalität quasi automatisch durch die Verwirklichung des Programms der Staatspartei. Im Dritten Reich basierte diese Vorstellung auf einer Art Kriminalbiologie, 
die kriminelle „Veranlagung“ als Vererbung „rassisch Minderwertiger“ ansah"258. Die Erklärung der Kriminalität aus sozialen Merkmalen, wie sie in kommunistischen Systemen dominiert, ist hingegen in begrenztem Ausmaß auch in anderen Staaten vorhanden; kaum jedoch die Utopie des verbrechensfreien Staates, die aus gesamtgesellschaftlicher Steuerung zur vermeintlichen Beseitigung von Unterdrückung resultieren soll und sich in der "präventiven Verbrechensbekämpfung“ bis hin zur „Schutzhaft" niederschlägt. Diese „Prävention“ beschränkte sich in der DDR auf die Lokalisierung von "Schwerpunkten“ angeblicher Kriminalität, in denen exemplarisch und hart Strafpolitik betrieben wurde.

Fabrikation und Kriminalisierung des "Gegners" blieben im Ergebnis in der DDR weit hinter Nationalsozialismus und Stalinismus zurück, wurden jedoch zeitweise mit der gleichen Hysterie betrieben wie in Polen. Insgesamt gesehen, konnten sich aber nicht einmal die totalitären Systeme ganz aus der Tradition ihrer jeweiligen politischen Kultur und der Rechtskultur lösen. Am ehesten ist dies noch in der sowjetischen Rechtsentwicklung zu verfolgen, die unter den Bedingungen des Ersten Weltkrieges einen weitgehenden Bruch und - unter den Bedingungen der Umwälzungen von 1928/30 und des „Terrors“ 1937/38 - eine zweite Revolution erlebte. Im Nationalsozialismus, der in der Justiz einiges an Kontinuität zu Weimar bewahrte, erlebte das Rechtssystem ebenfalls im Krieg eine tiefgreifende Zäsur; in dessen Folge wurde auch die polnische Rechtskultur unterbrochen.

Bei der Justiz der SBZ hingegen überwogen eindeutig die Elemente der Kontinuität zum deutschen Rechtswesen vor 1933. Denn noch 1945 galt es zunächst, Anschluß zu finden an die Zeit der Weimarer Republik. Die Entnazifizierung war insofern ambivalent, als sie zwar auf eine politische Neuausrichtung des Personals abzielte, zugleich aber den Abweg des Nationalsozialismus gleichsam ungeschehen machen sollte. Nach Kriegsende war zunächst die sowjetische Besatzungsherrschaft das wirklich Neue, ab 1949 veränderte sich jedoch auch das ostdeutsche Justizwesen grundlegend.

Welche Rolle spielte nun das Rechtswesen für die Durchsetzung und für die Praxis der totalitären Herrschaft? Ein Indiz für die Beanwortung dieser Frage sind zweifellos Debatten um die Abschaffung der Justiz. Solche Überlegungen waren vor allem in Sowjetrußland nach der Revolution und zu Beginn der dreißiger Jahre virulent. Auch in der SBZ kam dieser Gedanke zumindest kurzzeitig auf, anläßlich der Konferenz von Werder ${ }^{259}$. Doch er hatte keine Chance auf Verwirklichung. Keines der hier analysierten Systeme war so sehr auf die Justiz angewiesen wie die frühe DDR. Stalinismus und Nationalsozialismus ermächtigten die Geheimpolizei zur Nebenjustiz, in Polen übernahmen das die Militärgerichte. Zwar existierte bis in die fünfziger Jahre in der DDR ebenfalls ein Parallelsystem sowjetischer Militärgerichte, das aber auf Besatzungsrecht beruhte und in der spezifisch deutschlandpolitischen Situation seit 1951 kaum noch Bedeutung hatte.

258 Vgl. Wagner, Volksgemeinschaft ohne Verbrecher, S. $399 \mathrm{ff}$.

${ }_{259}$ Vgl. den berühmten Dialog zwischen Benjamin und Ulbricht, Braun, Die Zentrale Kommission, S. $18 \mathrm{f}$. 
Abgesehen von der DDR nahm die ordentliche Justiz immer nur eine sektorale Rolle ein, im „Dritten Reich“ zur Bekämpfung bestimmter politischer Gegner, in der Sowjetunion vor allem in Wirtschaftsstrafsachen und in Polen in nichtpolitischen Verfahren bis 1955 . Anders steht es um die Instrumentalisierung der Justiz als „Hebel“ zur gesellschaftlichen Umwälzung bzw. im Nationalsozialismus als Organ zur "Reinhaltung der Volksgemeinschaft“. In allen totalitären Systemen gingen diese Aufgaben an Verwaltung und Polizei über; die Justiz nahm hier eine Hilfsfunktion wahr. Die stärkere ideologische Durchdringung der exekutiven Apparate war dafür Voraussetzung. Allerdings sickerte auch unter den Juristen eine Art „neuer Moral“ ein, die sich stark an der totalitären Doktrin orientierte. Diese neue Legitimation justitiellen Handelns ist anscheinend ein Kennzeichen aller totalitären Diktaturen. Doch waren die Brüche gegenüber der Tradition in kommunistischen Diktaturen größer und dort an neue Generationen junger $\mathrm{Ka}$ der gebunden.

Die Übergänge zum Totalitarismus im Rechtswesen waren also fließend und gelangen keineswegs in kürzester Zeit. In der DDR sind sie zeitlich etwa ähnlich anzusetzen wie die öffentliche Selbstbeschreibung der Herrschaftsverhältnisse als „Diktatur des Proletariats“, faktisch die Diktatur der kommunistischen Partei. Selbst in der Historiographie der DDR war die Datierung unklar; frühestens Ende 1950, als spätester Punkt ist eine entsprechende Äußerung Ulbrichts von Anfang Mai 1953 anzusetzen ${ }^{260}$. In den Apparaten dauerte dieser Wandel vereinzelt noch länger.

Ein zentrales Element der Justizpolitik ist in allen Systemen - Demokratie oder Diktatur - die Rechtsetzung. Sie ist ganz entscheidend durch das politische System bestimmt. In der Diktatur verfügt die Staatspartei die Rechtsgebung unmittelbar (in kommunistischen Systemen) oder mittelbar über die Ministerien (im Nationalsozialismus). Die Ausarbeitung verbleibt zwar zumeist in Händen der Experten, doch 1. handelt es sich dabei um ausgesuchtes Personal, und 2. wandert die Rechtsetzung allmählich aus den Parlamenten in die Verwaltungen mit ihrem extensiven Verordnungswesen. Dieser Prozeß verzögert zwar die Justizpolitik der Diktatur, erhöht aber ihre scheinbare Legitimität enorm. Denn nach Erlaß haben die Gerichte einen „von oben“ bestimmten Handlungsrahmen.

Gerade bei einem hochprofessionellen Apparat wie der NS-Justiz spielte deshalb die Gesetzgebung eine zentrale Rolle für die politische Rechtsprechung. Sie machte das traditionelle System ohne massiven institutionellen und personellen Umbau für das Regime nutzbar. Dennoch ging die NS-Führung mit dem Maßnahmerecht der Gestapo, das dann in den besetzten Gebieten durch völlig formlose Handlungen abgelöst wurde, noch weit darüber hinaus.

Ähnliche Erscheinungen gelten zwar für den sowjetischen Stalinismus bis 1945 genauso; die Verrechtlichung spielte aber angesichts der unbegrenzten Interventionsfähigkeit in die Justiz und deren innerer Schwäche eine untergeordnete Rolle. Zeitweise - 1930 bis 1934 - existierten in der Sowjetunion sogar Tendenzen, völlig von der Gesetzgebung zu abstrahieren. Erst nach 1945, mit der Aufwertung der Justiz gegenüber der Polizei, nahm die Bedeutung der Gesetzgebung wieder zu. Doch 
auch in Polen blieb sie bis 1954 begrenzt. Die Justiz der SBZ war zunächst stark von der deutschen Verrechtlichungstradition geprägt, die durch die SMAD-Befehle überlagert wurde. Vereinzelt seit 1948, vor allem ab 1950 läßt sich nachverfolgen, wie der Rahmen der Gesetzgebung an Bedeutung verlor und durch extensive Auslegung ausgehöhlt wurde. Die Neukodifizierungen 1952/53 kamen nur teilweise zustande oder mußten wieder eingeschränkt werden. Erst in der zweiten Hälfte der fünfziger Jahre verschwand diese Mischlage allmählich durch Neuregelungen.

Aber gab es auch ein spezifisch totalitäres Recht? Als systembestimmendes Adjektiv läßt sich "totalitär" wohl nicht verwenden. Jede niedergelegte Regelung mußte vielmehr bis zu einem gewissen Grade den unbeschränkten Herrschaftsanspruch eingrenzen. Inhaltlich hingegen flossen die totalitären Ideologien in die Gesetzgebung ein, besonders in die rassistischen Kodifikationen des Dritten Reiches. Allen behandelten Justizsystemen war allerdings eine spezifische Form der Rechtsproduktion gemeinsam, die Aushöhlung des Gesetzgebungsverfahrens und die Expansion des Verordnungsrechts bis hin zur Verlagerung auf Geheimverordnungen. Letztere hatten aber nicht den Grad an Legitimität, den Recht im allgemeinen ausstrahlt. Also sollte man eher von Recht unter totalitärer Diktatur als von totalitärem Recht sprechen ${ }^{261}$.

\section{b. Organisation}

Sicher bestand ein funktionaler Zusammenhang zwischen der Staatsideologie und dem Apparat. In allen vier Diktaturen beanspruchte die jeweilige Staatspartei die Herrschaft über das Rechtssystem. Dennoch waren das System der Justizsteuerung und die Organisation von Repression recht unterschiedlich ausgeprägt. Für die Entwicklung in der DDR ist es besonders bedeutsam, daß die Abgabe der Kompetenzen die Justiz zwar ernsthaft beschnitt, in Vergleichsperspektive aber gering ausfiel. So hatten Geheimpolizei und zeitweise ZKK erhebliche Interventionsrechte in die Verfahren, sie konnten jedoch keine eigenen Urteile verhängen. Also mußte letztendlich jede dauerhafte Freiheitsentziehung vor Gericht abgehandelt werden. Wollte die SED-Führung also ihre Ziele mittels der Justiz durchsetzen, so mußte sie diese jeder Selbständigkeit berauben und deren Tätigkeit weitgehend ihrer Anleitung und Steuerung unterwerfen. Erleichtert wurde dies durch die personelle tabula rasa, die mit der Kompromittierung der Justiz unter dem NS-Regime begründet werden konnte. Ein vergleichbarer Schnitt war nur 1917/18 in Rußland vorgenommen worden. In Polen kam es nur zur partiellen Auswechslung des Personals, nach 1933 in Deutschland fast ausschließlich zur Rotation innerhalb der Justiz. Zwar versuchten alle kommunistischen Staatsparteien, eine flächendekkende Kaderpolitik in der Justiz zu betreiben; letztendlich kam es aber vor allem auf die konforme Besetzung der Schlüsselpositionen in den Mittelinstanzen an, wie sie auch in der NS-Justiz betrieben wurde.

In allen Fällen erwies sich das Berichtswesen in bestimmten Sparten der Rechtsprechung von entscheidender Bedeutung. Allein durch diesen Kanal konnten

261 Vgl. dagegen den nicht unproblematischen Ansatz von Podgorecki, Totalitarian Law, S. 6 ff., der selbst 1952-56 in der polnischen Justiz tätig war. 
Justizverwaltung und Staatspartei einen Überblick über die Prozesse erhalten, denen sie erhöhte Priorität beimaßen. Für die Steuerung grundlegend war neben der neuen Gesetzgebung, die den Rahmen für Bestrafungskampagnen abgab, die oberste Rechtsprechung, die deren Interpretation meist verschärfte. Das Ausmaß und die Formen der konkreten Justizsteuerung unterschieden sich jedoch erheblich. So war zwar die Anpassung der Richter im Nationalsozialismus und im Stalinismus vergleichsweise hoch, die Steuerung bei letzterem aber erheblich intensiver. In der DDR verband sich die Steuerung eng mit der Schulung der unzureichend ausgebildeten und unsicheren Juristen, die in einem traditionell komplexen Rechtsprechungssystem arbeiteten. In Polen wiederum lief der Großteil der politischen Justiz über einen Sonderapparat mit militärisch-hierarchischer Struktur. Allen kommunistischen Diktaturen gemein war die systematisierte Rolle der Staatspartei in der Rechtsprechung, sei es von ihrer Spitze oder von den regionalen Parteiapparaten. Hier war der etablierte KPdSU-Apparat den ,jungen" ostdeutschen und polnischen Kommunisten voraus. Die NSDAP beschränkte sich hingegen im wesentlichen auf die Einwirkung beim Reichsjustizministerium, wenn auch regionale Parteipotentaten immer wieder auf eigene Faust bei den Gerichten intervenierten.

Der politische Druck auf die reguläre Justiz war in der Sowjetunion und in der DDR am größten. Die KPdSU-Führung ging bis 1945 mit allen Staatsfunktionären erbarmungslos um, wenn sie nicht die an sie gestellten Forderungen erfüllten. Auch in der DDR wurden Richter kriminalisiert. Allerdings resultierte der Druck letztendlich mehr aus dem Fehlen anderer exekutiver Apparate, d.h. selbst bei der Inhaftierung von angeblichen Gegnern waren Juristen unverzichtbar.

Vergleicht man die Personalpolitik in allen Systemen, so tun sich zunächst erhebliche Unterschiede auf. Im Verhalten der verschiedenen Justizjuristen innerhalb etablierter Diktaturen ergeben sich hingegen eine Reihe von Gemeinsamkeiten. Im zentralen Bereich politischer Justiz, also in den politischen Strafkammern regionaler Gerichte, herrschte unter Richtern und ganz besonders Staatsanwälten hoher Konsens mit dem jeweiligen Regime. Dieser wurde zwar im allgemeinen recht unterschiedlich erzielt: durch Personalaustausch, durch Schulung, durch das Vorhandensein eines autoritären Rechtsdenkens. Daneben spielten aber sicher auch universelle Phänomene wie Aufstiegsorientierung, Streben nach Sicherheit im Beruf und die Anpassung an das umgebende Milieu eine Rolle. Freilich konnten nur die obersten Ränge unter den Juristen kommunistischer Staaten ein vergleichbares Sozialprestige erringen, wie es schon die Landgerichtsräte und Staatsanwälte des Dritten Reichs besaßen.

Vielfach wird auf den Zusammenhang zwischen De-Professionalisierung und Diktaturjustiz verwiesen. Tatsächlich geht mit dem Abbau von Verfahrenssicherungen und der entsprechenden Ausbildung der Juristen der Rechtsstaat verloren. Dennoch ist der Zusammenhang zwischen unzureichender juristischer Ausbildung und Willfährigkeit gegenüber diktatorischen Regimen nur mittelbar. Sowohl die späte Sowjetunion als auch das NS-Regime verfügten über gut ausgebildete Juristen, die härteste politische Urteile fällten. Hier ging es weniger um Anleitung als vielmehr um politische Überzeugung. Die volle juristische Ausbildung der Juristen, die im Dritten Reich tätig waren, stammte meist noch aus der Weimarer 
Republik. Dennoch hinderte dies nur die wenigsten daran, im nationalsozialistischen Sinne Recht zu sprechen. Die Volksrichter der DDR hingegen hatten in den fünfziger Jahren eklatante Ausbildungsmängel; entscheidend aber war das Anleitungssystem und die Anpassungsbereitschaft in einer politischen Justiz. Wegen ihrer schlechten Ausbildung orientierten sich viele Volksrichter enger an den Vorgaben des Steuerungssystems.

Während in allen anderen hier diskutierten Staaten die Sonder- und Nebengerichtsbarkeit enorme Ausmaße annahm, blieb sie in der DDR vergleichsweise schwach ausgeprägt. Die Sondergerichte des Nationalsozialismus erscheinen als das am weitesten entwickelte System, insbesondere in den besetzten Gebieten. Dagegen wurden in der Sowjetunion die politischen Bereiche zeitweise fast gänzlich von der ordentlichen Justiz abgekoppelt, samt Personal und institutioneller Zuordnung. Wie im Dritten Reich war der Übergang zu Geheimpolizei oder Sonderkommissionen fast fließend. Die Sonderstrafkammern in der SBZ/DDR hingegen verblieben in der ordentlichen Justiz. Die Strafkammern nach Befehl 201 konnten sich auf sowjetisches Militärrecht stützen und blieben - ebenso wie die Wirtschaftsstrafkammern - in den Instanzenzug integriert. Durch den Entzug der Ermittlungen, Vorabsprachen und die gezielte Auswahl der Juristen waren sie jedoch ein manipulierbares Gremium in Händen der Staatspartei.

Allen Rechtssystemen gemein war die Aufwertung des Staatsanwalts zum eigentlichen politischen Akteur vor Gericht. In den sozialistischen Staaten führte dies zur institutionellen Verselbständigung, im Nationalsozialismus nicht. Dort konnte sich die Staatsanwaltschaft mit ihren Begehren auch nicht in dem Maße wie in kommunistischen Rechtssystemen durchsetzen.

Die rechtlichen Verfahrensweisen der totalitären Diktaturen ähneln sich über weite Strecken. Auffallend ist in allen diesen Systemen die - wenn auch nicht sehr häufige - Verwendung der außerordentlichen Rechtsbehelfe, die rechtskräftige Entscheidungen korrigieren konnten, sei es durch Nichtigkeitsbeschwerde, Kassation oder Protest. Während die Justiz in Deutschland ab 1933 schrittweise immer mehr von ihrer hohen formalen Verfahrensmäßigkeit abging, wurde diese in den sozialistischen Staaten erst allmählich mit den Kampagnen zur „Gesetzlichkeit" durchgesetzt. Diese Formalität stellt die Gerichte heute, nach dem Systemwechsel, immer wieder vor große Probleme, wenn sie versuchen, Rechtsbeugungs-Paragraphen in Anwendung zu bringen.

\section{c. Justizpraxis}

Andere, in totalitären Diktaturen typische Verfahrensweisen, waren in den einzelnen Systemen recht unterschiedlich ausgeprägt, so die präventive Inhaftierung und die Verfolgung von Familienangehörigen. Im Dritten Reich entwickelte sich die "Schutzhaft" zu einem zentralen Mittel zur Bekämpfung politischer Gegner; eine begrenzte Präventionshaft existierte auch in der UdSSR, noch 1955/56 waren davon über hunderttausend Personen betroffen ${ }^{262}$. In Polen war das vergleichbare Verfahren weniger formalisiert, auch dort gab es präventive Lagereinweisungen;

262 Vgl. Werth/Moullec, Rapports secrets, S. 54. 
in der SBZ diskutierte man die "Schutzhaft" zwar, lehnte sie dann aber wegen ihrer Belastung aus der NS-Zeit ab.

Die „Sippenhaft“ war besonders in der Sowjetunion unter dem Stalinismus ein probates Unterdrückungsinstrument. Vergleichbares findet sich in geringerem Maße auch im Nationalsozialismus, dort vor allem gegen Ausländer gerichtet. Ansätze zur Sippenhaftung existierten auch in Volkspolen, so gegenüber Familien von Deserteuren. In der DDR sind lediglich Einzelfälle nachweisbar. Hier wurde als Hebel zur Kriminalisierung die Nichtanzeige von angeblichen Verbrechen Verwandter gewählt. Die eigentliche Kollektivbestrafung erfolgte in der DDR aber nicht über Gerichte, sondern über Leistungsentzug und Diskriminierung in anderen Bereichen.

Die Geheimpolizei, der zentrale Exekutor totalitärer Gewaltpolitik, war in der DDR der frühen fünfziger Jahre im Vergleich mit den anderen Diktaturen eher ein schwacher Faktor. Dies lag vor allem an ihrem langwierigen Aufbau am Gängelband der Sowjets. Noch zu Zeiten der SBZ wurden viele ihrer Ermittlungen von den Gerichten als unzureichend zurückgewiesen; später konnte sie sich erst allmählich im Gerichtswesen etablieren. Verglichen mit den anderen politischen Polizeien war das MfS bis 1955 personell unterbesetzt, hatte nur eine dünnes Informantennetz und vor allem: Es hatte keine eigene Strafkompetenz. Damit unterschied sich seine Rolle im Rechtswesen fundamental von Gestapo und NKWD. Aus der Perspektive von Personen, die in der DDR politischer Verbrechen bezichtigt wurden, nimmt sich dies natürlich etwas anders aus. Dennoch blieb es auch Mitte der fünfziger Jahren bei den „konzentrierten Schlägen“, $d$.h. eine flächendeckende "Gegnerbekämpfung" war noch nicht möglich. Als das MfS seit den siebziger Jahren seine volle Entfaltung erreicht hatte, verschob sich auch das Verhältnis zwischen Justiz und Geheimpolizei in der Herrschaftspolitik zugunsten der letzteren.

Bei der Strafpolitik dominierte in der DDR durchgehend der Freiheitsentzug; er war im Nationalsozialismus nur der Vorkriegszeit und in Polen und der Sowjetunion erst ab 1956 die wichtigste Strafe. Das lag in der geringeren Radikalität des Regimes begründet, zu einem erheblichen Teil aber in der Delegitimierung der Todesstrafe, die es in den anderen Diktaturen nicht gegeben hat. Als äußerste Strafmaßnahme blieb sie in Einzelfällen dennoch erhalten, in nicht wenigen Fällen als faktischer Justizmord.

In der Vollstreckung der Freiheitsstrafe fiel hingegen die Sowjetunion mit ihrem Lagersystem aus dem Rahmen, im Nationalsozialismus waren Lager und Justiz ja getrennt. Der Bruch mit dem Strafvollzug des Nationalsozialismus, wie er in der SBZ angestrebt wurde, fiel geringer aus als erwartet. Statt dessen blieben politische Gefangene besonders bis Mitte der fünfziger Jahre weitgehend entrechtet. Unmittelbar vom Tode bedroht waren Häftlinge, die unter dem Nationalsozialismus oder dem Stalinismus nicht in Gefängnisse, sondern in Lager des NKWD bzw. der SS gelangten. Schließlich boten allein die kommunistischen Systeme periodisch Amnestien, die einem Teil der politischen Häftlinge aber verweigert wurden. Die Amnestierungspolitik war stark politisch motiviert und galt als grundsätzliches Mittel zur Korrektur überharter Strafpolitik; zum Tragen kamen Amnestierungen jeweils nach politischen Kurswechseln. 
Die augenfälligste Gemeinsamkeit der Justiz unter allen Diktaturen ist das systembedingte Unrecht am Bürger. Offensichtlich ungerechte Rechtsprechung kommt in Einzelfällen überall vor; daß die Rechtssicherheit, wie sie sich in den Verfassungsstaaten allmählich herausgebildet hat, aufgehoben wird, ist hingegen ein politisches $\mathrm{Phänomen.}$

Im Zusammenhang mit totalitären Diktaturen wird immer wieder auf den allgegenwärtigen Terror verwiesen, den diese Regime ausübten. Führt man den Begriff aber auf seine Ursprünge zurück, so erscheint er vor allem in zweierlei Hinsicht anwendbar: für die Unterdrückung von Gegnern und für die Verbreitung von Angst. Diese Funktionen üben allerdings auch einige autoritäre Diktaturen aus. Deshalb erscheint der Terror-Begriff präziser anwendbar auf solche Phasen der vier Systeme, in denen mehr die Herrschaftssicherung und weniger die Verwirklichung der eigentlichen Herrschaftsziele im Vordergrund stand $^{263}$.

Auf die SBZ/DDR bezogen, dominierte der Terror in der Hauptphase der MGB-Tätigkeit, von 1946 bis Mitte 1950, als vor allem politische Gegner unterdrückt wurden; vergleichbar der Zeit von 1933 bis 1935 im Dritten Reich, 1944 bis 1947 in Polen und bis 1922 in Sowjetrußland. Danach brachen totalitäre Maßnahmeregime durch, die sich weniger mit politischen Gegnern, sondern mehr mit vermeintlichen Feinden beschäftigten, die aus ideologischen Gründen selbst definiert wurden. In allen Fällen mischten sich dabei ideologische Muster mit utilitaristischen Kampagnen. Diese Zäsurensetzung ist natürlich nicht eindeutig festzulegen, zeigt aber einige Spezifika auf: Die reaktive Repression läßt nach, der totalitäre Charakter bleibt erhalten, obwohl der offene Terror abnimmt.

In der Bekämpfung politischer Gegner vor Gericht ähnelten sich alle Systeme. Die zu Feinden Erklärten wurden entrechtet und zuweilen sogar noch während der Hauptverhandlung gedemütigt. Außerhalb des Gerichtssaals war ihre Behandlung jedoch recht unterschiedlich, wegen der differierenden Anwendung der Todesstrafe, vor allem aber wegen der eklatanten Sonderrechte der Geheimpolizei im Nationalsozialismus und Stalinismus. Einen der wenigen konkreten Ansätze zum Vergleich aller vier Justizsysteme bietet beispielsweise die Verfolgung der Zeugen Jehovas. Als besondere religiöse Gruppe, die nicht nur dem totalitären Anspruch im Wege stand, sondern vor allem den Wehrdienst und die Teilnahme an Pseudo-Wahlen verweigerte, hatte sie besonders zu leiden. Während die Zeugen Jehovas aber im Nationalsozialismus und in der Sowjetunion - neben der Justizverfolgung - in Lager eingewiesen wurden und deshalb akuter Todesgefahr ausgesetzt waren, gerieten sie in der DDR und in Polen "nur" in die Mühlen der politischen Justiz. Doch auch hier ist die Zahl der Betroffenen in Polen erheblich höher als in der DDR.

Relativ wenig geeignet für die Analyse von Rechtssystemen unter totalitärer Herrschaft sind die Verfahren wegen der NS-Vergangenheit ${ }^{264}$. Zumeist waren diese bereits abgeschlossen, als die politische Transformation sich in Polen oder

${ }^{263}$ Für einen differenzierten Begriff von Terror: Linz, Totalitarian and Authoritarian Regimes, S. 217. Hannah Arendt, Ursprünge, S. 651, grenzt Terror im allgemeinen von totalitärem Terror ab.

264 Vgl. dazu Henke/Woller, Politische Säuberung in Europa; zu Österreich: Garscha, Richter der Volksgerichte, S. $31 \mathrm{ff}$. 
der DDR voll ausprägte. Zudem zeigten fast alle Staaten Europas Durchbrechungen von traditionellen Verfahrensnormen bei der Abrechung mit dem Nationalsozialismus bzw. mit dem Faschismus, unabhängig davon, ob es sich um diktatorische oder demokratische Systeme handelte. Die Verhängung drakonischer Strafen war ebenso kein Privileg der Justiz unter kommunistischer Herrschaft, auch wenn sie dort stärker ausgeprägt war. Ein Spezifikum wird man wohl eher darin sehen müssen, daß in der SBZ/DDR und in der Sowjetunion die Geheimpolizei die Ermittlungen wegen NS-Taten übernahm, in der Sowjetunion auch die Prozesse selbst führte.

Der totalitäre Charakter der Regime materialisierte sich vor Gericht bei der Verfolgung von Personen, die keineswegs aktive politische Gegner des jeweiligen Systems waren, sondern auf Grund von Herkunftsmerkmalen zu solchen erklärt wurden. Hier treten das nationalsozialistische und die kommunistischen Regime auseinander: Letztere verfolgten solche Gruppen nicht mit totaler Ausschließlichkeit. Kennzeichnend für die kommunistischen Regime ab den dreißiger Jahren ist vielmehr die Vermischung sozialer mit politischen und wirtschaftlichen Mustern der Justizverfolgung. D.h., die Zugehörigkeit zur sogenannten Arbeiterklasse oder zur Bauernklasse schützte keineswegs vor Verfolgung, vielmehr hatten Bauern sogar besonders unter Strafaktionen zu leiden.

Bestrafungen auf Grund sozialer oder religiöser Merkmale sickerten auch ins Zivilrecht aller totalitären Staaten ein, doch nur im Rassismus des Dritten Reiches mit offen zur Schau gestellter Ausschließlichkeit gegen bestimmte Minderheiten; in kommunistischen Staaten zeigte sich die die Deformierung des Zivilrechts in der Bevorzugung der Staatswirtschaft und in der Benachteiligung angeblicher politischer Gegner. Schließlich waren alle Repressionsphasen bestimmten politischen Konstellationen unterworfen. Solange nicht politische Vernichtungskampagnen auf der Tagesordnung standen, unterschied sich die Strafpraxis der Gerichte meist nicht von der autoritärer Diktaturen.

In den Zielen, in den Steuerungsmechanismen und im Personal waren die Justizapparate im Nationalsozialismus und in sozialistischen Staaten verschieden, unter den kommunistischen Diktaturen aber recht ähnlich; bei letzteren differierte jedoch der Grad der Repression erheblich. In der Zeit bis 1954/55 ergingen in Polen und der Sowjetunion massenhaft rein politisch motivierte Todesurteile. Erst danach glich sich auch die Rechtsprechung innerhalb des Ostblocks an. Die DDR erscheint im Vergleich eher noch als gebremste Form des Totalitarismus. Dies zeigt, welch unterschiedliche Ausprägungen die Justiz auch unter stalinistischer Hegemonie haben konnte.

Eine isolierte Betrachtung von Einzelfaktoren in der Entwicklung des Justizapparats läßt schnell den Blick für die Spezifik der Diktatur verlieren. So erweisen sich Charakteristika wie Zentralisierung, Vereinheitlichung der Rechtsprechung, Verkürzung von Verfahren, Beachtung der Formalität und Rechtskonformität, Professionalität des Personals, „Volksnähe“ usw. als inhaltlich unterschiedlich ausfüllbar. Erst in einem undemokratischen politischen System mit Interventionen der Staatsspitze, mit der Ausprägung von Feind-Ideologien und der Aushebelung von Grundrechten wird Justiz unter Diktatur politisch wirksam. Die unterschiedlichen Formen der organisatorischen Entwicklung und der Personalpolitik 
in den vier Diktaturen zeigen, daß diese allein nicht hinreichend sind, um aus Recht Unrecht werden zu lassen.

Will man die Besonderheit der Justiz in totalitären Systemen herausisolieren, erweisen sich zunächst viele Phänomene nicht als spezifisch totalitär, sondern als Universalia der Justiz unter Diktatur. So bleibt als Fazit, daß sich die Justizgeschichte meist im Vorhof und nicht im Zentrum totalitärer Herrschaft abspielt. Unter totalitärer Herrschaft ist die Rolle der Justiz deshalb durchaus ambivalent: Einerseits erhöht sie durch ihre Verfahrensmäßigkeit die Legitimität der Strafpolitik der Regime, andererseits entstehen dadurch auch Spielräume für die Juristen, im Einzelfall drakonische Gesetze abzumildern.

Bei aller Ambivalenz und Differenz der einzelnen Justizsysteme bleibt doch entscheidend, ob das jeweilige Regime seine Ziele hier realisiert. Angesichts der massiven Kritik aller Staatsparteien an den Juristen scheinen die Ziele zumindest nicht in erwünschtem $\mathrm{Maß}$ durchgesetzt worden zu sein. Mit Blick auf andere Politiksektoren, vor allem aber auf die Opfer politischer und politisierter Justiz, ist unübersehbar, daß die Regime streckenweise doch in verheerendem Ausmaß ihre Vorstellungen verwirklicht haben. 